\title{
Therapeutic effects of mesenchymal stem cells-derived extracellular vesicles' miRNAs on retinal regeneration: a review
}

\author{
Ali Rajool Dezfuly ${ }^{\dagger}$, Azadeh Safaee ${ }^{\dagger}$ and Hossein Salehi* ${ }^{*}$
}

\begin{abstract}
Extracellular vesicles (EVs), which consist of microvesicles and exosomes, are secreted from all cells to transform vital information in the form of lipids, proteins, mRNAs and small RNAs such as microRNAs (miRNAs). Many studies demonstrated that EVs' miRNAs have effects on target cells. Numerous people suffer from the blindness caused by retinal degenerations. The death of retinal neurons is irreversible and creates permanent damage to the retina. In the absence of acceptable cures for retinal degenerative diseases, stem cells and their paracrine agents including EVs have become a promising therapeutic approach. Several studies showed that the therapeutic effects of stem cells are due to the miRNAs of their EVs. Considering the effects of microRNAs in retinal cells development and function and studies which provide the possible roles of mesenchymal stem cells-derived EVs miRNA content on retinal diseases, we focused on the similarities between these two groups of miRNAs that could be helpful for promoting new therapeutic techniques for retinal degenerative diseases.
\end{abstract}

Keywords: Extracellular vesicles, Retina, miRNA, Mesenchymal stem cells

\section{Introduction}

The retina is a part of the central nervous system (CNS) which originates from diencephalon. The inner sensory retina and retinal pigment epithelium (RPE) are two layers of it $[1,2]$. The association neurons (amacrine and horizontal cells), the conducting neurons (bipolar and ganglion cells), the photoreceptor neurons (cone and rod receptors), and the supporting Müller cells are four cell groups of inner sensory retina whereas the RPE is made up of cuboidal cells which are organized in one layer[1]. The light photons are transformed to electrochemical signals by the retina and projected to the brain via the optic nerve. The whole process gives the organism the ability of vision [3].

\footnotetext{
*Correspondence: ho_salehi@med.mui.ac.ir

${ }^{\dagger}$ Ali Rajool Dezfuly and Azadeh Safaee have contributed equally to this work.

Department of Anatomical and Molecular Biology Sciences, School of Medicine, Isfahan University of Medical Sciences, Isfahan, Iran
}

Many people suffer from the blindness caused by retinal degenerations around the world. The death of retinal neurons, same as the CNS, is irreversible and causes permanent damage to the retina. Degenerative inherited retinal diseases such as retinitis pigmentosa and age-related macular degeneration (AMD) are important causes of visual disability $[1,3-6]$. The principal reason of retinal degeneration is the loss of photoreceptors, but no effective treatment has been discovered yet [7]. Retina's structure and anatomical position have made it an ideal tissue for examining new treatment methods such as prosthetic therapy, gene therapy and cell therapy for its neurodegenerative diseases. It is an easily accessible structure of the central nervous system which is quite isolated from the other parts of the body. Researches on cell therapy have become prevalent in recent decades. One of the cell therapy advantages is restricting degeneration via delivering trophic and neuroprotective agents that might inhibit the progression of the visual disease. original author(s) and the source, provide a link to the Creative Commons licence, and indicate if changes were made. The images or other third party material in this article are included in the article's Creative Commons licence, unless indicated otherwise in a credit line to the material. If material is not included in the article's Creative Commons licence and your intended use is not permitted by statutory regulation or exceeds the permitted use, you will need to obtain permission directly from the copyright holder. To view a copy of this licence, visit http://creativecommons.org/licenses/by/4.0/. The Creative Commons Public Domain Dedication waiver (http://creativeco mmons.org/publicdomain/zero/1.0/) applies to the data made available in this article, unless otherwise stated in a credit line to the data. 
Another advantage of cell therapy over other methods is the possible differentiation of transplanted cells that might replace the dead cells and restore the function of the tissue [8]. Considering the specifications of stem cells such as their differentiation capacity, multipotency and self-renewal, stem cell therapy has become an important therapeutic approach [1,3]. Different types of stem cells have been used for retinal differentiation and transplantation including induced pluripotent stem cells (iPSCs), isolated retinal stem cells (RSCs), human embryonic stem cells (hESCs) and mesenchymal stem cells (MSCs) $[9,10]$. MSCs do not have the clinical limitations of other stem cells and owing to their immunomodulatory and autologous features, easy isolation and relative abundance, they are more promising choices than other types of stem cells for retinal regeneration [10].

Many studies on regenerative medicine have shown that most of MSCs will be lost in the cell therapy process, this suggests that the main part of tissue regeneration is possibly made by the paracrine factors of the MSCs [11-14]. One of the main components of MSCs paracrine factors which are highly regarded as tissue regenerators are EVs. The inner components of EVs generally consist of proteins and nucleic acids, especially miRNAs [15]. As new studies have suggested that EVs miRNA content seems to play a more important role in retinal regeneration than other components [12], in this review, we will discuss the potential role of MSCs-derived EVs' (MSCEVs) miRNAs as a treatment for retinal diseases.

\section{Mesenchymal stem cells (MSCs)}

MSCs are non-hematopoietic stem cells which are derived from various somatic tissues and have the selfrenewal capacity. They can be found in different tissues including umbilical cord, embryonic tissues, fetal membranes, dental pulp, adipose tissue, liver, cartilage, skin, breast milk, skeletal muscle, peripheral blood, corneal limbal stroma of the eye and bone marrow $[16,17]$. MSCs can migrate to the sites of injury to advance tissue regeneration and suppress the immune reactions by regulating the function of both innate and acquired immune systems [17]. Because of their anti-inflammatory [16], regenerative and immunosuppressive features, they are being used widely in the field of cellular therapy studies nowadays [11]. According to the International Society for Cellular Therapy (ISCT) the minimal requirements of the MSCs are the expression of cell surface markers CD73, CD90 and CD105, and negative expression of CD34, CD45, or CD11b, CD79- $\alpha$, or CD19, CD14 and HLA-DR markers. The other main requirement is the plastic adherence in standard culture conditions. Moreover, MSCs must be able to differentiate into mesenchymal cells such as chondrocytes, osteoblasts, adipocytes and fibroblasts in vitro $[1,11,18]$. Moreover, researches have shown that MSCs can differentiate into a range of numerous cells such as cardiomyocytes, muscle fibers, renal tubular cells, hepatocytes, pancreatic islands and neurons [11]. So these kinds of cells could be used in many types of tissue regeneration including the retina $[12,16]$. For example, Özmert et al. treated 32 patients of retinitis pigmentosa with subtenon space transplantation of Wharton's jelly mesenchymal stem cells (WJ-MSCs) in a clinical trial. They concluded that the subtenon injection of WJ-MSCs could restrict the disease progression while being completely safe after twelve months of followup [19]. Despite the fact that therapeutic use of MSCs was promising, the possible unwanted differentiation of transplanted cells remains a safety issue [20]. Moreover, administration of MSCs for inflammatory bowel disease (IBD) and idiopathic pulmonary fibrosis (IPF) patients who were receiving immunosuppressive drugs shortly before MSC injection caused serious respiratory and gastrointestinal infections, suggesting that applying MSCs in combination or instantly after administering immunosuppressive drugs could be harmful [21].

Also, it has been shown that the positive effects of MSC therapy are substantially due to their trophic and immunosuppressive secreted factors and most of the transplanted cells will not differentiate and integrate into retinal tissue [20, 22]. MSCs secrete various trophic factors including FGF-2, IGF-1, BDNF, HGF, VEGF, IGF1, TGF- $\beta 1$, bFGF and GDNF which attribute to neuronal survival and regeneration [23].

Recent studies have shown that these kinds of cells also release EVs which play an important part in cellular communications that promote tissue regeneration $[11,24]$.

\section{Extracellular vesicles}

EVs are secreted vesicles which are approximately found in all body fluids and the extracellular matrix [3]. They are secreted from all cells to transform vital information as lipids, proteins, mRNAs and small RNAs. EVs' proteins are mostly a representation of their parent cells; however, the number of certain types of molecules such as cytokines, proteinases, chemokines, cell-specific antigens, cytoplasmic enzymes, signal transduction proteins, heat shock proteins and the ones which are related to cell adhesion and membrane trafficking are higher in the vesicles [25]. EVs include exosomes, microvesicles and apoptotic bodies. They are categorized by the proteins which are located on their surface, the range of their size in nanometer, their inner components and their biogenesis pathway [3].

Exosome formation is via the inward budding of the late endosome membranes which are called multivesicular bodies (MVBs). As the MVBs fuse with cell membrane, 
they would be released in the extracellular space [26]. The size of exosomes is considered as $30-150 \mathrm{~nm}$ [3]. Significant physiological and pathological functions have been attributed to exosomes including antigen presentation, inflammation regulation, immunological responses, angiogenesis processes, neuroprotection, regeneration processes, discarding inessential proteins and diffusing pathogens or oncogenes [27]. Exosomes can regulate the cellular status and their features would change in numerous diseases including cancer [28]. This suggests them as diagnostic and therapeutic tools [15]. For example, Galardi et al. showed that proteins that are characteristically associated with retinoblastoma vitreous seeding (RBVS) invasion and metastasis have been upregulated in RBVS exosomes [29]. Exosomes also have a drug delivery function $[25,30]$. Schindler et al. demonstrated that exosomes which are loaded with doxorubicin, an anthracycline antibiotic that is prescribed in the treatment process of many kind of cancers, would be absorbed by cells quickly and their inner doxorubicin would be re-distributed from endosomes to the cytoplasm and nucleus of the recipient cells [31].

Another type of EVs that are formed through the outward budding of cell membrane is microvesicles which their sizes are 100-1000 nm [3]. Microvesicles are also called shedding vesicles, microparticles, shedding bodies, ectosomes and oncosomes. A number of functions are attributed to microvesicles such as intercellular signaling and changing the extracellular environment. They also facilitate cell invasion through cell-independent matrix proteolysis [32]. Microvesicles, same as exosomes, carry mRNA, short interfering RNA (siRNA) and ectopically expressed reporter proteins, but it has been shown that plasmid DNAs, which have reporter functions, could only be transferred to target cells by microvesicles [32, 33]. Researches demonstrated that microvesicles have also crucial roles in stem cell expansion and renewal [34], tumor progression [35, 36], coagulation [37] and inflammation [38].

Apoptotic bodies are formed via the membrane blebbing of apoptotic cells. Their usual size is more than $1000 \mathrm{~nm}$ [39]. As far as we know to date, no therapeutic effect of apoptotic bodies has been seen in eye diseases [3]. However, exosomes have noteworthy therapeutic effects against many diseases including neurologic ones [40-42]. MSC-derived exosomes' (MSC-Exo) neuroprotective effect was also discovered in retinal cell injuries such as retinal cell degeneration, refractory macular holes, retinal detachment and optic nerve injury. MSCExos could reduce cell apoptosis and restrict the area of the injury in these diseases [27].

The main reason that why the EVs have become a research interest is their inner load which contain
mRNAs, miRNAs, lipids and proteins. EVs' cell signaling task is done by these components [3]. Many studies have shown that mRNAs and miRNAs play important roles in this task. While mRNAs can induce translation of new proteins in target cells, miRNAs can regulate the expression of genes [43, 44]. EVs' multiple therapeutic effects are done by entering mRNAs, miRNAs and proteins into target cells [3]. MSC-EVs express adhesion molecules such as CD29, CD73 and CD44 which allow them to adhere to the damaged and inflamed sites of tissues [21]. Considering the source of EVs, their inner components vary. The two other factors which also influence the inner cargo and subsequently the therapeutic effects of exosomes are the source cell passages and its phase of differentiation [3]. It has been shown that the neuroprotective efficacy of MSC-Exos reduces with raising cell passages [45]. It has also been indicated that exosomes' cargos vary at different stages of their source cell differentiation. For instance, exosomal miRNAs were differentially expressed in distinct stages of BMSCs osteogenic differentiation [46]. The composition of EVs' cargos is not just a sample of the cytoplasm of their cell of origin. Studies demonstrated that some proteins, mRNAs, miRNAs and transfer RNAs are more abundant in EVs than the cytoplasm of their original cells [47-49].

Ocular therapies which are based on EVs have many advantages over cell-based therapies. Retina MSCbased therapy has incurred safety concerns. For example, a report showed that three patients with AMD who underwent intravitreal injection of adiposederived MSCs, became blind because of the hemorrhage and retinal detachment [50]. One explanation for these pathologies is the adherence of transplanted MSCs to the inner limiting membrane of retina that would make an epiretinal membrane [51-53]. Another explanation would be the possible result of undesired differentiation of transplanted MSCs [20]. Other complications of cell therapy are the lack of information of the rate of cell death and cell division after administration [54]. Moreover, an important downside of cell therapy in retina is that the transplanted cells would not become integrated into the retina efficiently [13, 55]. The occasionally cell integration will be done through the digestion of inner limiting membrane and retinal glial activity modulation that might damage the retina themselves [22]. Since many studies have shown that keeping the therapeutic benefits of cell therapy, the EV therapy would avoid most of the above complications and also some EVs can cross the inner limiting membrane freely, it would be a better choice than cell therapy $[12,15]$. 


\section{miRNAs}

miRNAs are a subdivision of evolutionary conserved long non-coding RNAs with approximately 22 nucleotides and a post-transcriptive repressive influence on gene expression [56-58]. First step in the biogenesis of miRNAs is the production of partially complementary primary RNA transcripts (pri-miRNA) mostly by RNA polymerase II and sometimes by RNA polymerase III. miRNAs will derive from these structures. Pri-miRNAs become hairpin structures by self-annealing. Then, the miRNA processing complex, which is made of Drosha ribonuclease and the DiGeorge Critical Region 8 (Dgcr8) proteins, will make a cut in the hairpin structure at the end of 11 base pairs (bp) from the foundation of the hairpin stem [59]. A seventy nucleotide sequence called precursor miRNA (pre-miRNA) will be released as a result [56]. The pre-miRNA is transferred to the cytoplasm by Exportin-5. Then, the Dicer endoribonuclease will attach to the pre-miRNA and cleave it to release a $\sim 22$ nucleotide long double strand RNA named miRNA* duplex. Since the pre-miRNA itself has a $5^{\prime}$ phosphate at one end and a $3^{\prime}$ two-nucleotides' overhang at the other end, the dicer cleavage makes one phosphate at the $5^{\prime}$ end of each new strand, and a two-nucleotides' overhang at the $3^{\prime}$ end of each new strand. Afterward, the miRNA* duplex will be incorporated into the Argonaute protein (Ago) which is a part of the RNA-induced silencing complex (RISC) and one strand will be removed. The remaining strand that is connected to RISC will attach partially to target mRNAs and repress their translation or induce degradation (Fig. 1). One miRNA can bind to myriads of target mRNAs [56, 60, 61].

miRNA nomenclature is based on an annotation system which was introduced by Ambros et al. [62]. In brief, miRNA genes are numbered by the sequence of their discovery. Identical or nearly identical miRNAs from different species get the same number. A miRNA number is always accompanied by a prefix: mir or miR. The pre-miRNA is shown by "mir" prefix and the mature miRNA is preceded by "miR." They are followed by a dash and then the number comes (e.g., mir-25 and
miR-25). Identical mature miRNAs with one or two different nucleotides in their sequences are distinct by a lower case letter (e.g., miR-36a and miR-36b). A dash and a number suffix will be added to the names of premiRNAs that make identical mature miRNAs despite locating on different loci of the genome (e.g., mir-42a-1 and mir-42a-2 produce an identical mature miRNA, miR42a). In the miRNA formation process, a miRNA duplex will be cleaved to two different mature miRNA strands: the one that comes from the $5^{\prime}$ arm is shown by $5 \mathrm{p}$ (e.g., miR-146b-5p) and the one from the $3^{\prime}$ arm by $3 p$ (e.g., miR-146b-3p). Having said that, if the relative level of cell abundance of same miRNAs' two strands is known, the arm with the lower expression will get an asterisk following the number (for instance miR-9 is more abundant than miR-9*). miRNA names can also indicate the species of origin by a three-letter prefix: for example, "hsa" stands for Homo sapiens in hsa-miR-132 and "rno" for Rattus norvegicus in rno-miR-125 [62, 63].

Defects in miRNAs synthesis can make serious problems in the development process and is related to pathologies including inherited genetic disorders, diabetes, cancers, heart failure and neurodegenerative diseases. miRNAs maintain the healthy condition of gene networks and modulate the ups and downs of gene expression in developed tissues [56]. As well as other tissues, miRNAs play important roles in retina and some of them are more enriched in retinal cells (Fig. 2) [64]. Many studies showed their role in the function and survival of different retinal cells such as photoreceptors or Müller glias $[65,66]$. Here, we discuss retinal cell miRNAs (Table 1) similarities with MSCs-EVs' miRNAs (Table 2) and their possible therapeutic effects on retinal diseases.

\section{miRNAs of EVs}

Literatures have shown different procedures of loading miRNAs into EVs. Some studies demonstrated that when MVBs bind to plasma membrane and EVs are made, RISC complex is associated with them [67, 68]. Other studies which concluded that RISC or Argonaute2 (Ago2) is not present in EVs indicated that packing miRNAs

\footnotetext{
(See figure on next page.)

Fig. 1 MiRNA synthesis pathway. Biogenesis of miRNA begins with transcription of a miRNA gene (Canonical pathway) or the intron region of a protein-coding gene (Mirtron pathway) mainly by RNA polymerase II, and sometimes by RNA polymerase III in the nucleus. Canonical pathway: The sequences from miRNA genes transcription self-anneal and make hairpin-like structures called primary miRNAs (pri-miRNAs). Pri-miRNAs are being cut by DGCR8/Drosha complex and become pre-miRNAs. Mirtron pathway: Pre-miRNAs which are the result of intron regions of protein-coding genes are not dependent on Drosha complex. They are divided by spliceosome from the primary transcript of mRNAs. Then, they will self-anneal and become pre-miRNAs directly. All Pre-miRNAs from both pathways leave the nucleus and enter the cytoplasm by Exportin-5. There, the pre-miRNAs are cleaved by the Dicer/TRBP complex, yielding an about 22 nucleotides long miRNA: miRNA* duplex molecule. Then, this molecule will be loaded into the Argonaute (Ago) part of RNA-induced silencing complex (RISC). After discarding one of the strands, the other one will remain in the RISC and binds to 3' untranslated regions of target mRNAs. miRNAs binding to target mRNAs lead to their translational repression, deadenylation and cleavage
} 


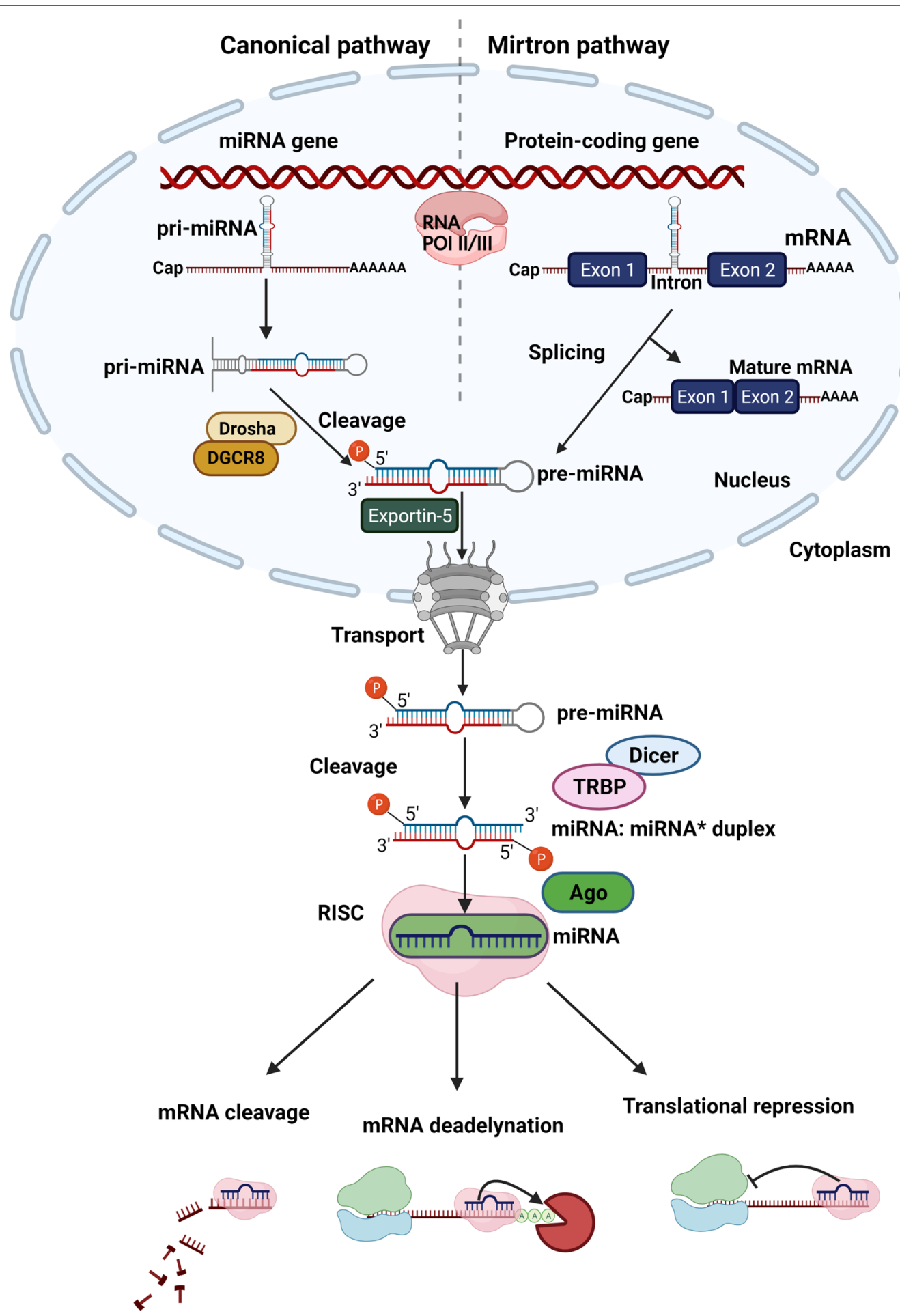

Fig. 1 (See legend on previous page.)

takes place by a type of ubiquitous proteins called heterogeneous nuclear ribonucleoproteins (hnRNP) [69]. Some motifs of miRNAs either alone or associated with proteins such as Ago2, Alix and MEX3C can be detected by and attached to hnRNP [70]. For instance, the loading of GGAG motif of miRNAs into EVs is controlled by the attached nuclear hnRNPA2B1 (ribonucleoprotein A2B1) [71]. 


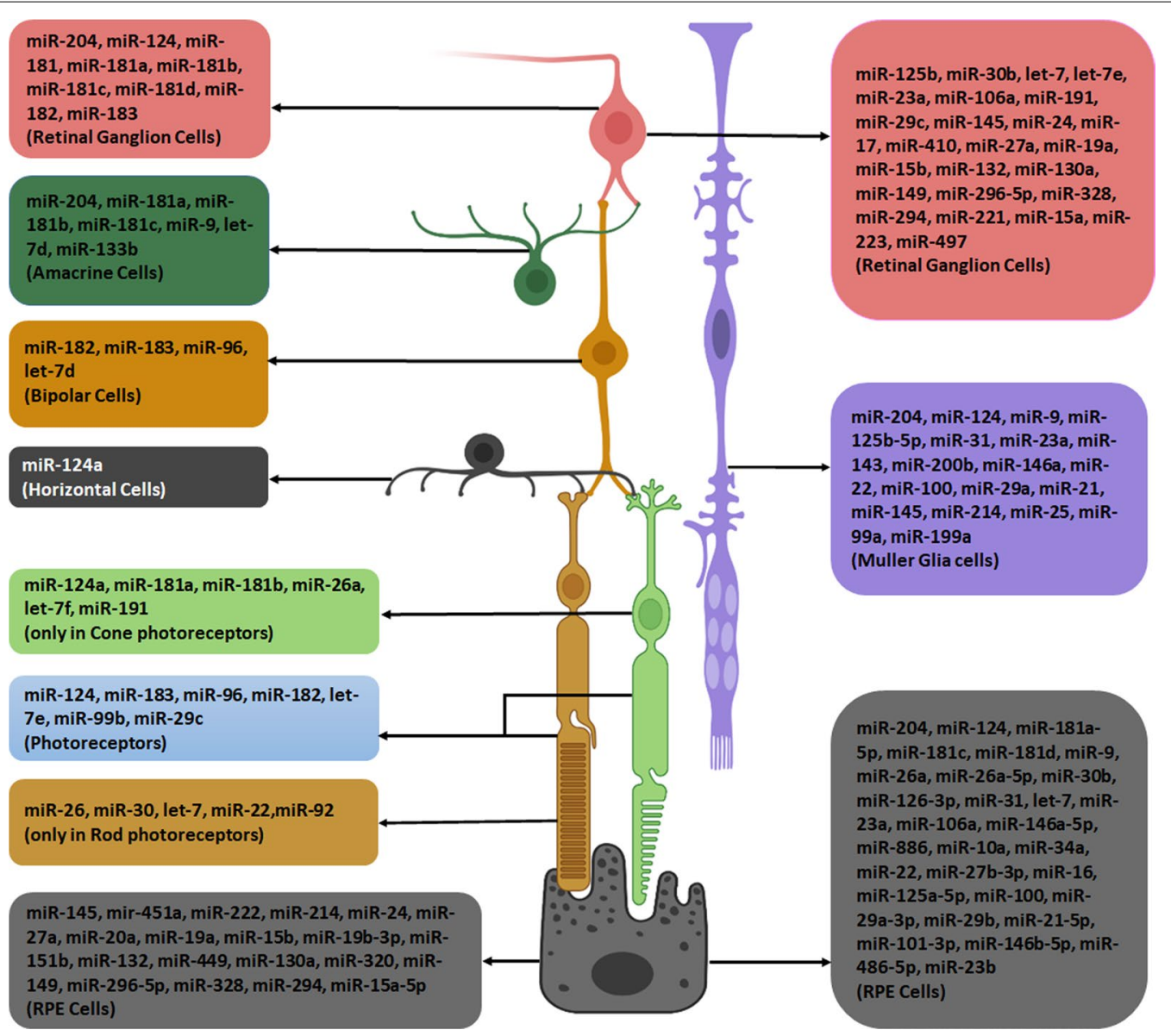

Fig. 2 MiRNAs enriched in retinal cells which are also present in MSC-EVs

Other proteins such as synaptotagmin-binding cytoplasmic RNA-interacting protein (SYNCRIP) detect miRNAs' motifs which bind to the GGCU motif [72]. As a study showed that the mutation in Alix protein diminishes miRNAs levels in EVs, it can be concluded that this protein is also important in packing miRNAs into EVs $[61,73]$.

EVs inner cargos enter the target cells by two methods: endocytosis and fusion [70]. EVs are mainly taken up by endocytosis, according to previous studies [74-77]. Clathrin-dependent endocytosis and clathrin-independent pathways that are mediated by caveolin, phagocytosis, macropinocytosis and lipid raft-mediated uptake are different types of this mechanism [74]. Considering the cell types and components of EVs, a group of them may be absorbed by more than one mechanism[78]. The direct fusion of EVs' membrane with cell membrane is the second mechanism of EVs entering into the target cells [79]. It was reported that spontaneous transfer of EVs took place between dendritic cells by fusion and release of the inner cargo into the cytoplasmic matrix [75].
Many literatures demonstrated that EVs miRNAs may affect target cells. Valadi et al. made the first report on evident transfer and function of mRNAs and miRNAs of EVs. They found new mouse proteins in the target cells after conveying the cargo of mouse EVs to human mast cells [44].

In addition, Song et al. indicated the transfer of functional miRNAs of MSC-EVs. After treating MSCs with IL- $1 \beta$, the expression of miR-146a increased. Then, miR146a was packaged into EVs selectively. As a result of coculturing the MSC-EVs with macrophages, the level of miR-146a in macrophages had been raised which led to M2 polarization [80].

Many studies have shown the differences of miRNAs between EVs and their parental MSCs. A research showed that the expression of mir- 15 and mir-21 was significantly higher in MSCs than their EVs [81]. Baglio et al. manifested that the miR-34a-5p, miR-34c-5p, miR-15a-5p and miR-136-3p are more represented in MSCs than their EVs and miR-4485, miR-150-5p, miR-6087 and miR-486-5p are enriched in MSC-EVs compared to MSCs [82]. 
Table 1 miRNAs of retina

\begin{tabular}{|c|c|c|c|}
\hline Retina miRNAs & References & Retina miRNAs & References \\
\hline miR-204 & {$[60,64-66,90-107]$} & miR-142b & {$[66,108,109]$} \\
\hline miR-124a & {$[64,90,93,95,98,99,101,104,105,110,111]$} & miR-7a & {$[66,107-109,112]$} \\
\hline miR-9 & {$[65,66,90,92,94,95,99,101,103,105,107,108,111,113-117]$} & $\mathrm{miR}-27 \mathrm{c}$ & {$[66,108,109]$} \\
\hline miR-9* & {$[66,90,99,107,108]$} & miR-25 & {$[97,107,108]$} \\
\hline miR-29 & {$[90,95]$} & miR-133 & [95] \\
\hline miR-181a & {$[60,90,94,95,98-101,105-107,118-120]$} & miR-1 & [95] \\
\hline miR-182 & {$[60,64,65,90,93-95,97-101,103-107,111,120-122]$} & miR-185 & {$[95,97]$} \\
\hline miR-183 & {$[60,64,65,90,93-95,97-101,104,106,107,111,120-122]$} & miR-219 & [95] \\
\hline miR-183* & {$[106,107]$} & miR-124a-1 & {$[65]$} \\
\hline miR-125b & {$[90,92,98,99,107,113,123,124]$} & miR-132 & {$[65,99,101,107]$} \\
\hline miR-26a & {$[90,98,107,120,123]$} & miR-23a & {$[65,66,101,107,123,125]$} \\
\hline miR-181 & {$[90]$} & miR-449a & {$[126]$} \\
\hline miR-96 & {$[60,64,65,90,93-95,97,99-101,104,106,107,121,122]$} & miR-449b-5p & [126] \\
\hline let-7 & {$[65,66,90,93,94,98,113-115,117]$} & miR-9-1 & {$[97]$} \\
\hline let-7i & {$[90,107,125]$} & miR-181b-1 & {$[97]$} \\
\hline miR-106b & {$[90,97,101,107,127]$} & miR-181a-1 & {$[97]$} \\
\hline miR-30b & {$[90,92,101]$} & miR-181a-1* & {$[107]$} \\
\hline miR-139 & {$[90,125]$} & miR-29c & {$[64,97,99,101,105,107]$} \\
\hline miR-126 & {$[90,128]$} & miR-194-1 & {$[97]$} \\
\hline miR-107 & {$[90]$} & miR-194-2 & {$[97]$} \\
\hline miR-103 & {$[90,107]$} & miR-7-2 & {$[97]$} \\
\hline $\operatorname{miR}-422 a$ & {$[90]$} & miR-9-3 & [97] \\
\hline miR-422b & [90] & miR-181-c & [97] \\
\hline miR-335 & {$[90,95,97]$} & miR-181-d & [97] \\
\hline miR-31 & {$[66,90,97,101,108,109]$} & miR-7-3 & {$[97]$} \\
\hline miR-106 & {$[66,90]$} & miR-216b & {$[97]$} \\
\hline miR-129-3p & {$[90,100,101,107,129]$} & miR-217 & {$[97,99]$} \\
\hline miR-691 & {$[90,107]$} & miR-9-2 & {$[97]$} \\
\hline miR-26b & {$[90,107,123]$} & miR-219-1 & {$[97]$} \\
\hline miR-35 & {$[90]$} & miR-30c & {$[98,101]$} \\
\hline miR-886-5p & {$[91]$} & miR-213 & [99] \\
\hline miR-184 & {$[65,91,94,97,99,101,126,130]$} & miR-454a & [99] \\
\hline miR-146a & {$[66,91,108,109,131]$} & let-7d & {$[95,99,101,103,107,123]$} \\
\hline miR-10a & {$[91]$} & miR-205 & {$[99]$} \\
\hline miR-203 & {$[66,91,132]$} & let-7b & {$[64,99,100,107,123]$} \\
\hline miR-194 & {$[91,95]$} & miR-130a-3p & {$[133]$} \\
\hline miR-200b & {$[128,134]$} & miR-20a-5p & {$[124,133]$} \\
\hline miR-200b* & {$[107]$} & miR-93-5p & [133] \\
\hline miR-34a & {$[65,107,135]$} & miR-9-3p & [133] \\
\hline miR-182-5p & {$[136]$} & miR-709 & {$[107,133]$} \\
\hline miR-183-5p & {$[136]$} & let-7a & {$[66,107,123,124]$} \\
\hline miR-26a-5p & {$[124,136]$} & miR-16 & {$[107,123,137]$} \\
\hline miR-181a-5p & {$[124,136]$} & miR-320 & {$[107,123]$} \\
\hline miR-204-5p & {$[124,136]$} & let-7e & {$[101,107,123]$} \\
\hline miR-22-3p & [136] & miR-7 & {$[65,138]$} \\
\hline let-7a-5p & {$[124,136]$} & miR-200c & [101] \\
\hline miR-191-5p & [136] & miR-221 & [101] \\
\hline miR-124-3p & [136] & miR-33 & {$[101,107]$} \\
\hline miR-9-5p & {$[133,136]$} & miR-342-3p & {$[101]$} \\
\hline
\end{tabular}


Table 1 (continued)

\begin{tabular}{|c|c|c|c|}
\hline Retina miRNAs & References & Retina miRNAs & References \\
\hline miR-127-3p & [136] & miR-365 & [101] \\
\hline miR-192-5p & [136] & miR-467a & [101] \\
\hline let-7f-5p & {$[124,136]$} & miR-470 & [101] \\
\hline$m i R-27 b-3 p$ & {$[124,136]$} & miR-542-3p & [101] \\
\hline miR-96-5p & [136] & miR-652 & [101] \\
\hline miR-26b-5p & [136] & miR-695 & [101] \\
\hline miR-30b-5p & {$[124,136]$} & miR-774 & [101] \\
\hline miR-92a-3p & {$[133,136]$} & miR-375 & [101] \\
\hline miR-99b-5p & [136] & $\operatorname{miR}-465 c-5 p$ & [101] \\
\hline miR-125b-5p & {$[66,124,136]$} & miR-30a & {$[101,107]$} \\
\hline miR-151a-5p & [136] & miR-15a & {$[101,107]$} \\
\hline miR-211-5p & {$[124,136]$} & miR-223 & [101] \\
\hline miR-126-5p & [136] & miR-290-5p & {$[101,107]$} \\
\hline miR-143-3p & [136] & miR-29b & {$[101,107,139,140]$} \\
\hline miR-16-5p & {$[124,136]$} & miR-379 & {$[101]$} \\
\hline let-7 g-5p & {$[124,136]$} & miR-380-3p & [101] \\
\hline miR-148a-3p & [136] & miR-384-5p & [101] \\
\hline miR-181b-5p & [136] & miR-409-5p & [101] \\
\hline miR-125a-5p & {$[107,124,136]$} & miR-433 & [101] \\
\hline miR-92b-3p & {$[136]$} & miR-497 & [101] \\
\hline miR-181a-2-3p & [136] & miR-541 & [101] \\
\hline miR-181c-5p & [136] & miR-551b & {$[101,107]$} \\
\hline miR-30d-5p & {$[124,136]$} & miR-676 & [101] \\
\hline miR-100-5p & {$[136]$} & miR-713 & {$[101,107]$} \\
\hline let-7c-5p & [136] & miR-742 & [101] \\
\hline miR-103a-3p & {$[124,136]$} & miR-875-3p & [101] \\
\hline miR-29b-3p & {$[136]$} & miR-378 & [101] \\
\hline miR-151a-3p & [136] & $\operatorname{miR}-465 b-5 p$ & [101] \\
\hline miR-186-5p & [136] & miR-28 & {$[60,141]$} \\
\hline miR-21-5p & {$[124,136]$} & miR-145 & {$[66,101,111,142]$} \\
\hline miR-30a-5p & {$[99,124,136]$} & miR-149 & {$[101]$} \\
\hline miR-146a-5p & [136] & miR-188-5p & [101] \\
\hline miR-101-3p & {$[124,136]$} & miR-339-5p & [101] \\
\hline miR-126-3p & {$[101,136]$} & miR-130a & {$[101,107]$} \\
\hline miR-146b-5p & [136] & miR-883b-5p & [101] \\
\hline miR-266-5p & [136] & miR-490 & [101] \\
\hline$m i R-486-5 p$ & [136] & miR-381 & [101] \\
\hline miR-99a-5p & [136] & miR-680 & [101] \\
\hline$m i R-23 b-3 p$ & {$[124,136]$} & miR-882 & [101] \\
\hline miR-30e-5p & [136] & miR-500 & [101] \\
\hline let-7b-5p & [136] & miR-495 & [101] \\
\hline miR-10a-5p & [136] & miR-335-5p & [101] \\
\hline miR-27a-3p & {$[124,136]$} & miR-296-5p & [101] \\
\hline miR-29a-3p & [136] & miR-328 & [101] \\
\hline miR-181a-3p & [136] & miR-294 & [101] \\
\hline miR-142-5p & [136] & miR-467e & [101] \\
\hline miR-145-5p & [136] & miR-329 & [101] \\
\hline miR-451a & [136] & miR-466d-3p & [101] \\
\hline miR-23a-3p & {$[124,136]$} & miR-34c & [101] \\
\hline
\end{tabular}


Table 1 (continued)

\begin{tabular}{|c|c|c|c|}
\hline Retina miRNAs & References & Retina miRNAs & References \\
\hline miR-124 & {$[60,66,92-94,107,108,114,133,143]$} & miR-484 & [101] \\
\hline miR-125a & {$[92,125]$} & miR-191 & {$[101,107,120]$} \\
\hline miR-762 & [144] & miR-382 & {$[101]$} \\
\hline miR-24a & {$[93,104,114,145]$} & miR-468 & [101] \\
\hline miR-133b & [93] & miR-681 & [101] \\
\hline miR-218 & {$[93,101]$} & miR-455 & [101] \\
\hline miR-196a & [93] & miR-99a & {$[66]$} \\
\hline miR-129 & {$[93,104,117,144]$} & miR-135a & {$[66,107]$} \\
\hline miR-222 & {$[93,104,117,125,144]$} & miR-21 & {$[66,128]$} \\
\hline miR-214 & {$[93,104,111,117,125,128,144]$} & miR-29a & {$[66,107,111,146]$} \\
\hline miR-155 & {$[93,99,104,117,144,147]$} & miR-143 & {$[66,107,111]$} \\
\hline miR-210 & {$[94,97,106,107]$} & miR-199a-3p & {$[66]$} \\
\hline miR-140 & {$[94,106,107]$} & miR-199a-5p & {$[66]$} \\
\hline miR-211 & {$[60,64,65,94,96,100,102]$} & miR-199b & {$[66]$} \\
\hline miR-181b & {$[60,94,95,99,101,106,107,118,120]$} & miR-199b* & {$[66]$} \\
\hline let-7f & {$[94,107,120]$} & miR-17-5p & [128] \\
\hline miR-22 & {$[66,94,107,125]$} & let-7e-5p & [124] \\
\hline miR-26 & [94] & miR-19b-3p & [124] \\
\hline miR-30 & [94] & miR-19a-3p & [124] \\
\hline miR-92 & {$[94,95]$} & miR-106b-5p & [124] \\
\hline miR-125 & {$[65,66,94,114,115,117]$} & miR-15a-5p & [124] \\
\hline miR-34 & {$[132]$} & miR-455-3p & [124] \\
\hline miR-350 & {$[101,132]$} & miR-34a-5p & [124] \\
\hline miR-410 & {$[101,132]$} & miR-24-3p & [124] \\
\hline miR-216 & {$[99,132]$} & miR-30c-5p & [124] \\
\hline miR-212 & {$[107,132]$} & miR-301b & [111] \\
\hline miR-181c & {$[95,101,111,129]$} & miR-199 & [1111] \\
\hline miR-181c* & [129] & $\operatorname{miR}-27 b$ & [107] \\
\hline miR-129-5p & [129] & miR-338-3p & [107] \\
\hline miR-99b & {$[101,107,129]$} & miR-138 & {$[107]$} \\
\hline miR-23b & {$[98,107,123,129]$} & miR-127 & {$[107]$} \\
\hline miR-24 & {$[101,107,123,129]$} & miR-151-5p & {$[107]$} \\
\hline miR-30d & {$[101,129]$} & miR-193 & {$[107]$} \\
\hline miR-503 & {$[101,129]$} & miR-136 & [107] \\
\hline miR-27a & {$[101,107,129]$} & miR-195 & {$[107]$} \\
\hline miR-135 & {$[148]$} & miR-148a & {$[106,107]$} \\
\hline miR-18a & {$[107,127,128,149]$} & miR-452 & {$[107]$} \\
\hline miR-130b & {$[127]$} & miR-542 & {$[107]$} \\
\hline miR-20a & {$[107,127,128]$} & miR-292-5p & {$[107]$} \\
\hline miR-34b-5p & {$[127]$} & miR-744 & [107] \\
\hline miR-216a & {$[66,97,127]$} & miR-689 & [107] \\
\hline miR-20b & {$[107,127]$} & miR-423-5p & {$[107]$} \\
\hline miR-17 & {$[66,101,107,127,150]$} & miR-677 & [107] \\
\hline miR-18b & {$[127]$} & miR-301a & {$[107]$} \\
\hline miR-106a & {$[101,107,127]$} & miR-130b & [107] \\
\hline miR-19a & {$[99,107,127]$} & miR-374 & {$[107]$} \\
\hline miR-93 & {$[107,127]$} & miR-32 & [107] \\
\hline miR-15b & {$[101,107,123,127,137]$} & miR-146b & {$[107]$} \\
\hline let-7a-2 & {$[125]$} & miR-153 & [107] \\
\hline
\end{tabular}


Table 1 (continued)

\begin{tabular}{llll}
\hline Retina miRNAs & References & Retina miRNAs & References \\
\hline let-7c & {$[107,125]$} & miR-19b & {$[107]$} \\
let-7f-2 & {$[125]$} & miR-207 & {$[107]$} \\
miR-100 & {$[66,125,129]$} & miR-489 & {$[107]$} \\
miR-125b-1 & {$[125]$} & miR-700 & {$[107]$} \\
miR-125b-2 & {$[125]$} & miR-92b & {$[99,107]$} \\
miR-151b & {$[125]$} & miR-101a & {$[107]$} \\
miR-152 & {$[101,125]$} & miR-690 & {$[107]$} \\
miR-181d & {$[101,125]$} & miR-720 & {$[107]$} \\
miR-26a-1 & {$[125]$} & miR-7b & {$[107]$} \\
miR-26a-2 & {$[125]$} & miR-361 & {$[97]$} \\
miR-3120 & {$[125]$} & miR-181a-2 & {$[97]$} \\
miR-4521 & {$[125]$} & miR-181b-2 & {$[97]$} \\
miR-98 & {$[95,107,125]$} & miR-219-2 & {$[97]$} \\
miR-206 & {$[90]$} & miR-7-1 & {$[97]$} \\
miR-150 & {$[151]$} & - & - \\
\hline
\end{tabular}

There are differences among MSC-EVs' miRNAs from various sources. Baglio et al. compared the miRNA contents of EVs derived from bone marrow and adipose MSCs. Most abundant miRNAs of bone marrow-derived MSC-EVs were miR-143-3p, miR-10b-5p, miR-486-5p, miR-22-3p and miR-21-5p, whereas, miR-486-5p, miR10a-5p, miR-10b-5p, miR-191-5p and miR-222-3p were the most frequent miRNAs of adipose-derived MSCEVs [82]. 171 miRNAs of hBMSC-EVs were disclosed in another research. While 148 miRNAs constitute 0.03 to $0.7 \%$ of the total reads, the 23 most abundant miRNAs made up $79.1 \%$ of them [83]. Luther et al. showed that the highest expressed EVs miRNA of mouse bone marrow-derived MSCs is miR-21a-5p which is responsible for MSCs cardioprotection [84]. The variety of miRNA profile among MSC-EVs may suggest that the expression of miRNAs is due to multiple factors and the effects of MSC-EVs may be the result of each miRNA synergistical activity with other elements [70]. MSC-EVs' miRNAs are provided in Table 2.

\section{MSCs' miRNAs potential therapeutic effects}

Over the last years, the effects of many miRNAs on retinal cells development and function have been revealed and the expression of miRNAs in normal and pathological conditions have been investigated. MSC-EVs contain some miRNAs which their roles in retinal cells' function and development have been proved, so studying them as therapeutic agents for retinal neurodegenerative diseases has not been overlooked.

Therapeutic effects of a number of MSC-EVs' miRNAs on retinal degenerative diseases have been assessed (Fig. 3). For example, Mead and Tomarev showed that by knocking down the Ago2 which plays a critical role in regulating the biological function of miRNA and the consequent reduction of miRNA abundance in exosomes, the BMSC-derived exosomes (BMSC-Exos) had lost their effects in advancing RGC neuroprotection, axon viability/regeneration and $\mathrm{RGC}$ functional maintenance [12]. They concluded that while knocking down Ago2 does not have an influence on exosomes' protein content, the above results demonstrated the dependency of RGC treatment on miRNA in comparison to the protein. BMSC-derived exosomes contain miR-17-92 which can downregulate phosphatase and tensin homolog (PTEN) expression [85]. As PTEN expression is a major suppressor of RGC axonal growth and survival [86, 87], RGC neuroprotection was done probably by miR-17-92 [12]. miR-21 and miR-146a which were identified in exosomes of umbilical cord MSCs and BMSCs, respectively, may be another candidates of RGC protection and survival $[12,88]$. In another study, Zhang et al. showed that MSC exosomes containing miR-126 ameliorate the inflammation and promote vascular repair in diabetic retinopathy (DR). They indicated that miR-126 reduces the inflammation in diabetic rats by inhibiting HMGB1 signaling pathway [89].

Having knowledge of the similarities between miRNAs that have an effect on retinal cells development and function and the miRNA content of MSC-EVs, we can design research and therapies more effectively and specifically for retinal degenerative diseases. Functions of miRNAs in retina can be divided into different categories. Many of them take part in differentiation process (e.g., miR-204, miR-124, miR-30b, miR-133b, ...), a remarkable number in development (e.g., miR-181, miR-126, miR-155, 
Table 2 miRNAs of MSC-EVs

\begin{tabular}{|c|c|c|c|}
\hline MSCs'EVs miRNAs & References & MSCs' EVs miRNAs & References \\
\hline miR-146a & {$[21,61,152-161]$} & miR-494 & {$[156-158,162]$} \\
\hline miR-155 & {$[152,158]$} & miR-140-5p & {$[162]$} \\
\hline miR-21 & {$[21,40,152-154,156,158-160,163-165]$} & miR-196a & {$[61]$} \\
\hline miR-27b & {$[152,158]$} & miR-27a & [61] \\
\hline let-7 & [152] & miR-206 & {$[61,166]$} \\
\hline miR-126 & {$[61,152,156,160,167,168]$} & miR-199a & {$[61,156,165]$} \\
\hline miR-886 & {$[152]$} & miR-302a & {$[61,159]$} \\
\hline miR-22 & {$[21,40,42,61,70,154,156,164,169,170]$} & miR-133 & {$[61,70]$} \\
\hline miR-133b & {$[40,42,61,156,157,163,164,166,169,171]$} & miR-155-5p & {$[61]$} \\
\hline miR-19a & {$[21,40,70,156,169]$} & miR-16-5p & {$[61,83,172,173]$} \\
\hline miR-100 & {$[153,154,156,159,165,174]$} & $\operatorname{miR}-223-3 p$ & {$[61]$} \\
\hline miR-143 & {$[42,153,154,158,163]$} & miR-15a & [61] \\
\hline miR-181 & {$[70,153,160,161]$} & miR-15b & {$[61]$} \\
\hline miR-221 & {$[40,153,154,156,157,165,174]$} & miR-125a-3p & {$[61]$} \\
\hline miR-145-5p & {$[70,83,153,172,175]$} & miR-142-3p & {$[61,83,173,174]$} \\
\hline miR-16 & {$[61,156,157,165,170,174]$} & miR-223 & {$[61,70,156,158,174]$} \\
\hline miR-17 & {$[21,156]$} & miR-630 & {$[155]$} \\
\hline miR-130a & {$[156,160,167]$} & miR-204 & [166] \\
\hline miR-132 & {$[154,156,160,167]$} & miR-328 & {$[166]$} \\
\hline let-7b & {$[21,154,156,158,160,161,167,168]$} & $\operatorname{miR}-210$ & {$[40,156,159]$} \\
\hline let-7c & {$[21,70,154,156,160,167]$} & $\operatorname{miR}-23 a-3 p$ & {$[70,83,88,173,175]$} \\
\hline miR-486-5p & {$[3,70,82,88]$} & miR-1260b & {$[70,165,175]$} \\
\hline miR-10a-5p & {$[70,82]$} & miR-1246 & {$[3,70,83]$} \\
\hline miR-10b-5p & {$[70,82,88]$} & miR-451a & {$[70,83]$} \\
\hline miR-191-5p & {$[70,82]$} & miR-4454 & {$[70,83]$} \\
\hline miR-222-3p & {$[70,82,83,173]$} & $\operatorname{miR}-21 a-5 p$ & {$[70]$} \\
\hline miR-143-3p & {$[70,82,83,88]$} & miR-486b-5p & [70] \\
\hline miR-22-3p & {$[70,82,83,88]$} & miR-486a-3p & [70] \\
\hline $\operatorname{miR}-21-5 p$ & {$[3,21,61,70,82,83,88,156,172,173,175]$} & miR-486a-5p & [70] \\
\hline let-7a-5p & {$[3,70,82,83,172,173,175]$} & miR-486b-3p & {$[70]$} \\
\hline miR-127-3p & {$[21,82,83]$} & miR-125a & {$[156,174]$} \\
\hline miR-99b-5p & {$[82]$} & miR-1792 & {$[156]$} \\
\hline miR-100-5p & {$[70,82,83,88,172,173,175]$} & miR-1587 & [156] \\
\hline miR-92a-3p & {$[3,70,82,172]$} & miR-124a & [156] \\
\hline miR-26a-5p & {$[82,156]$} & miR-101-3p & [156] \\
\hline miR-146a-5p & {$[82]$} & $\operatorname{miR}-23 b-5 p$ & [156] \\
\hline miR-4485 & {$[82]$} & $\operatorname{miR}-339-3 p$ & [156] \\
\hline miR-146b-5p & {$[82]$} & $\operatorname{miR}-425-5 p$ & [156] \\
\hline miR-151a-3p & {$[82]$} & miR-34a & {$[156]$} \\
\hline let-7f-5p & {$[70,82,88,175]$} & miR-210-3p & {$[156]$} \\
\hline miR-92b-3p & {$[82]$} & miR-294 & {$[156]$} \\
\hline$m i R-423-5 p$ & {$[3,82]$} & miR-133b-3p & [156] \\
\hline miR-27b-3p & {$[82,83]$} & miR-200b & {$[156]$} \\
\hline let-7i-5p & {$[82]$} & miR-99a & [174] \\
\hline miR-28-3p & {$[82]$} & miR-627 & [174] \\
\hline miR-125b-5p & {$[21,61,70,82,83,88,159,172,173,175]$} & miR-142-5p & [174] \\
\hline miR-19b & {$[174]$} & miR-383 & [174] \\
\hline miR-124 & {$[154,163]$} & miR-501 & [174] \\
\hline miR-233 & {$[21]$} & miR-601 & [174] \\
\hline
\end{tabular}


Table 2 (continued)

\begin{tabular}{|c|c|c|c|}
\hline MSCs' EVs miRNAs & References & MSCs' EVs miRNAs & References \\
\hline miR-181-5p & {$[21]$} & miR-17-3p & {$[174]$} \\
\hline miR-145 & {$[21,154,156,159,161,164,165]$} & miR-497 & {$[176]$} \\
\hline miR-223-5p & {$[21]$} & miR-486 & {$[174]$} \\
\hline miR-30 & {$[21,61,70]$} & miR-451 & [174] \\
\hline miR-92a & {$[154]$} & miR-564 & {$[174]$} \\
\hline miR-146 & [21] & miR-30a & [158] \\
\hline miR-30b & {$[156,168]$} & miR-410 & {$[159,161]$} \\
\hline miR-181c & {$[158,159,161,168]$} & miR-181b & {$[161]$} \\
\hline miR-126-3p & {$[61,168]$} & miR-181d & [161] \\
\hline miR-4484 & [168] & miR-1252 & [161] \\
\hline miR-619-5p & [168] & miR-4434 & [161] \\
\hline miR-6879-5p & [168] & miR-4669 & [161] \\
\hline miR-291a-3p & [168] & miR-199b-3p & [83] \\
\hline miR-23b & {$[42,70,154,156,158,164]$} & miR-7975 & [83] \\
\hline miR-122 & {$[40,70,154]$} & let-7b-5p & [83] \\
\hline miR-1224-5p & {$[154]$} & miR-29a-3p & [83] \\
\hline miR-1228 & [154] & miR-144-3p & [83] \\
\hline miR-1234 & [154] & miR-29b-3p & [83] \\
\hline miR-1237 & [154] & miR-630 & [83] \\
\hline miR-1238 & [154] & miR-221-3p & {$[3,83,173]$} \\
\hline $\operatorname{miR}-150^{*}$ & [154] & let-7i-5p & {$[83]$} \\
\hline let-7b* & [154] & miR-424-5p & [83] \\
\hline let-7d* & [154] & miR-191-5p & [83] \\
\hline miR-198 & [154] & miR-25-3p & {$[83,172]$} \\
\hline miR-296-5p & [154] & miR-130a-3p & [83] \\
\hline miR-572 & [154] & miR-376a-3p & [83] \\
\hline miR-765 & [154] & miR-4286 & [83] \\
\hline miR-933 & [154] & miR-15a-5p & {$[83]$} \\
\hline miR-149 & [154] & miR-24-3p & {$[83,172,173]$} \\
\hline miR-149* & [154] & $\operatorname{miR}-34 a-5 p$ & {$[83]$} \\
\hline miR-191 & {$[154,165]$} & miR-122-5p & {$[3,83]$} \\
\hline miR-191* & [154] & miR-181a-5p & {$[83]$} \\
\hline $\operatorname{miR}-425^{*}$ & [154] & miR-199a-5p & [83] \\
\hline miR-574-5p & [154] & miR-495-3p & [83] \\
\hline miR-575 & [154] & miR-196a-5p & [83] \\
\hline miR-638 & [154] & miR-320e & [83] \\
\hline miR-663 & [154] & miR-148a-3p & [83] \\
\hline miR-671-5p & [154] & miR-93-5p & [83] \\
\hline miR-923 & [154] & miR-377-3p & [83] \\
\hline miR-940 & {$[154]$} & miR-382-5p & [83] \\
\hline let-7a & {$[154,156,158,165]$} & miR-15b-5p & [83] \\
\hline let-7d & {$[154]$} & miR-376c-3p & [83] \\
\hline let-7e & {$[154,156]$} & miR-374a-5p & [83] \\
\hline let-7f & {$[154,156,165]$} & let-7e-5p & [83] \\
\hline let-7i & {$[154]$} & miR-379-5p & [83] \\
\hline miR-103 & [154] & let-7c-5p & {$[83]$} \\
\hline miR-107 & [154] & miR-1260a & {$[165,175]$} \\
\hline miR-125a-5p & {$[83,154]$} & miR-320a & [3] \\
\hline miR-125b & {$[40,154,156,159,164,165,174]$} & miR-195 & [165] \\
\hline
\end{tabular}


Table 2 (continued)

\begin{tabular}{llll}
\hline MSCs' EVs miRNAs & References & MSCs' EVs miRNAs & References \\
\hline miR-151-5p & {$[154,156]$} & miR-106a-5p & {$[172]$} \\
miR-181a & {$[154,158,161]$} & miR-19b-3p & {$[172]$} \\
miR-199a-3p & {$[70,83,154,161,175]$} & miR-320 & {$[154]$} \\
miR-214 & {$[154]$} & miR-361-5p & {$[154]$} \\
miR-222 & {$[154,165,174]$} & miR-574-3p & {$[154]$} \\
miR-23a & {$[154,156,159,165]$} & miR-26a & {$[154]$} \\
miR-24 & {$[154,174]$} & miR-17-92 cluster: (miR-17, miR-18a, miR-19a, $[12,21,40,70,177]$ \\
miR-31 & {$[154,174]$} & miR-19b, miR-20a and miR-92a) & {$[178]$} \\
\hline
\end{tabular}

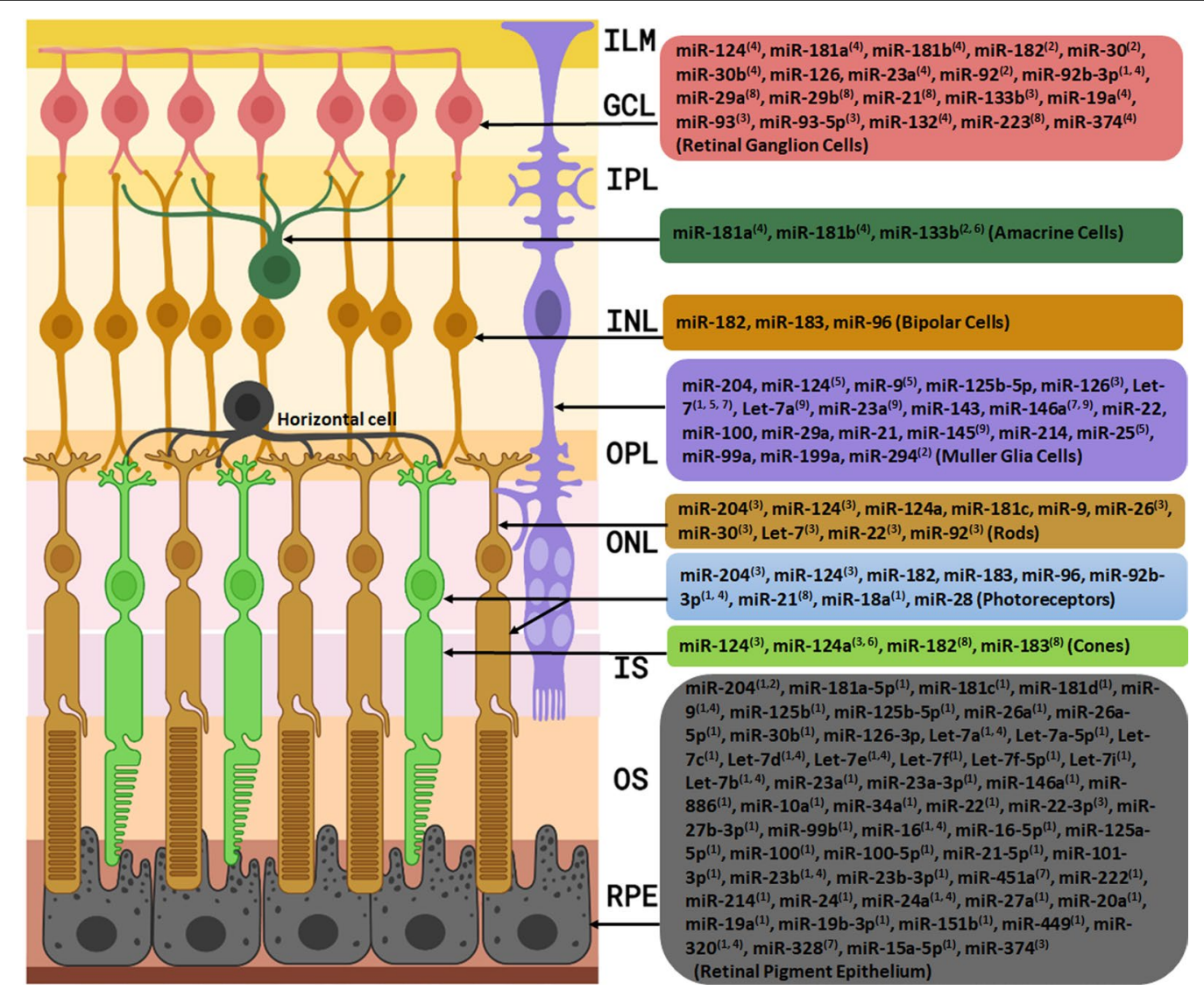

Fig. 3 MSC-EVs' miRNAs with studied effects on retinal cells. ILM, inner limiting membrane; GCL, ganglion cell layer; IPL, inner plexiform layer; INL, inner nuclear layer; OPL, outer plexiform layer; ONL, outer nuclear layer; IS, inner segment of photoreceptors; OS, outer segment of photoreceptors; RPE, retinal pigment epithelium. General effects of miRNAs on retinal cells: ${ }^{1}$ differentiaition, ${ }^{2}$ function, ${ }^{3}$ survival \& apoptosis reduction, ${ }^{4}$ development \& growth, ${ }^{5}$ reprogramming,${ }^{6}$ maturation, ${ }^{7}$ proliferation, ${ }^{8}$ protection \& maintenance, ${ }^{9}$ dedifferentiation

miR-17, ...), and a group of them in cell proliferation (e.g., miR-103, miR-124, miR-34a, miR-15b, ...). Some of them will decrease cell apoptosis and contribute to cell survival and maintenance (e.g., miR-30, miR-124, miR-22, miR$29 \mathrm{a}, \ldots$...) while a few participate in neurons' connectivity and plasticity (miR-124, miR-133b, miR-132). Moreover, therapeutic effects of a number of miRNAs have been discovered in some of retinal diseases. miR-200b, miR148a-3p and miR-15a act against DR while miR-361, miR-497 and miR-140 are retinoblastoma tumor suppressors. It had also been reported that miR-222 can prevent the progression of retinal degeneration and miR-124 has 


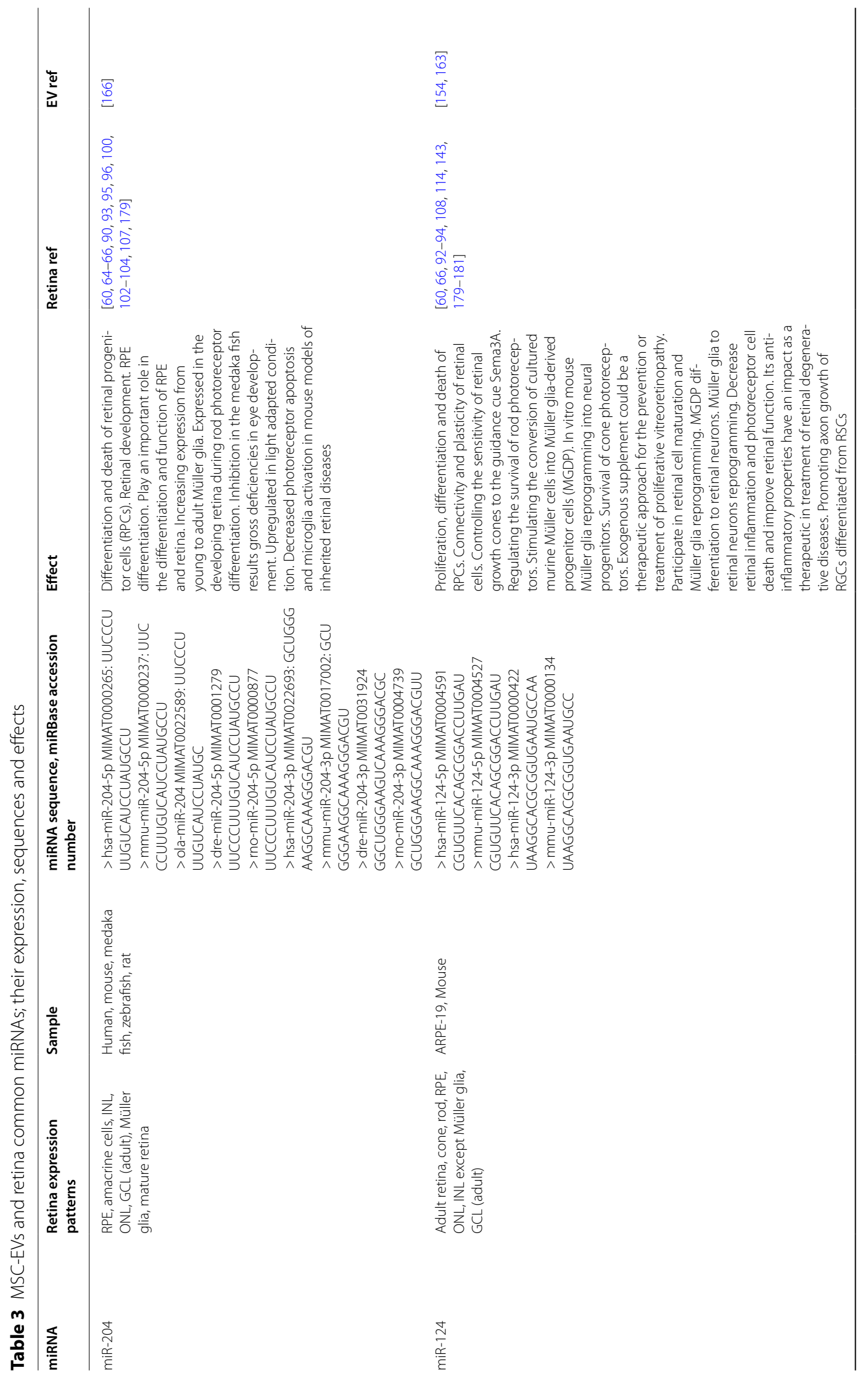




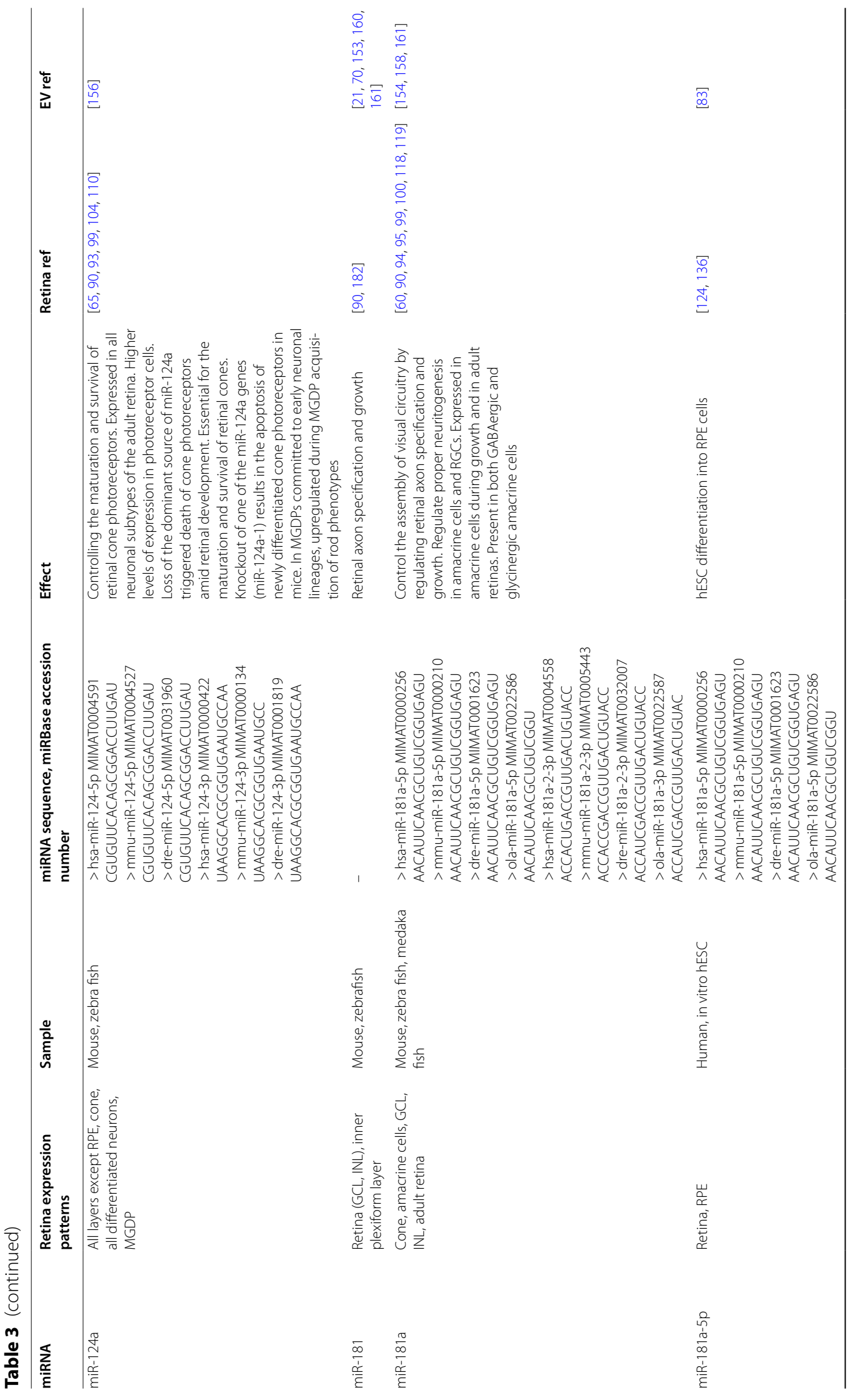




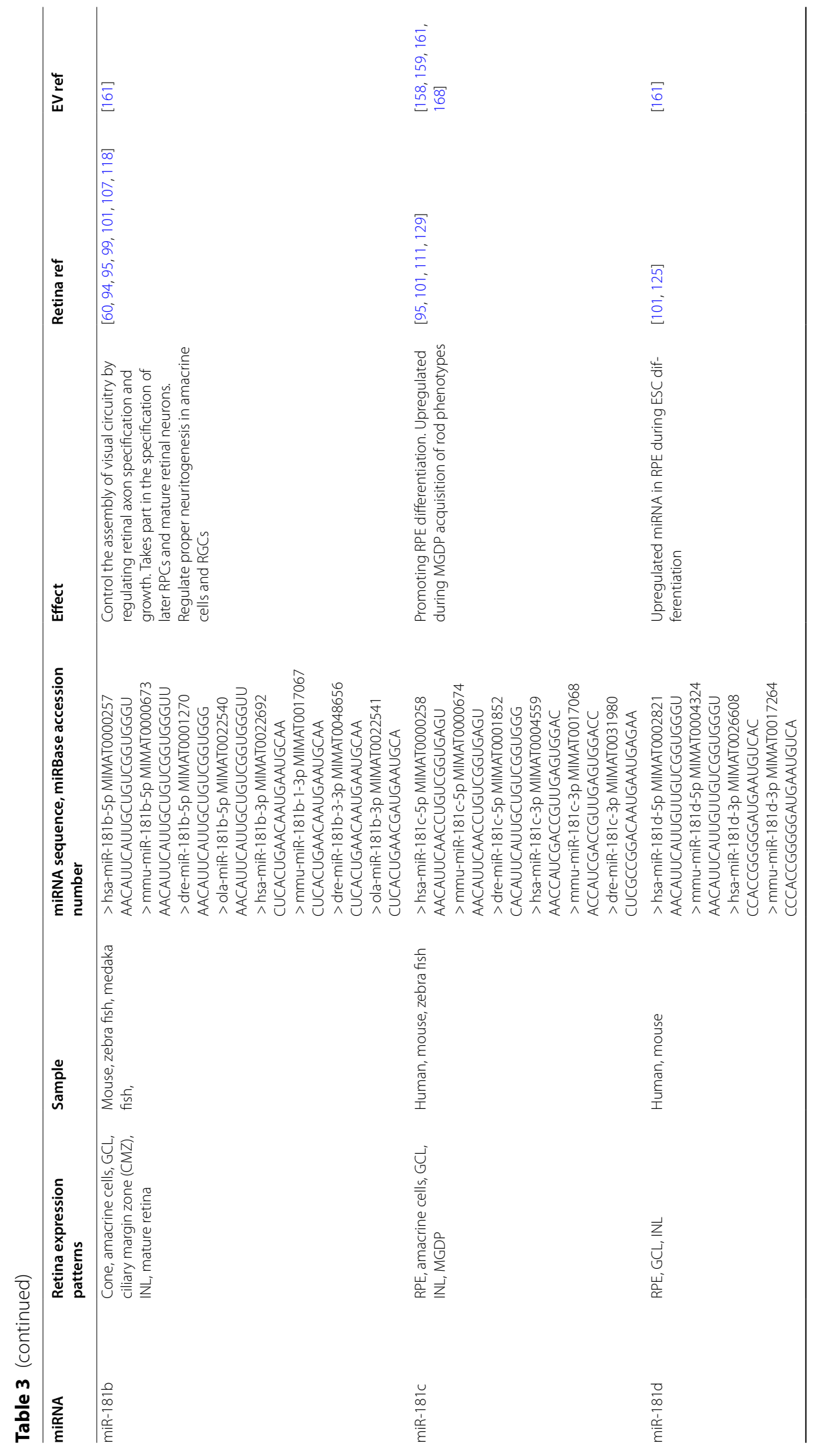




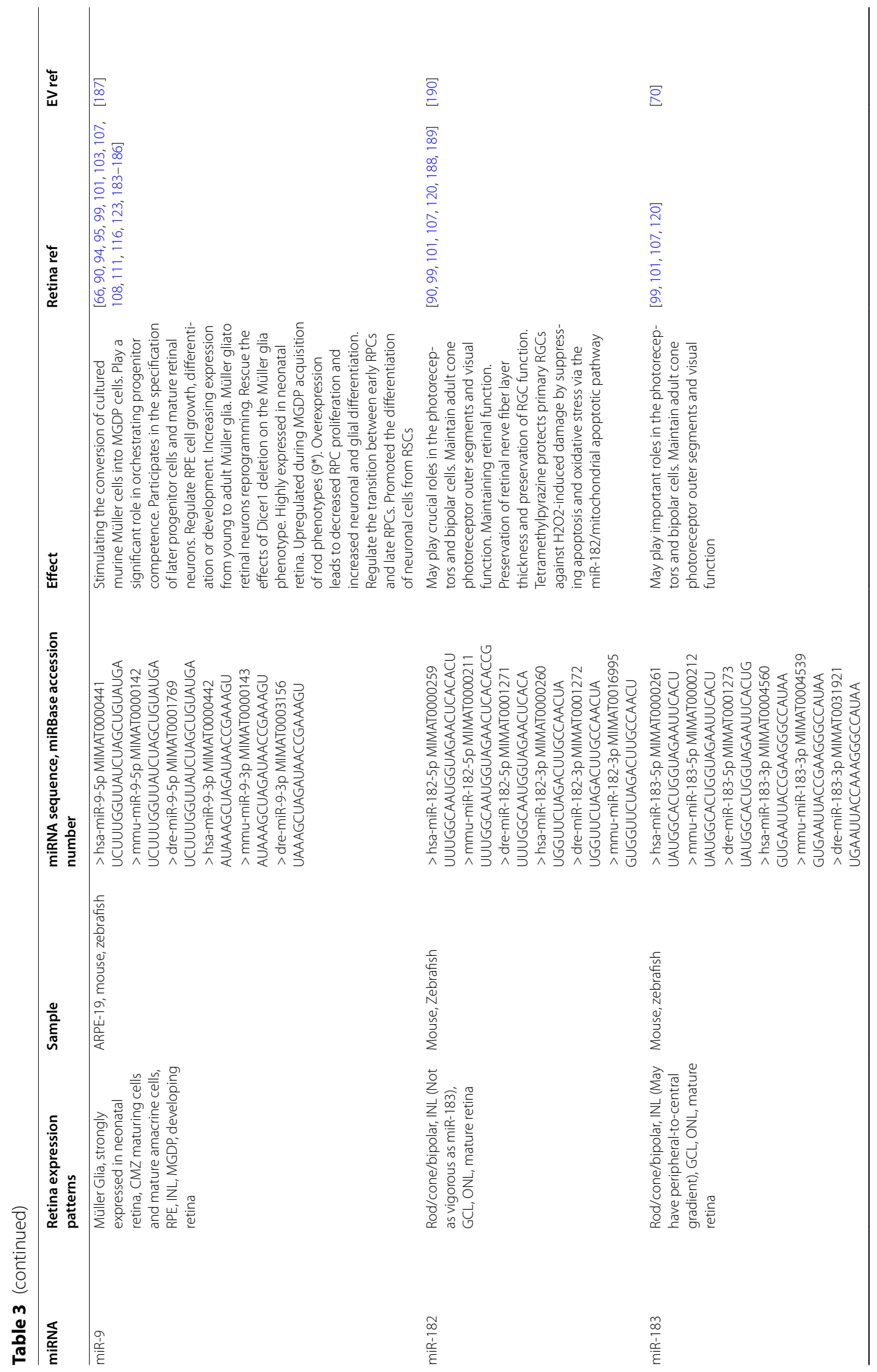




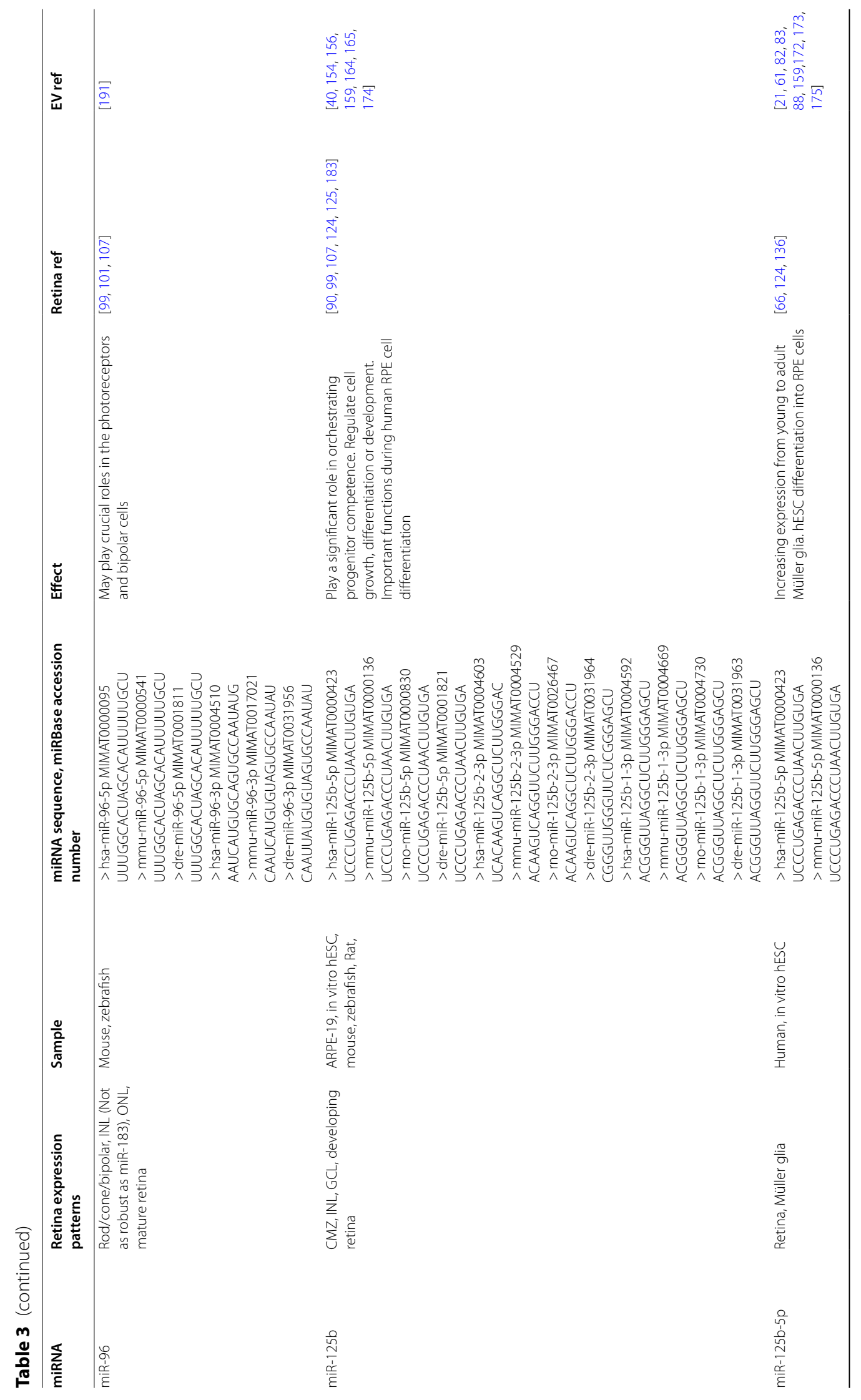




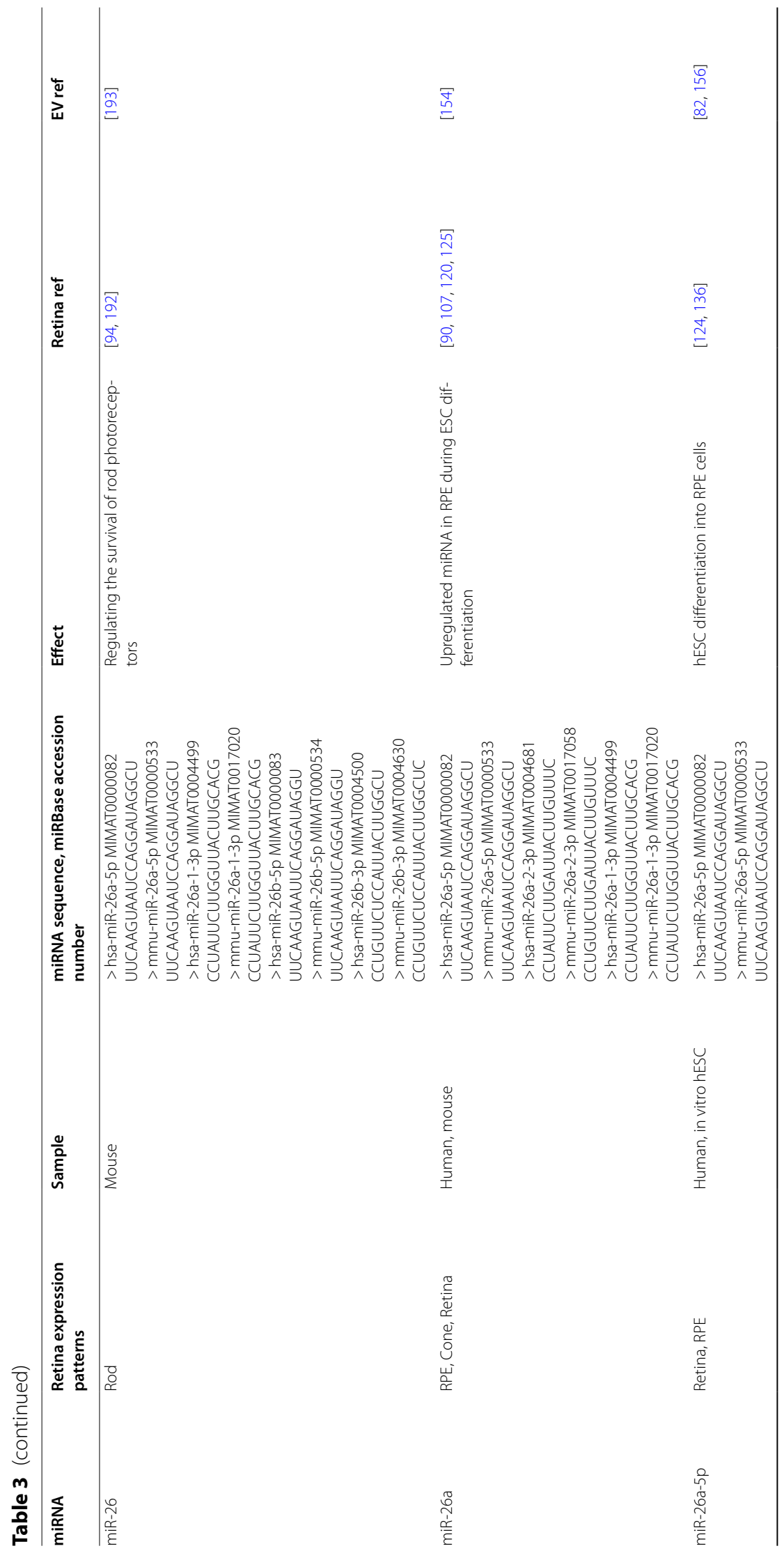




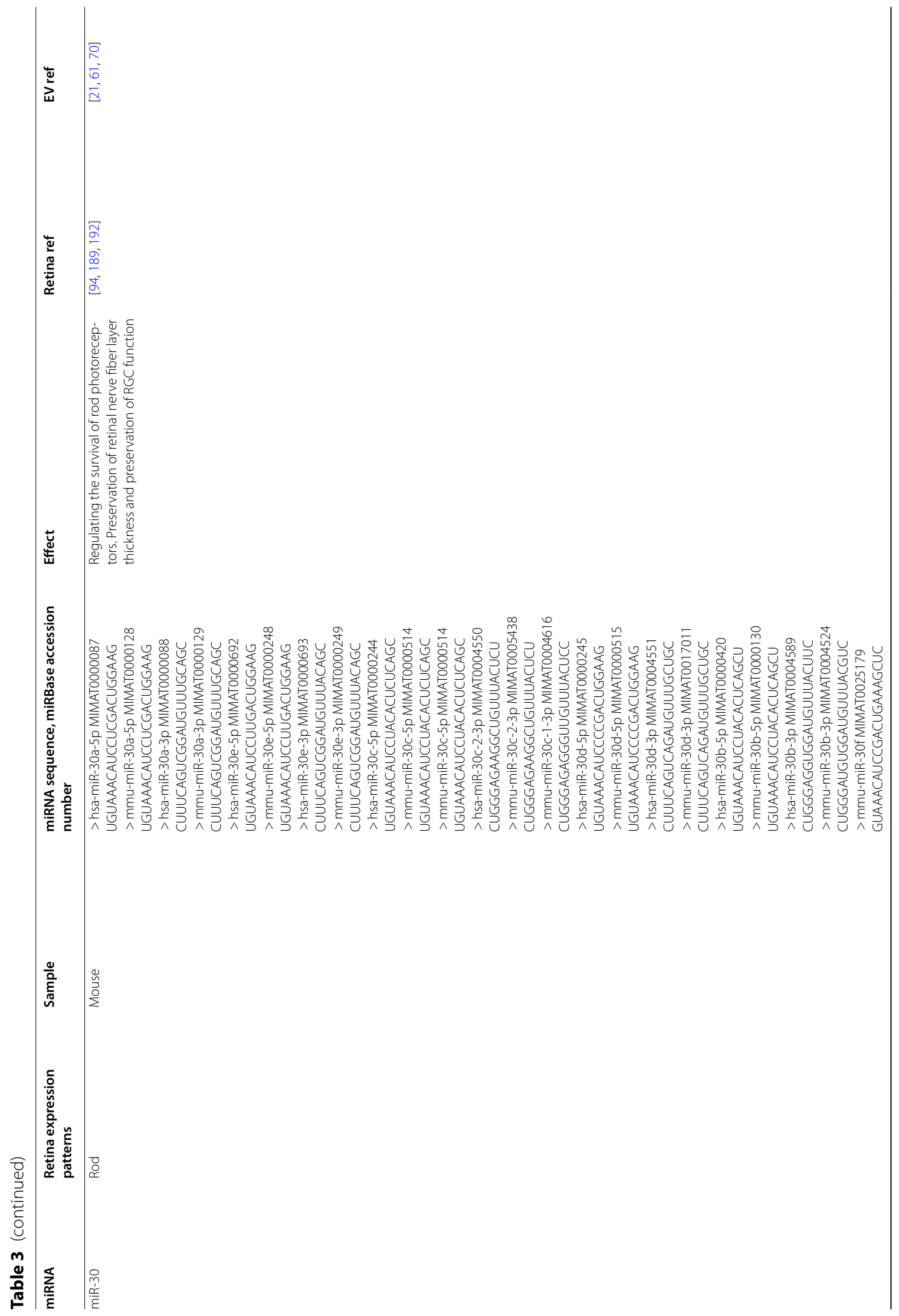




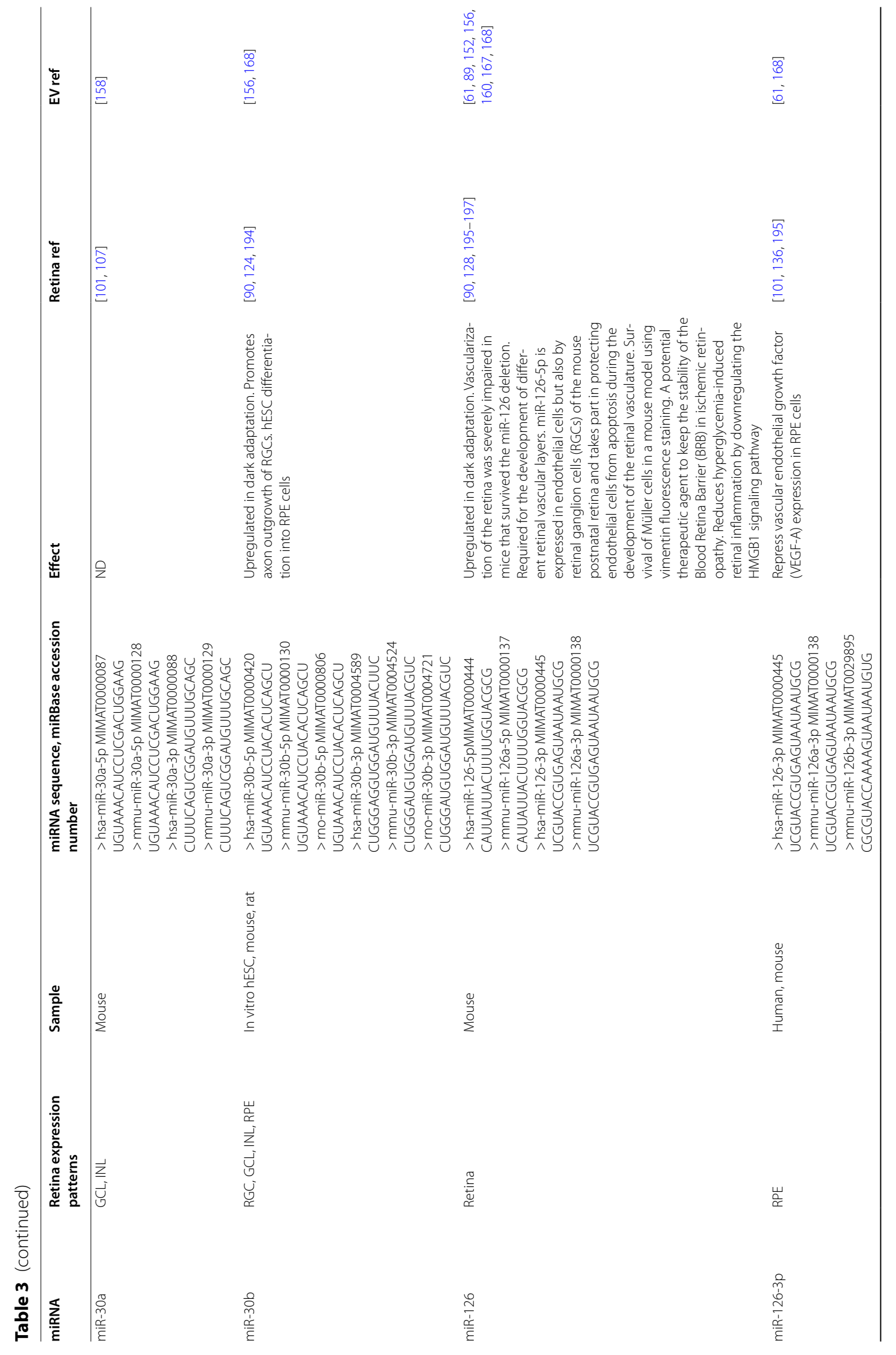




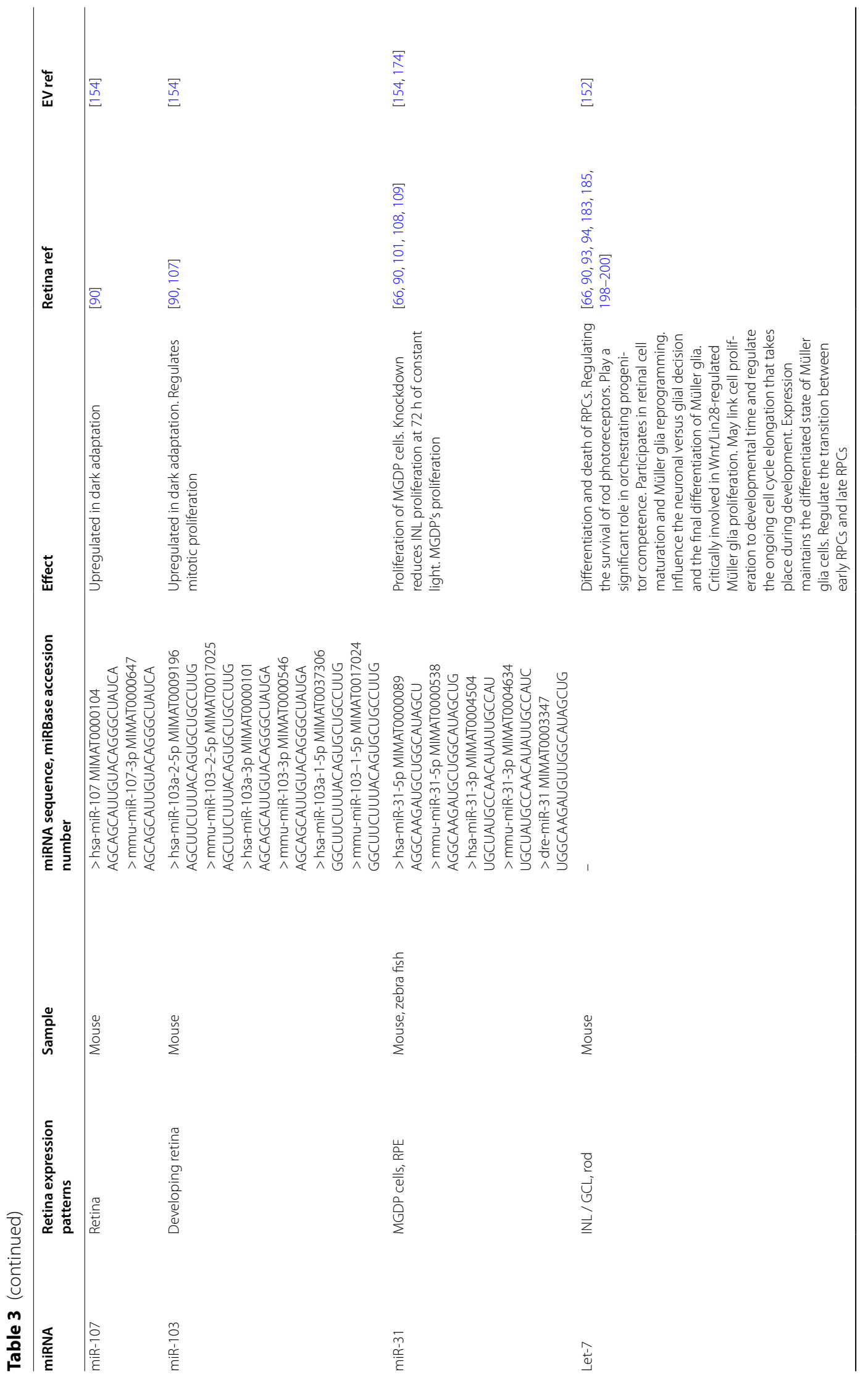




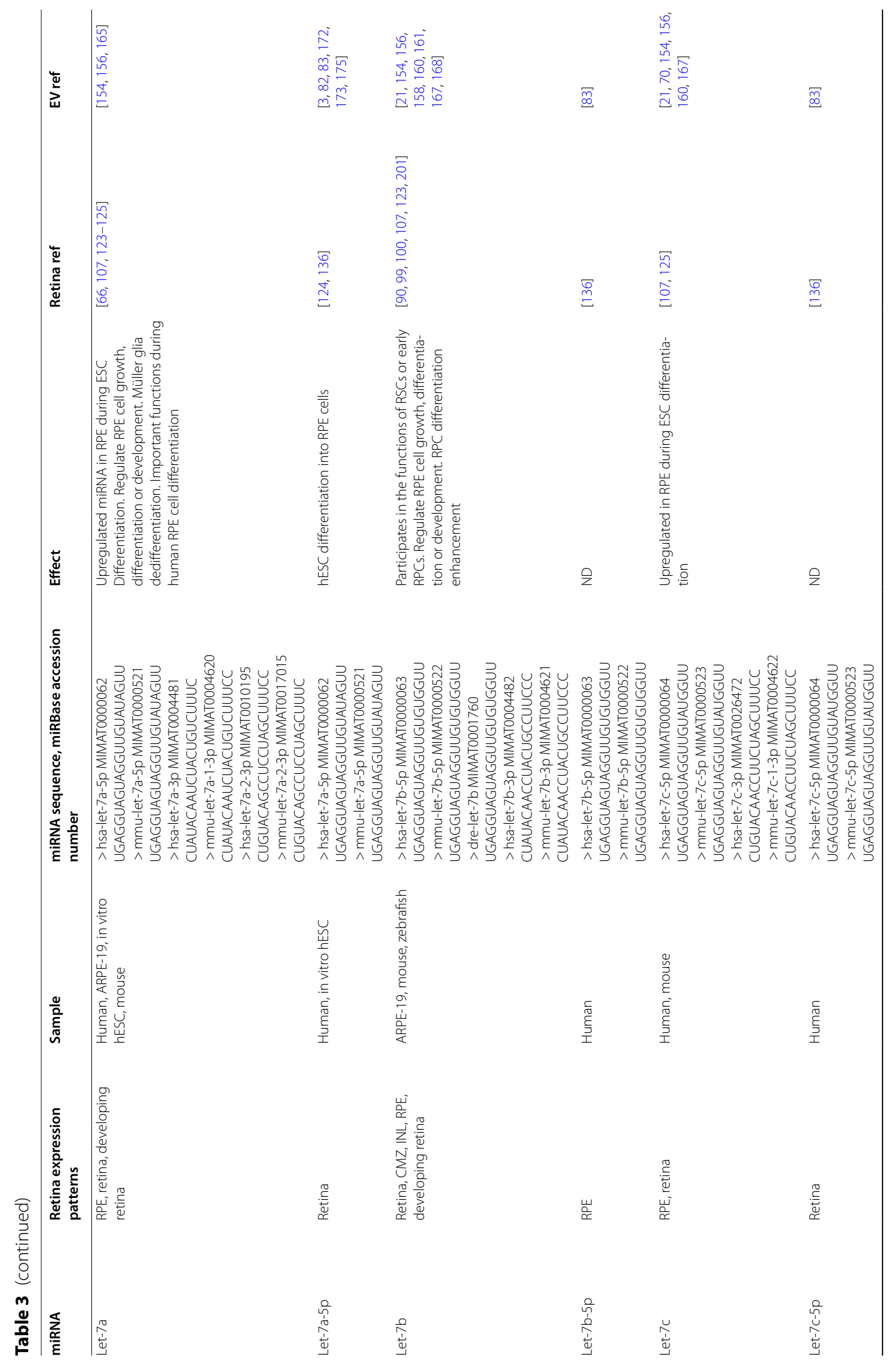




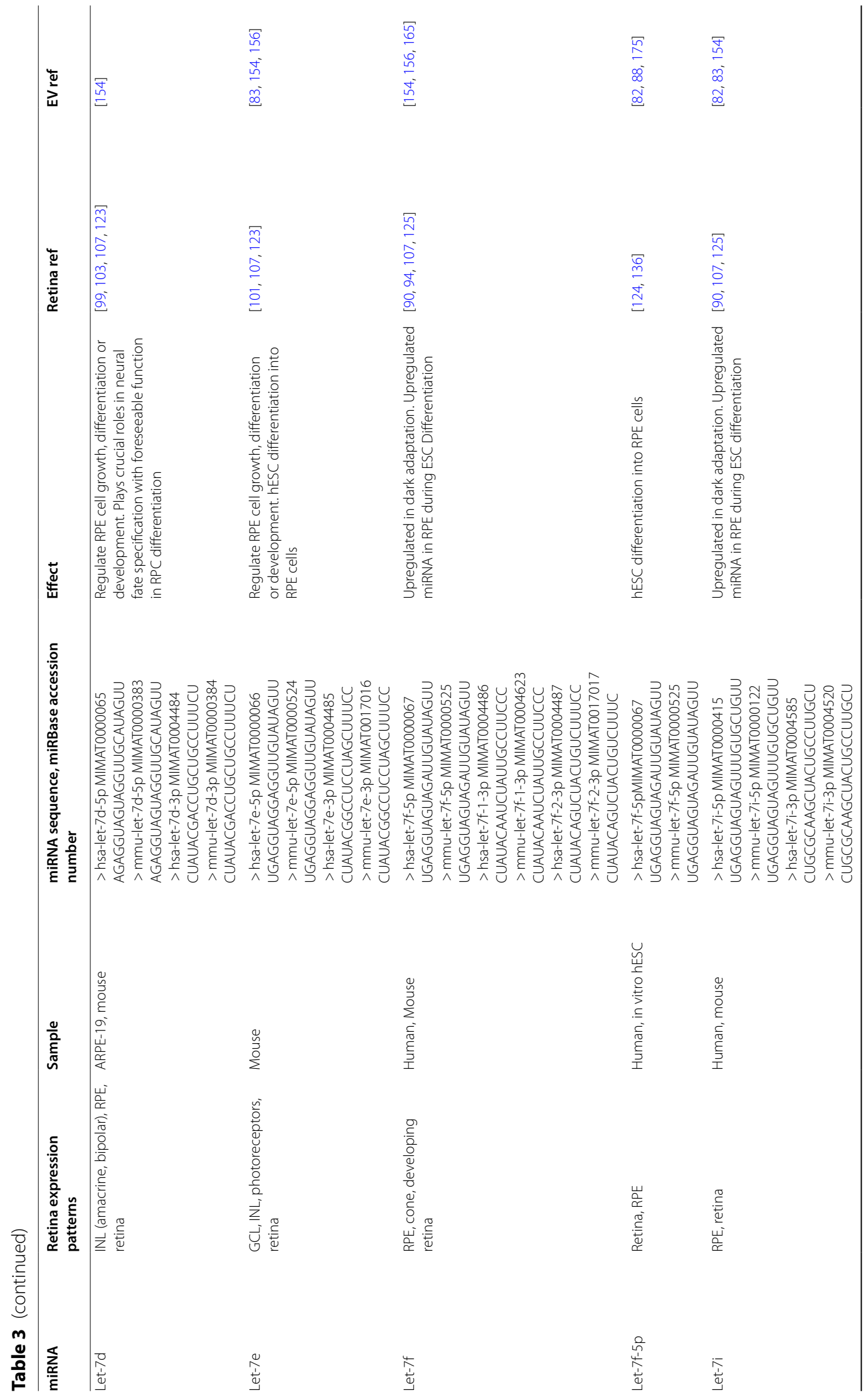




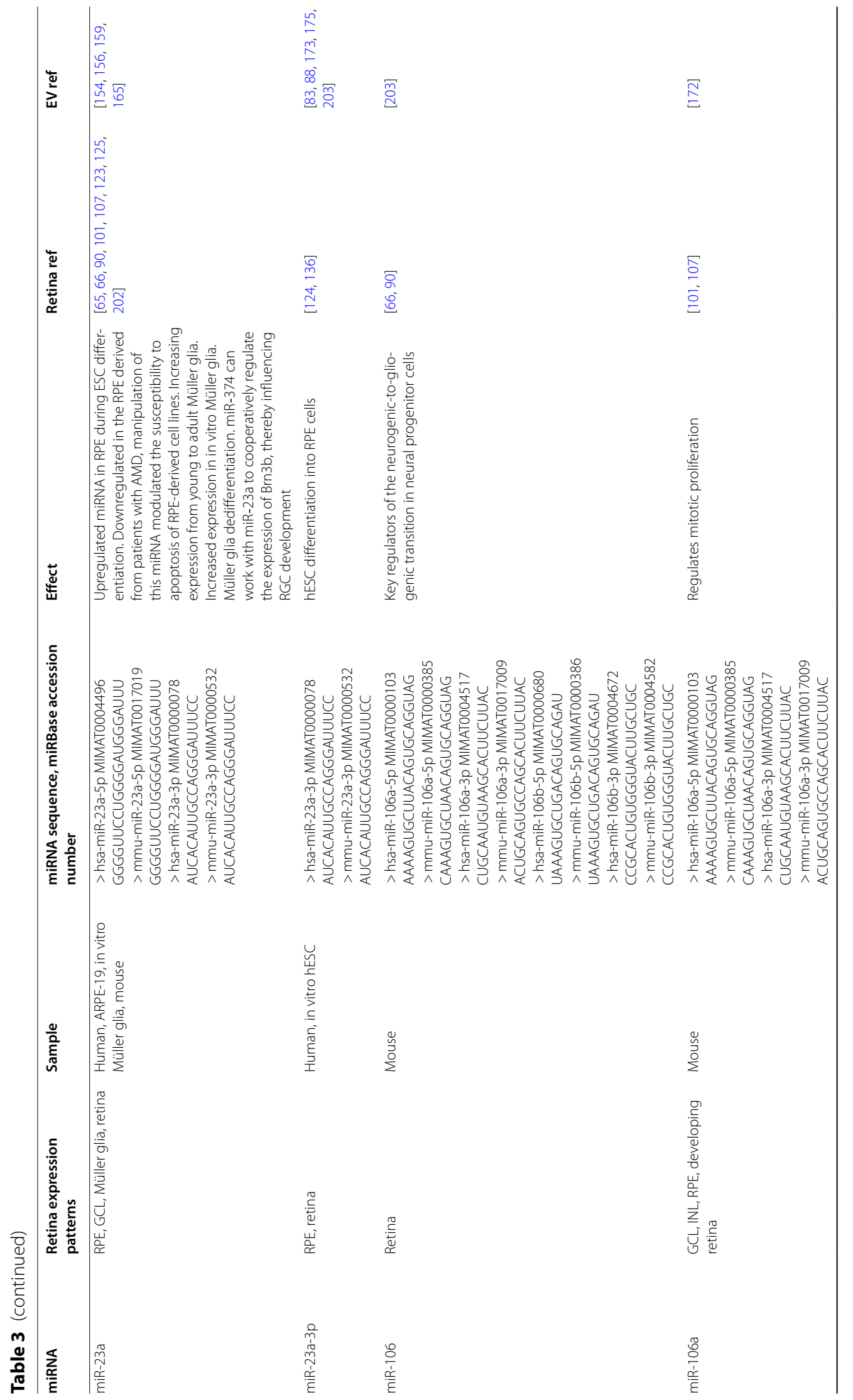




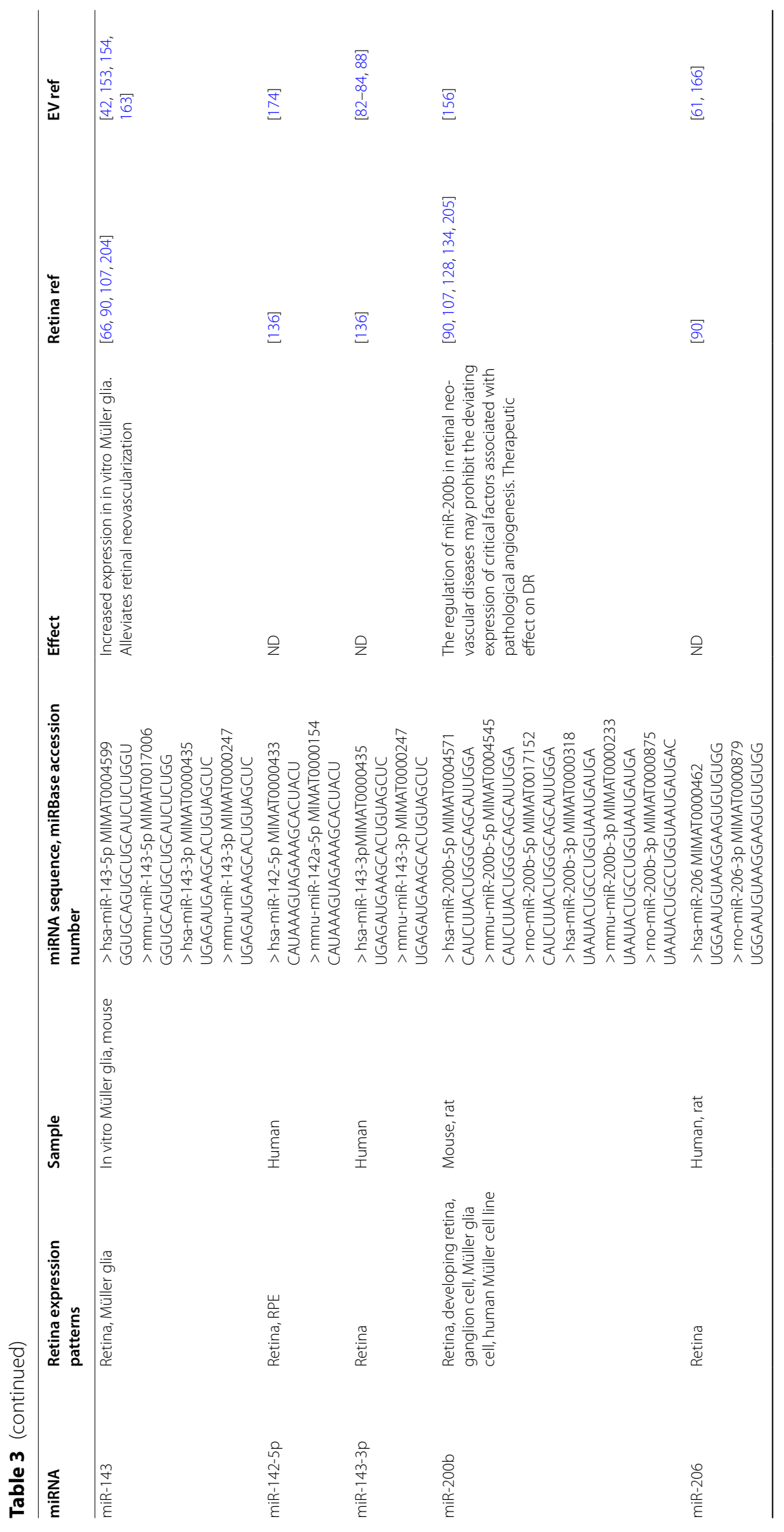


Rajool Dezfuly et al. Stem Cell Res Ther ～(2021) 12:530

Page 27 of 51

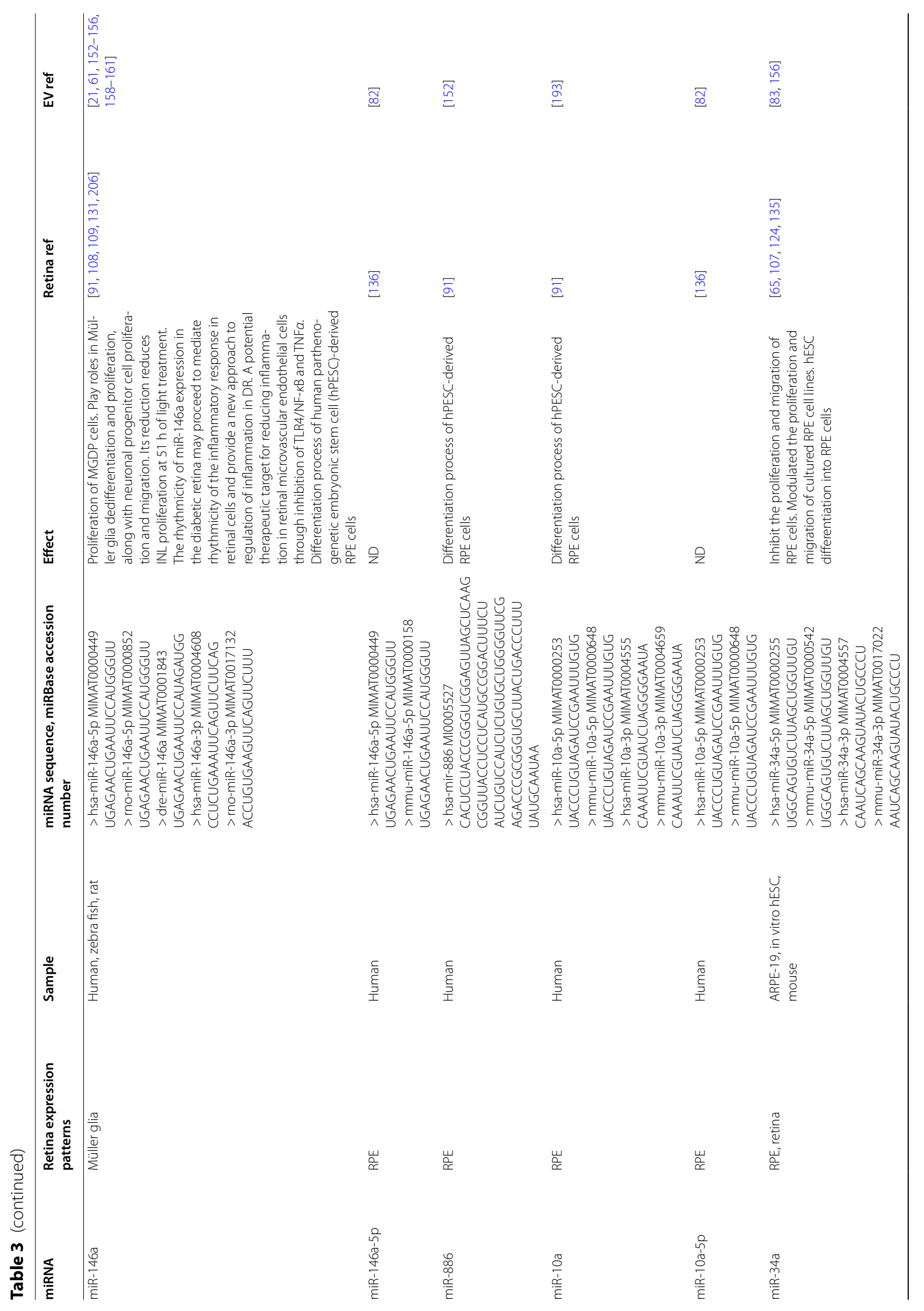




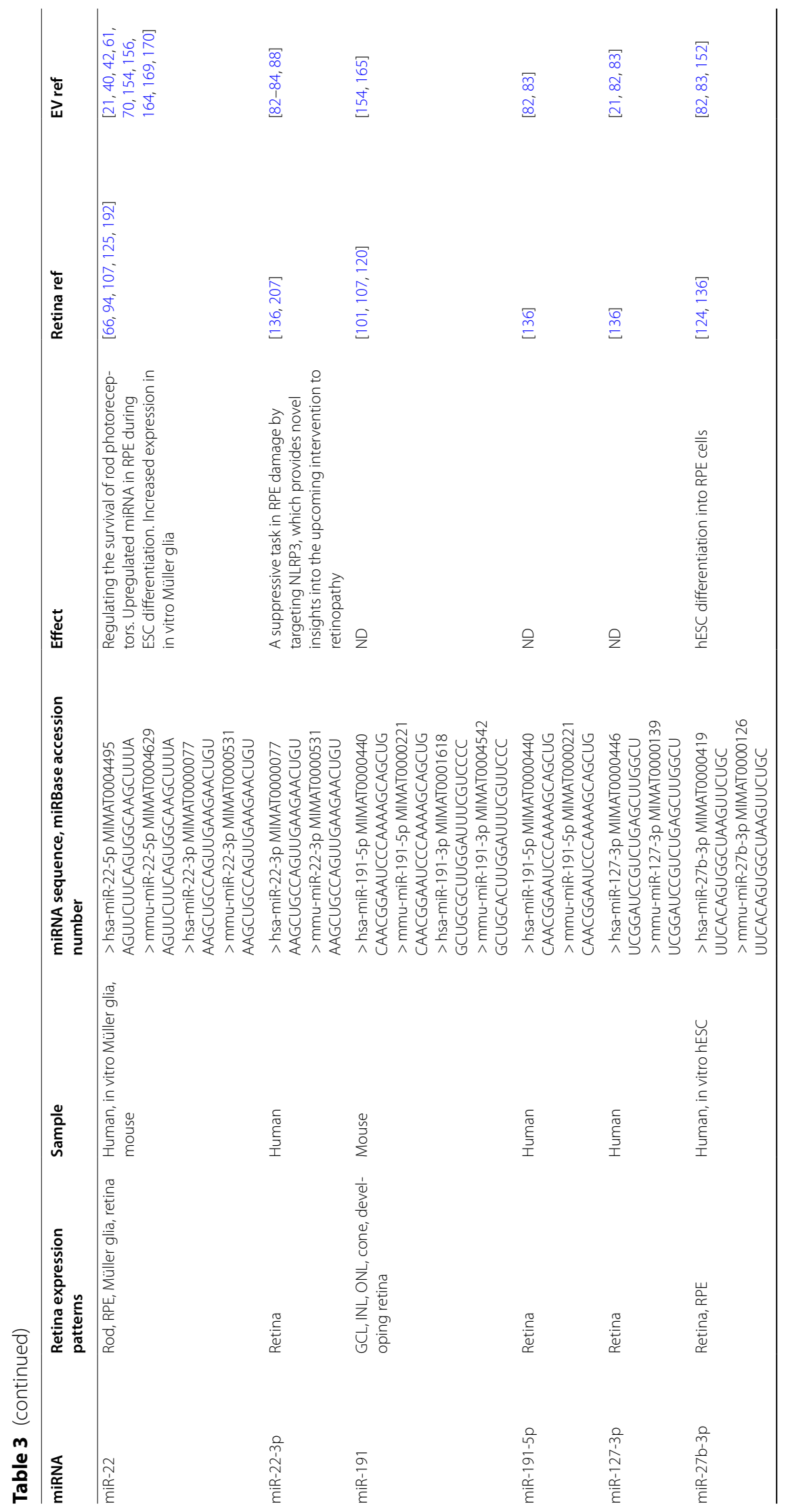




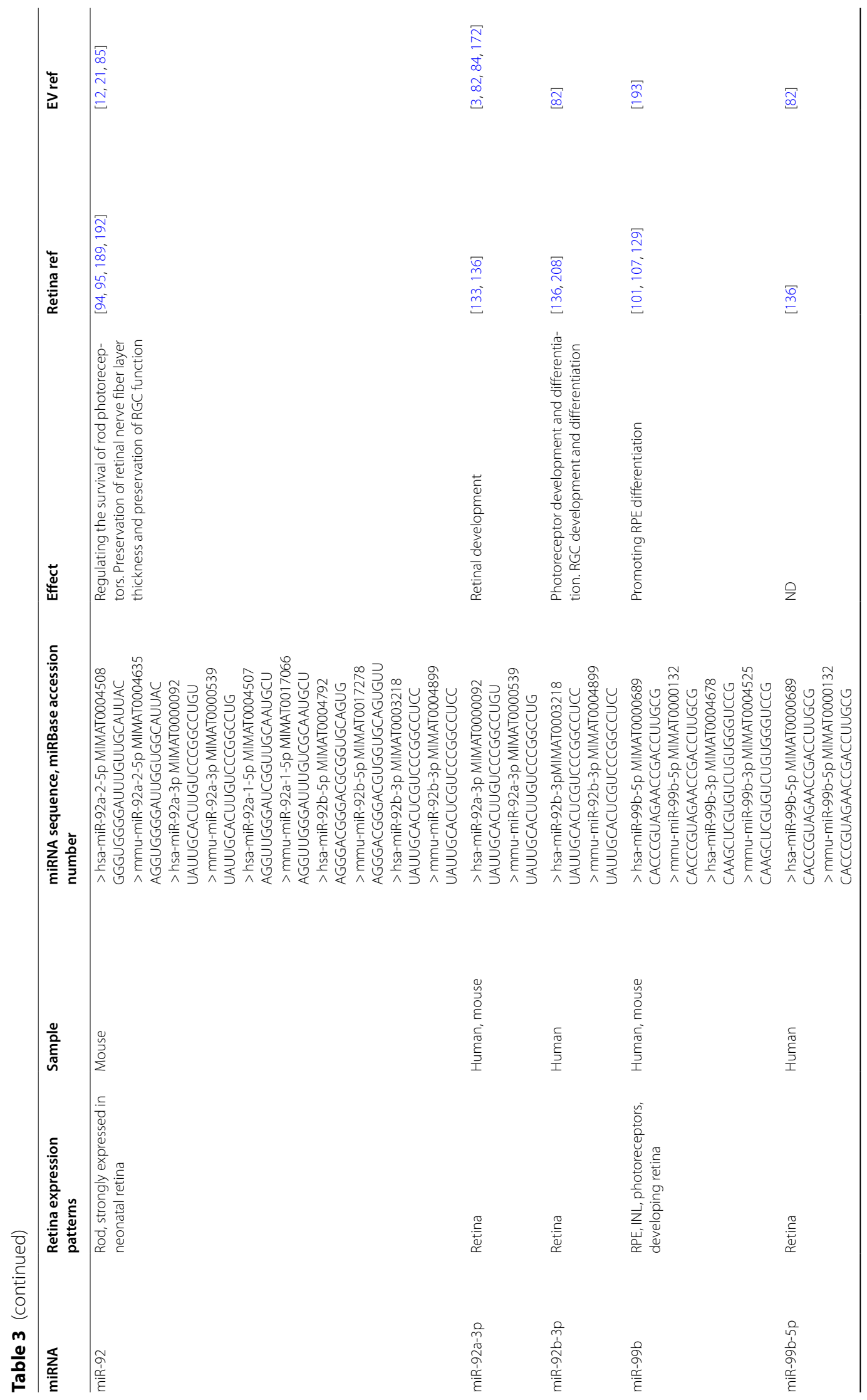




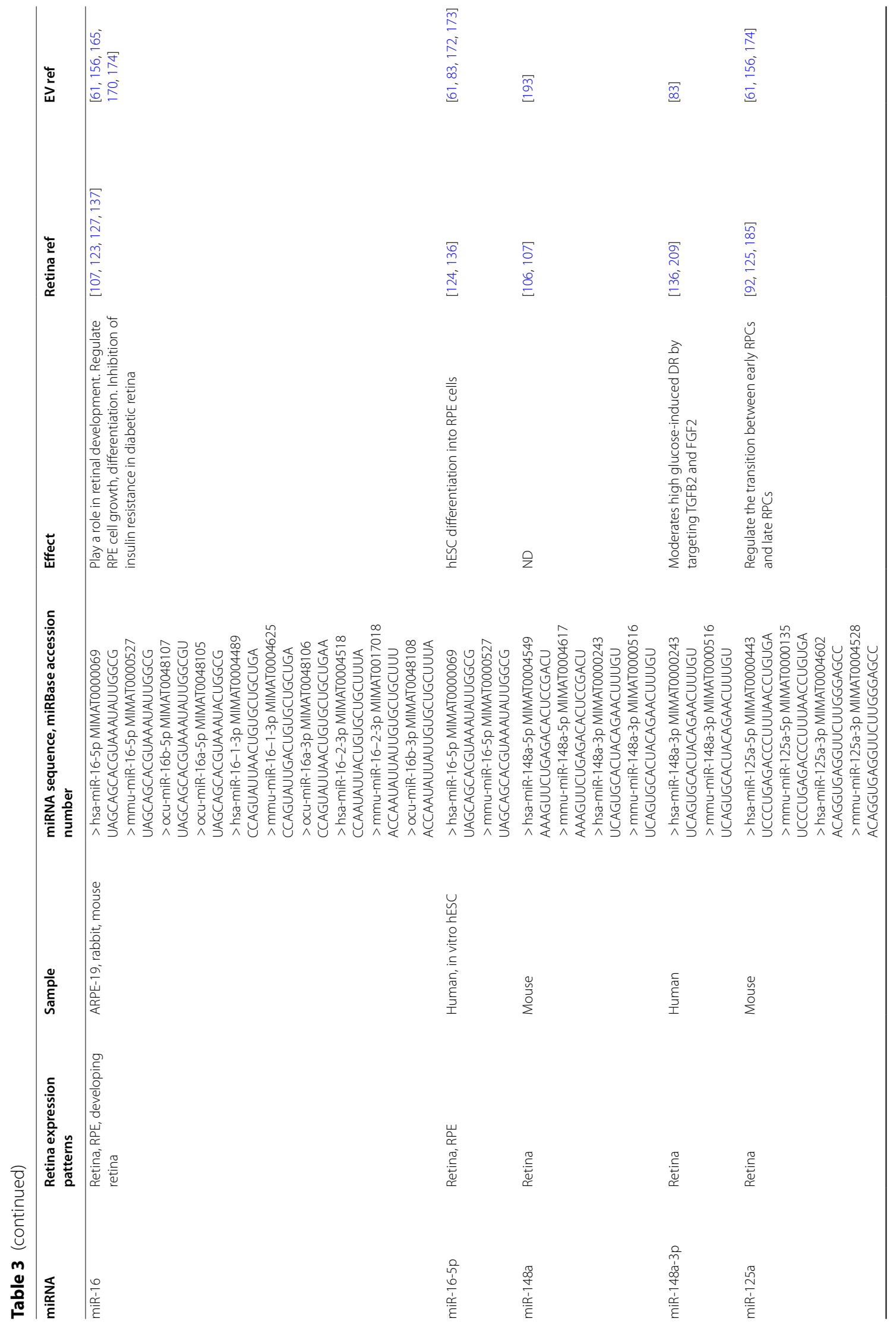




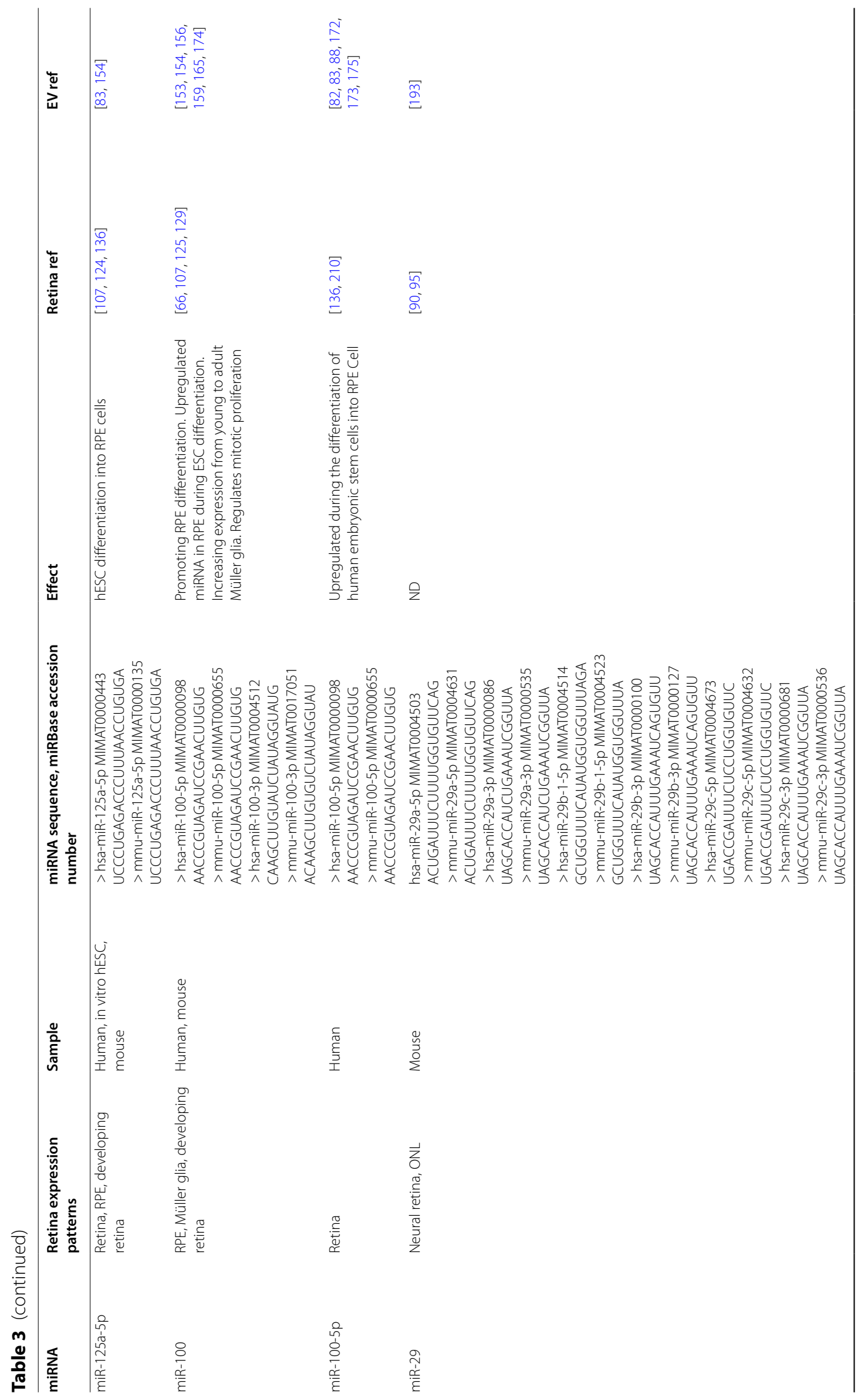


Rajool Dezfuly et al. Stem Cell Res Ther ～(2021) 12:530

Page 32 of 51

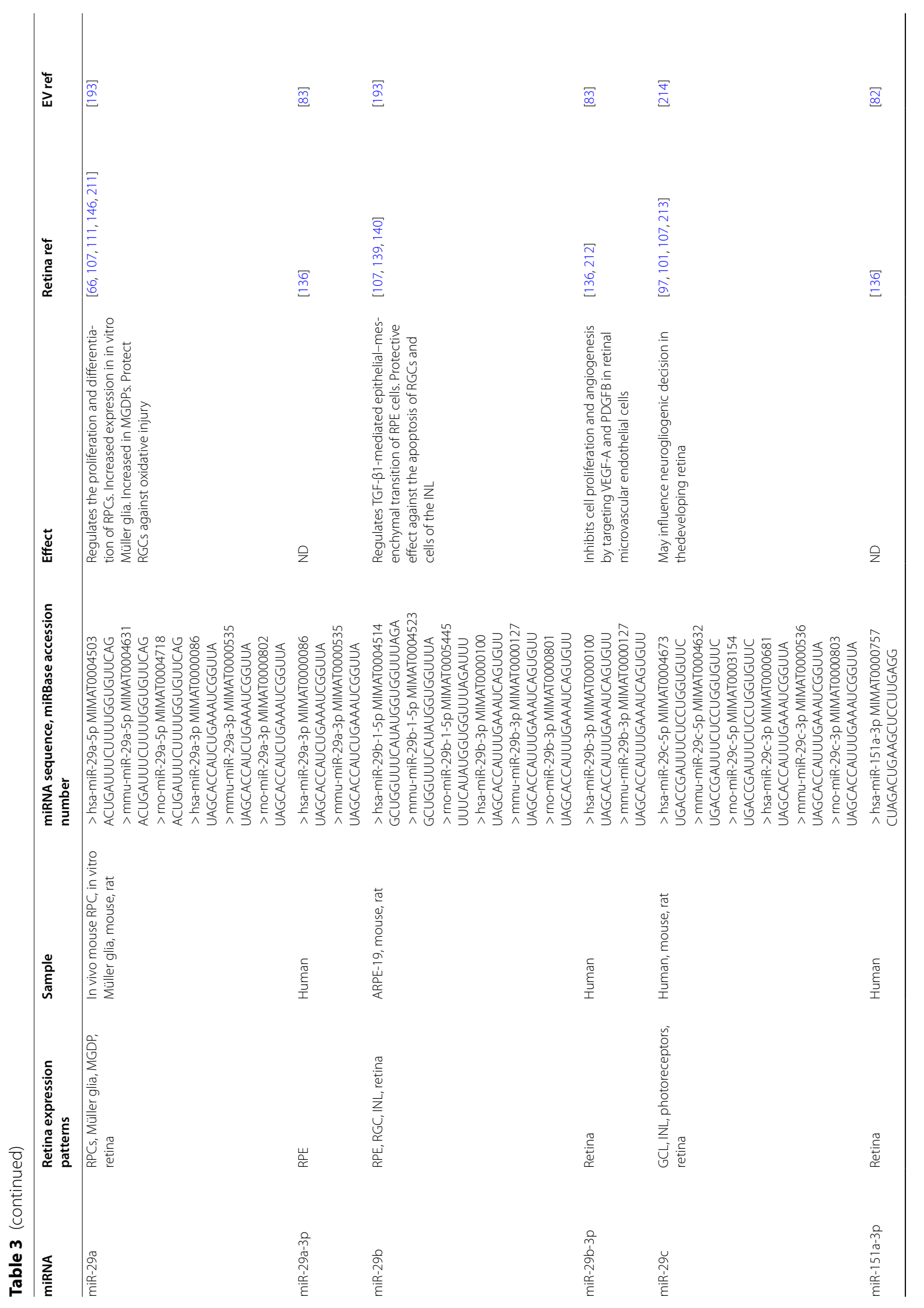


Rajool Dezfuly et al. Stem Cell Res Ther ～(2021) 12:530

Page 33 of 51

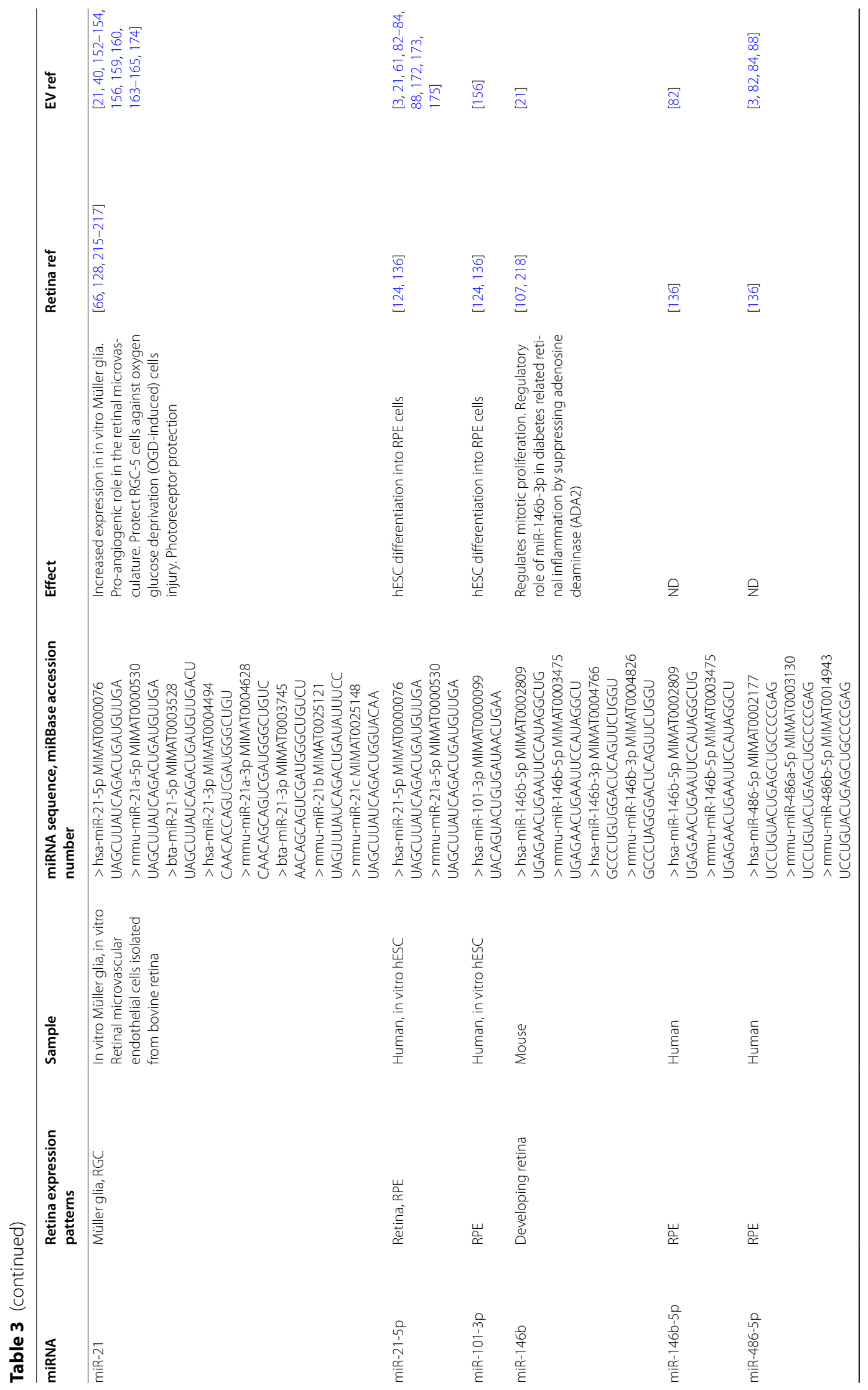




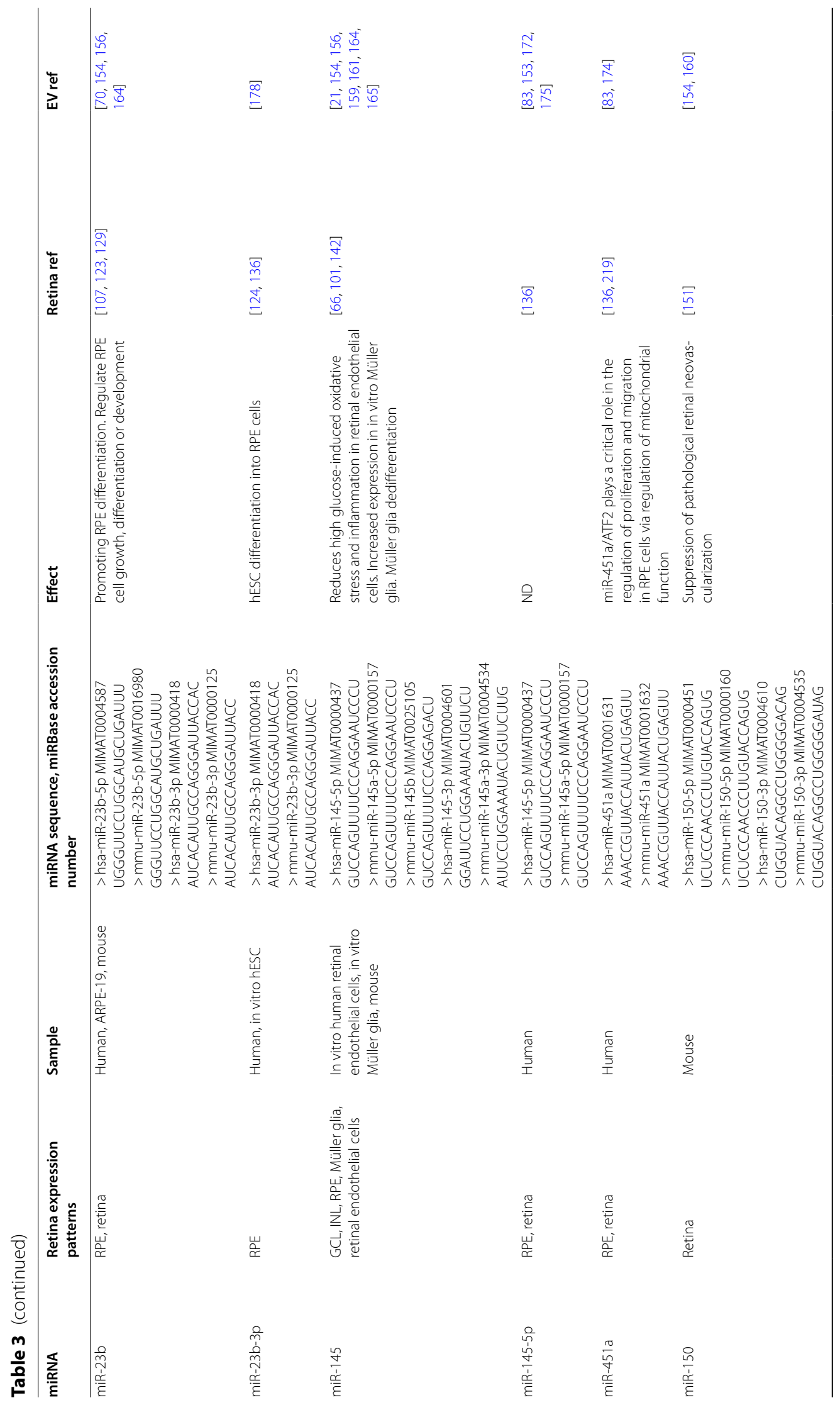


Rajool Dezfuly et al. Stem Cell Res Ther ～(2021) 12:530

Page 35 of 51

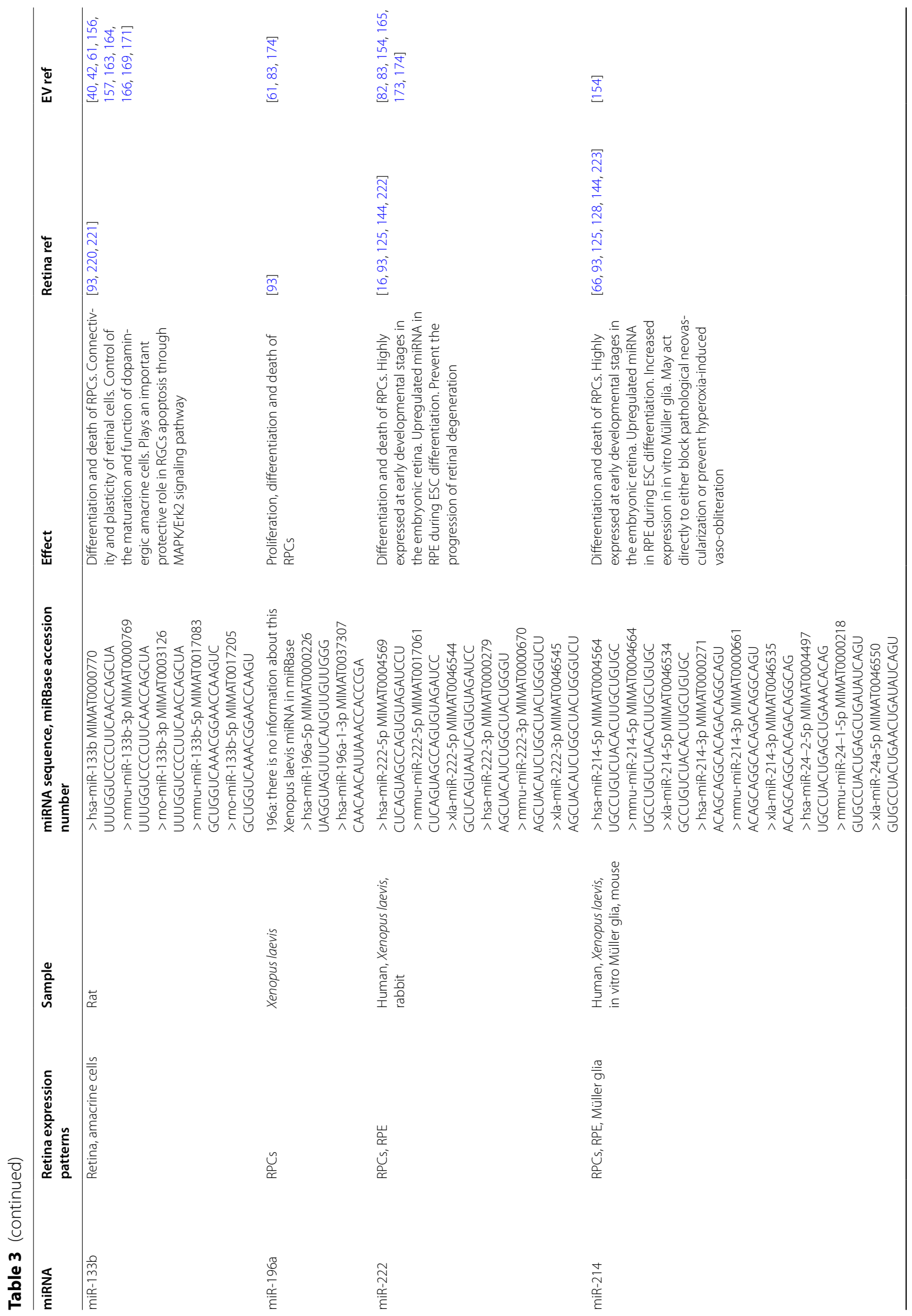




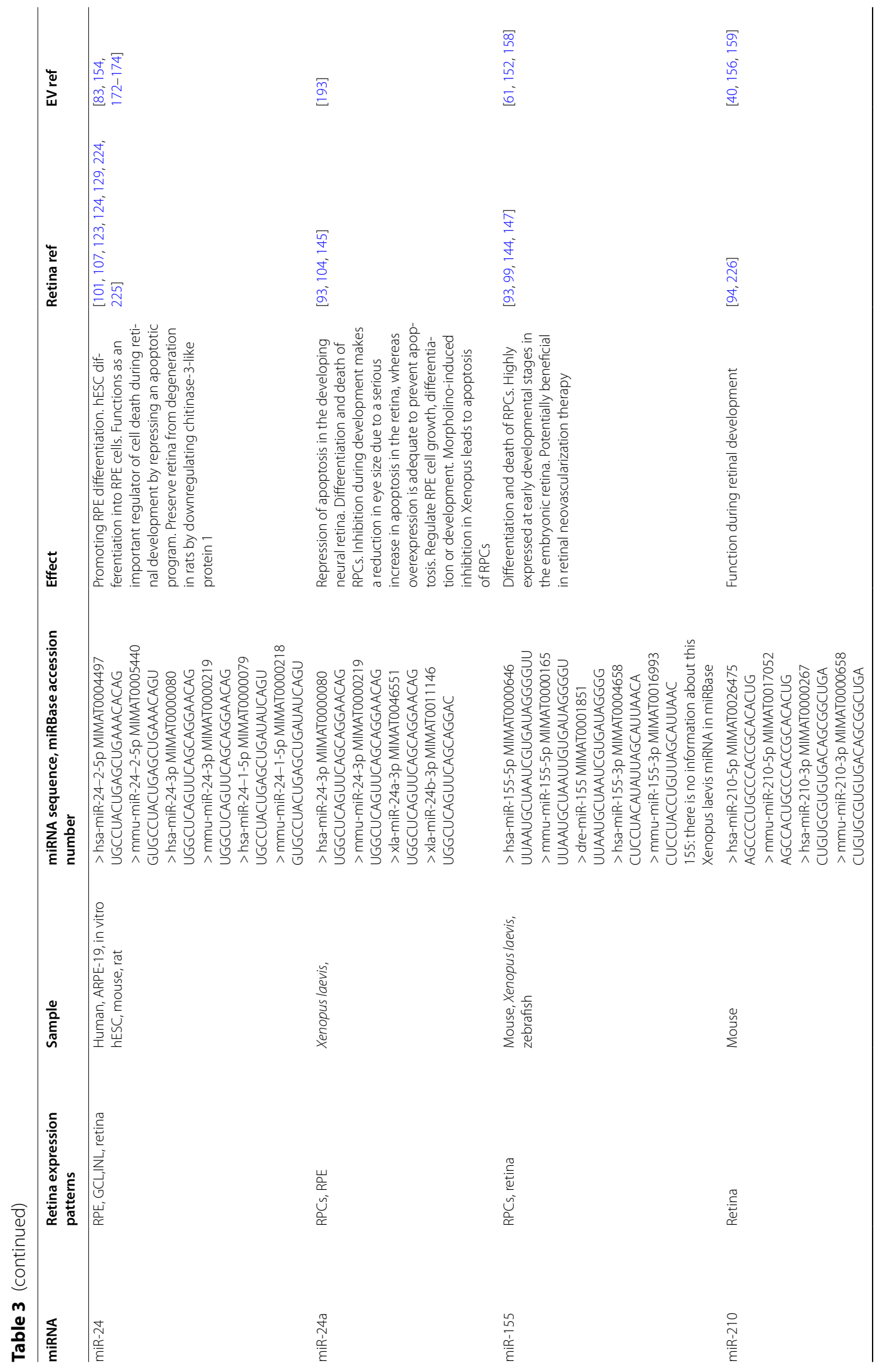


Rajool Dezfuly et al. Stem Cell Res Ther ～(2021) 12:530

Page 37 of 51

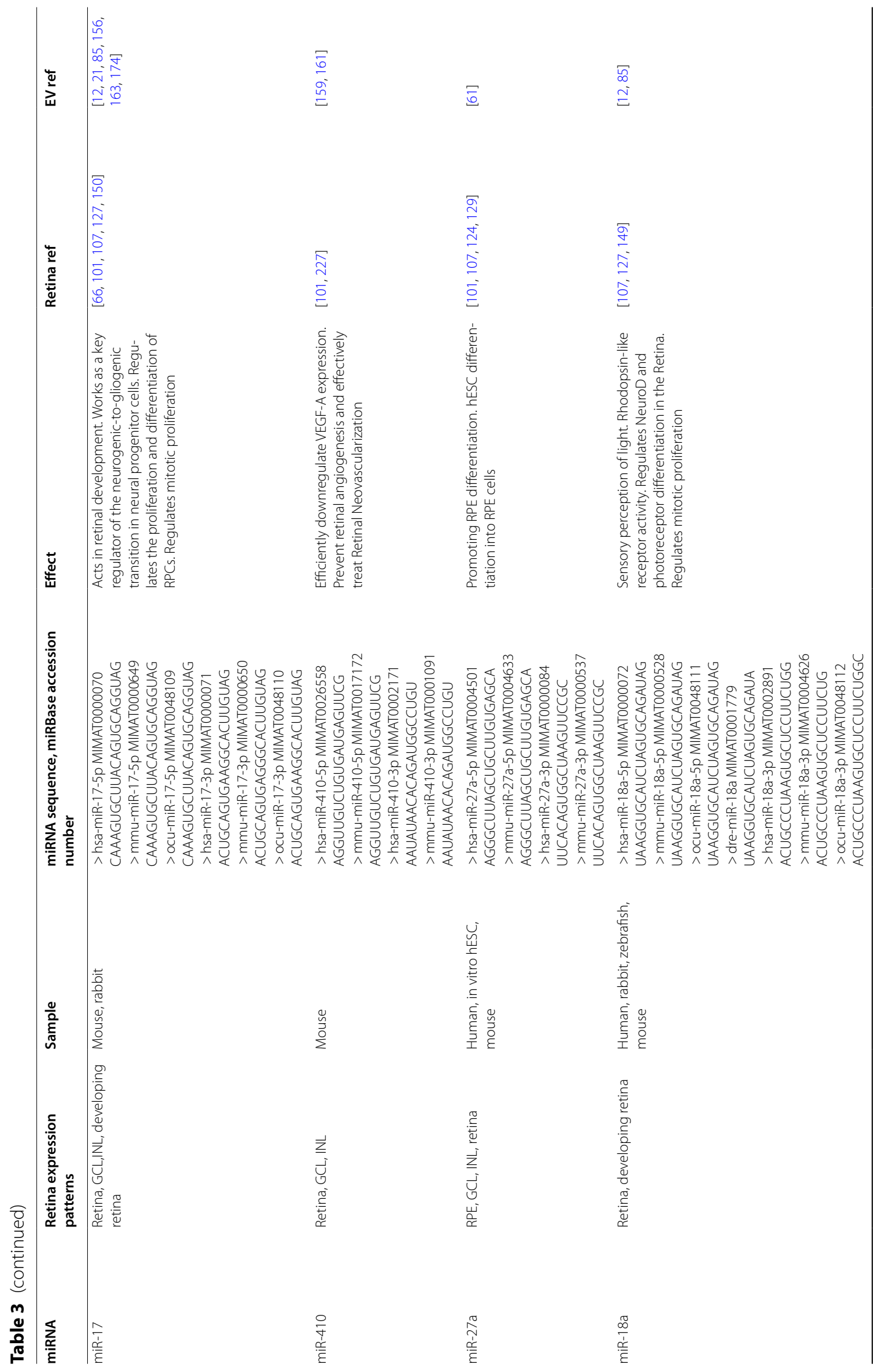




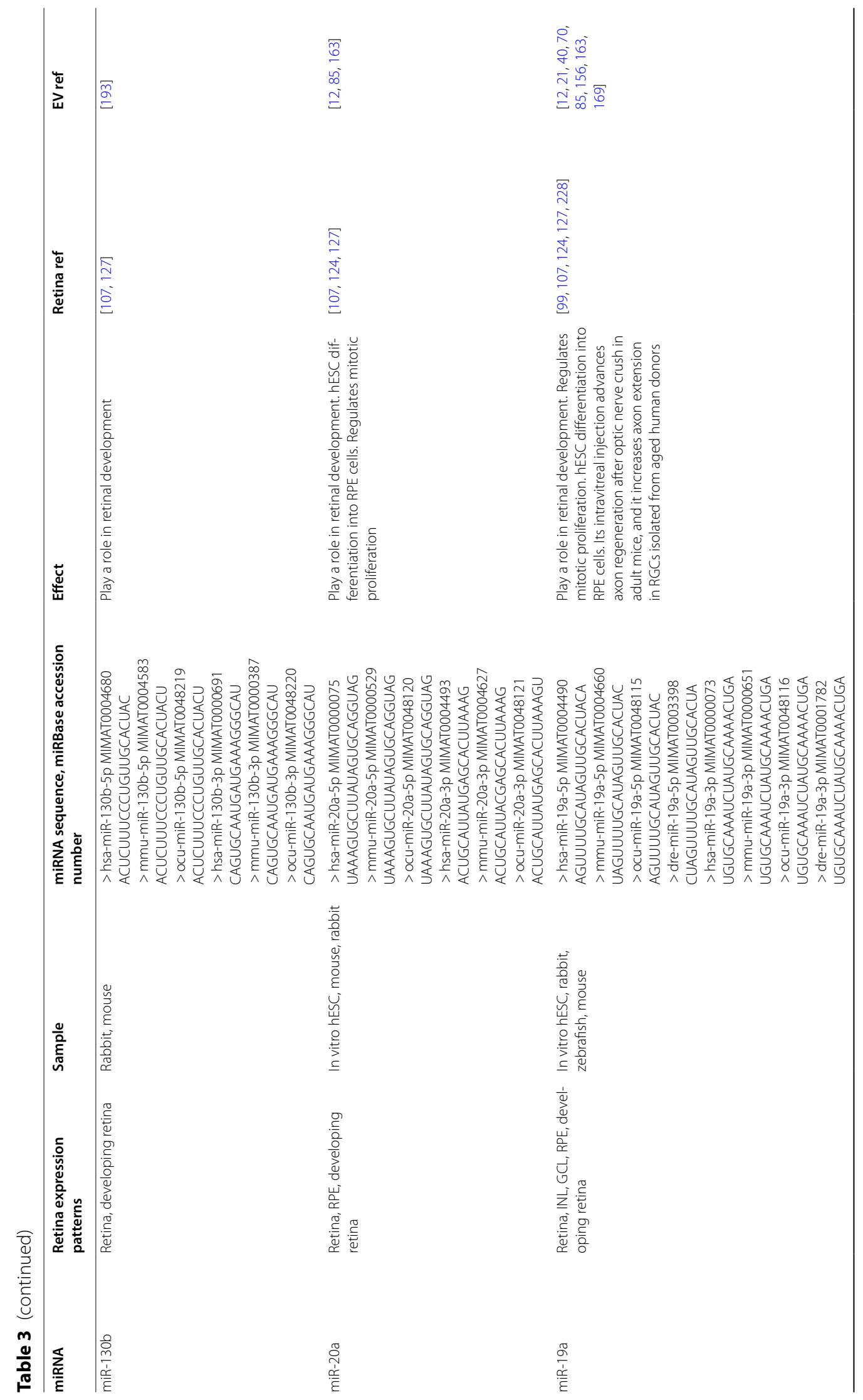




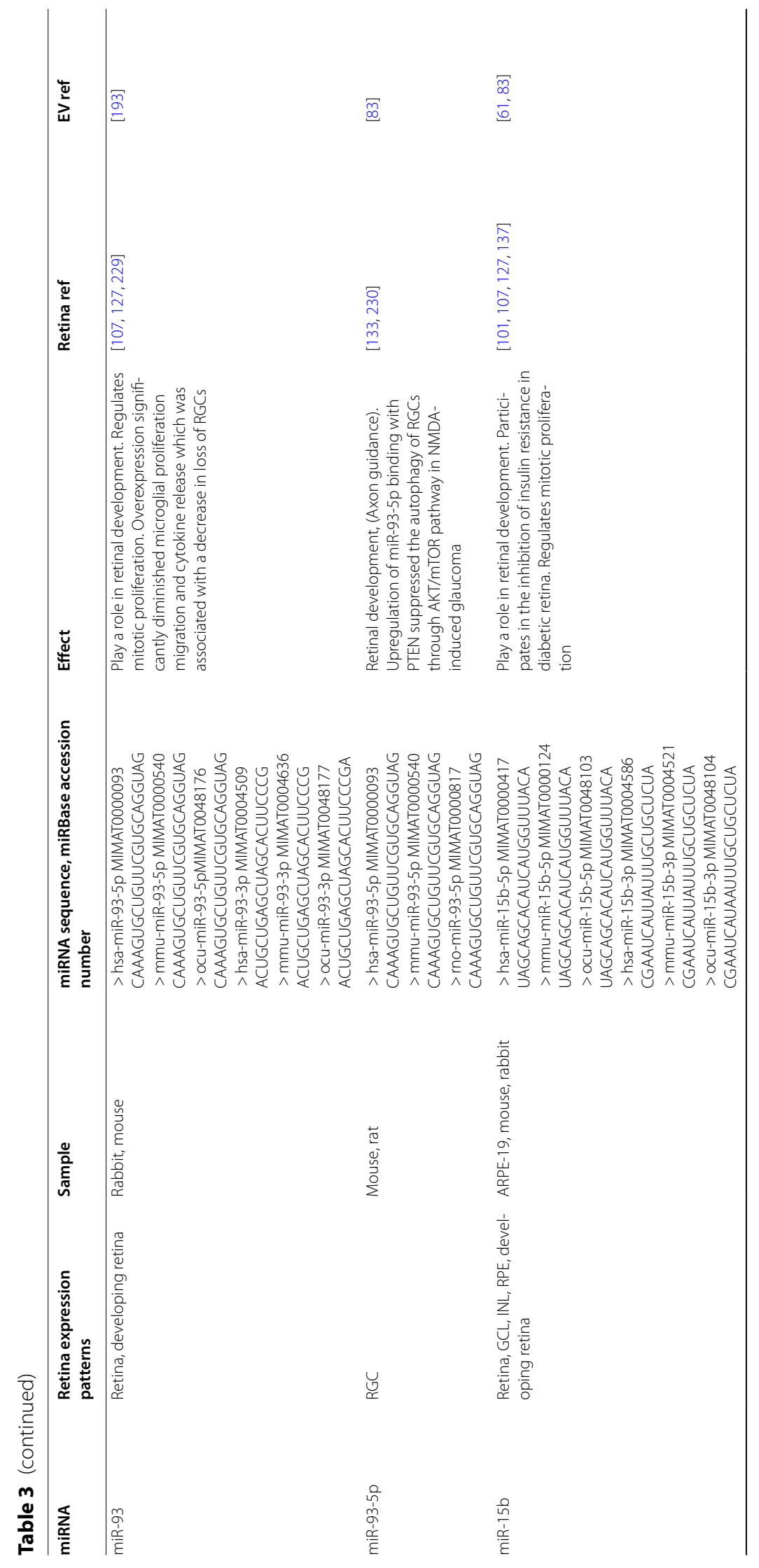


Rajool Dezfuly et al. Stem Cell Res Ther ～(2021) 12:530

Page 40 of 51

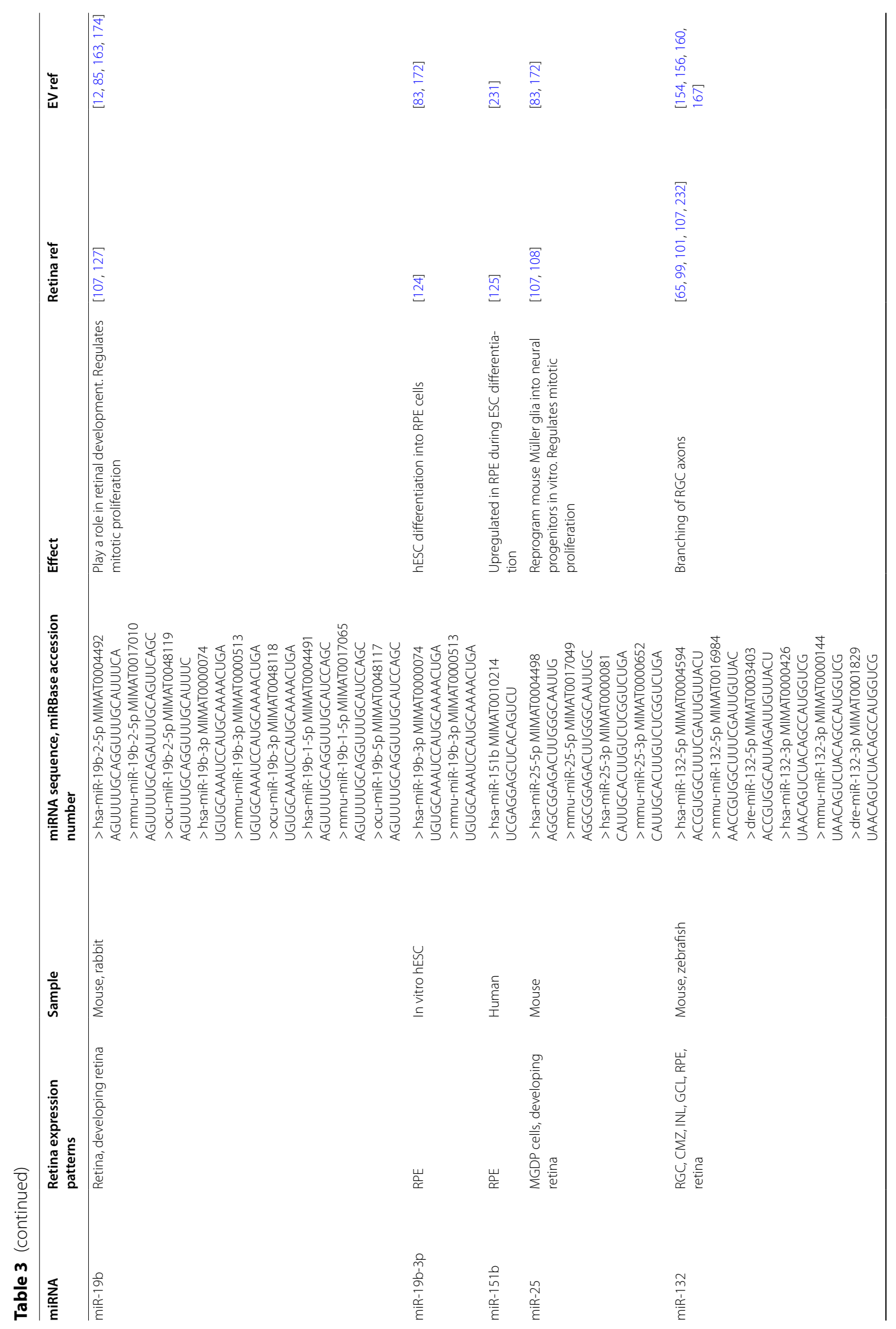




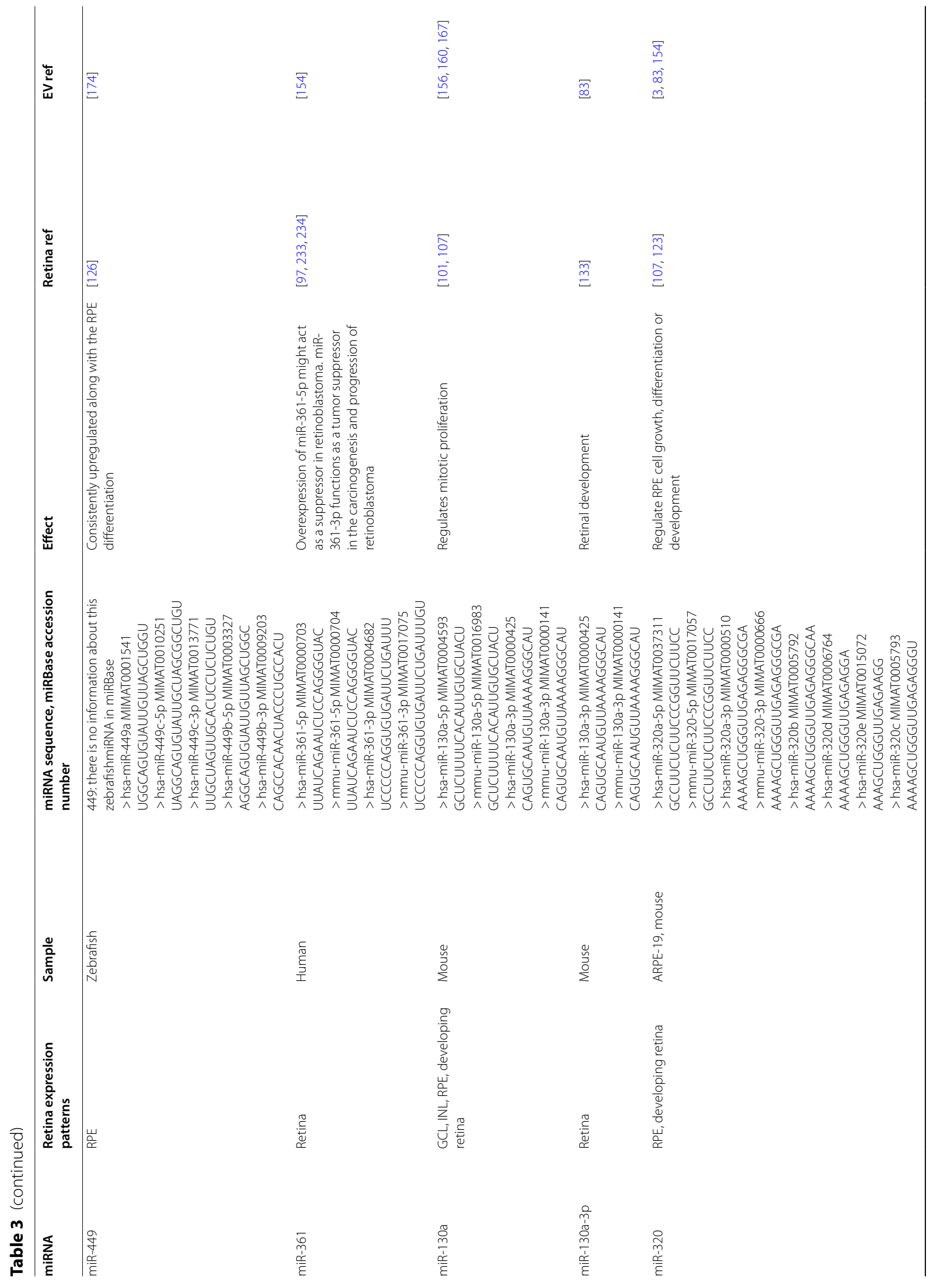




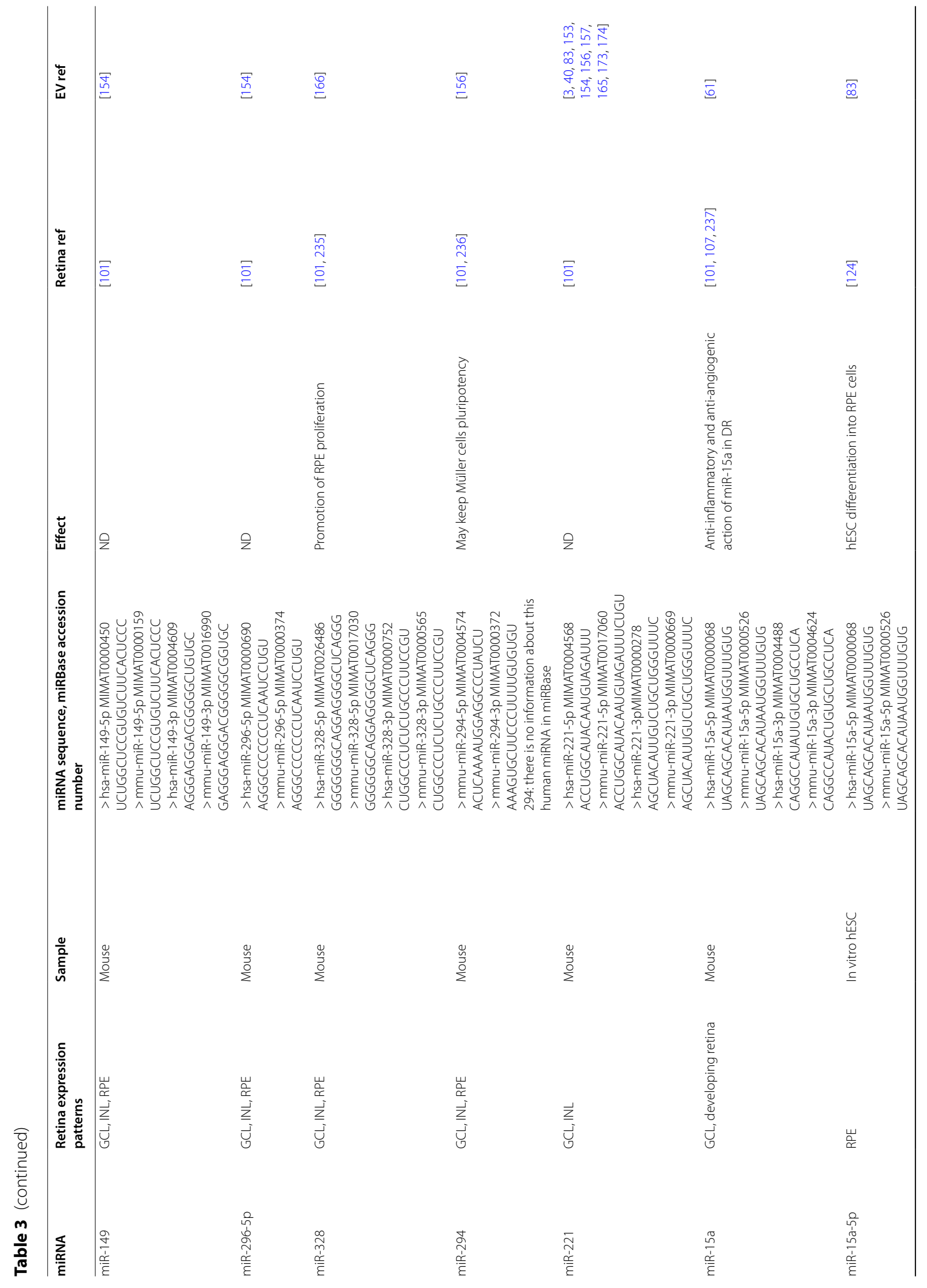




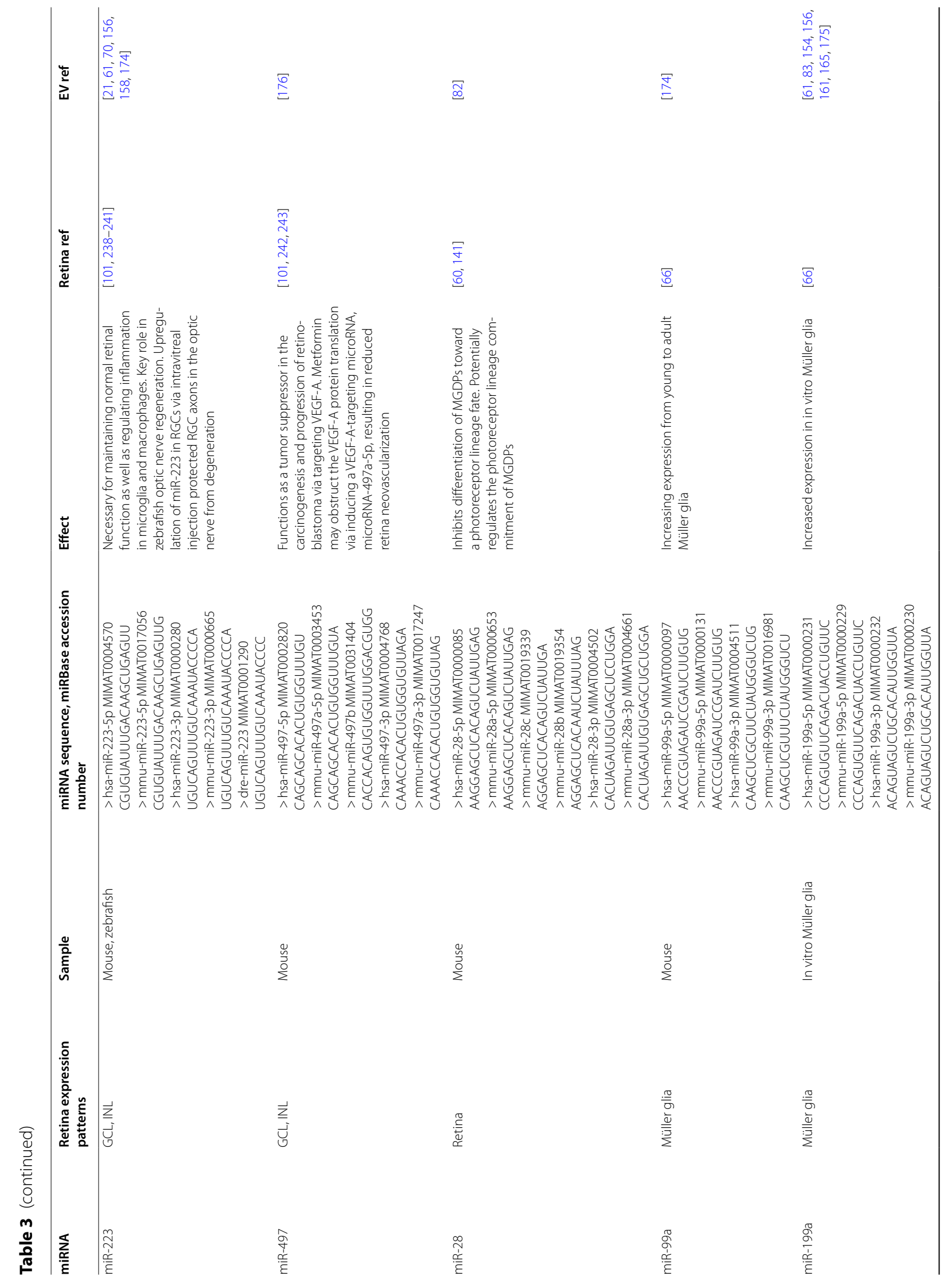




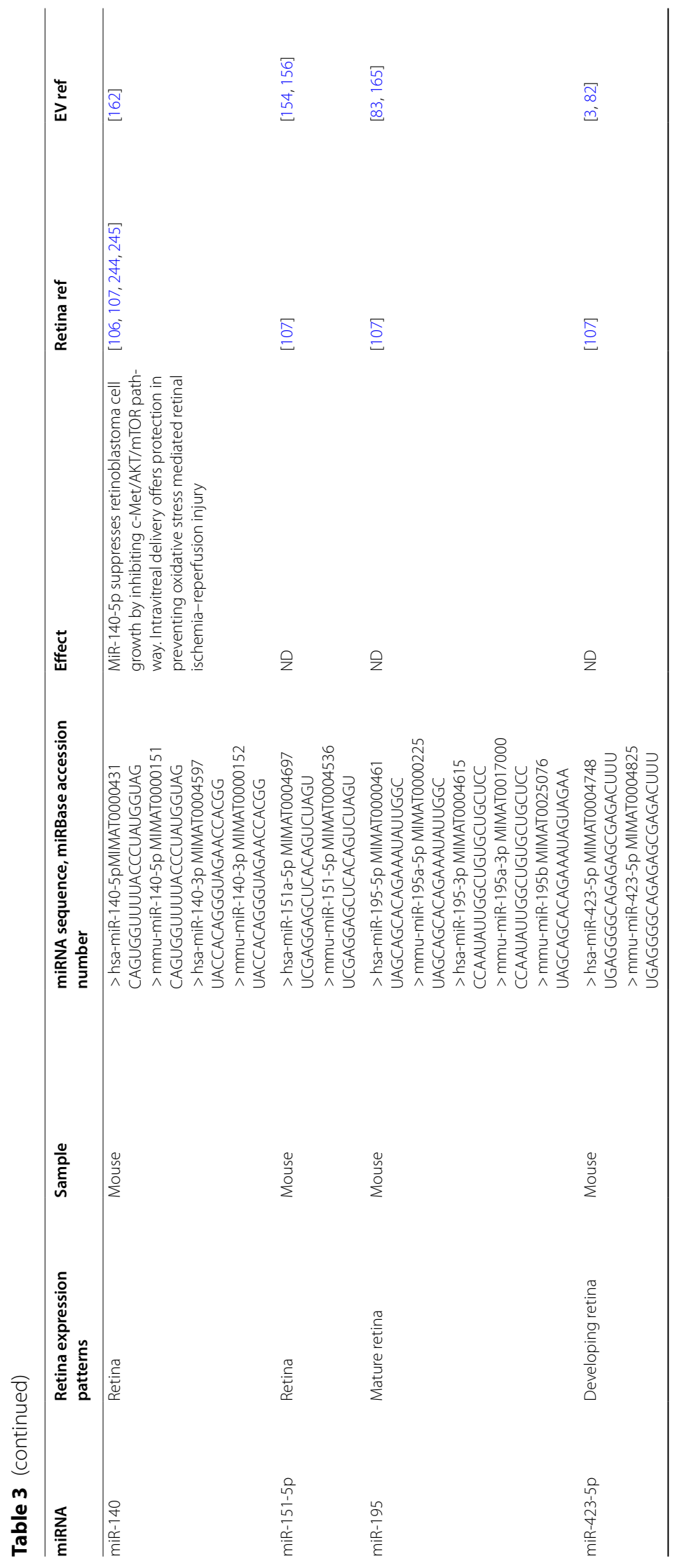


Rajool Dezfuly et al. Stem Cell Res Ther ～(2021) 12:530

Page 45 of 51

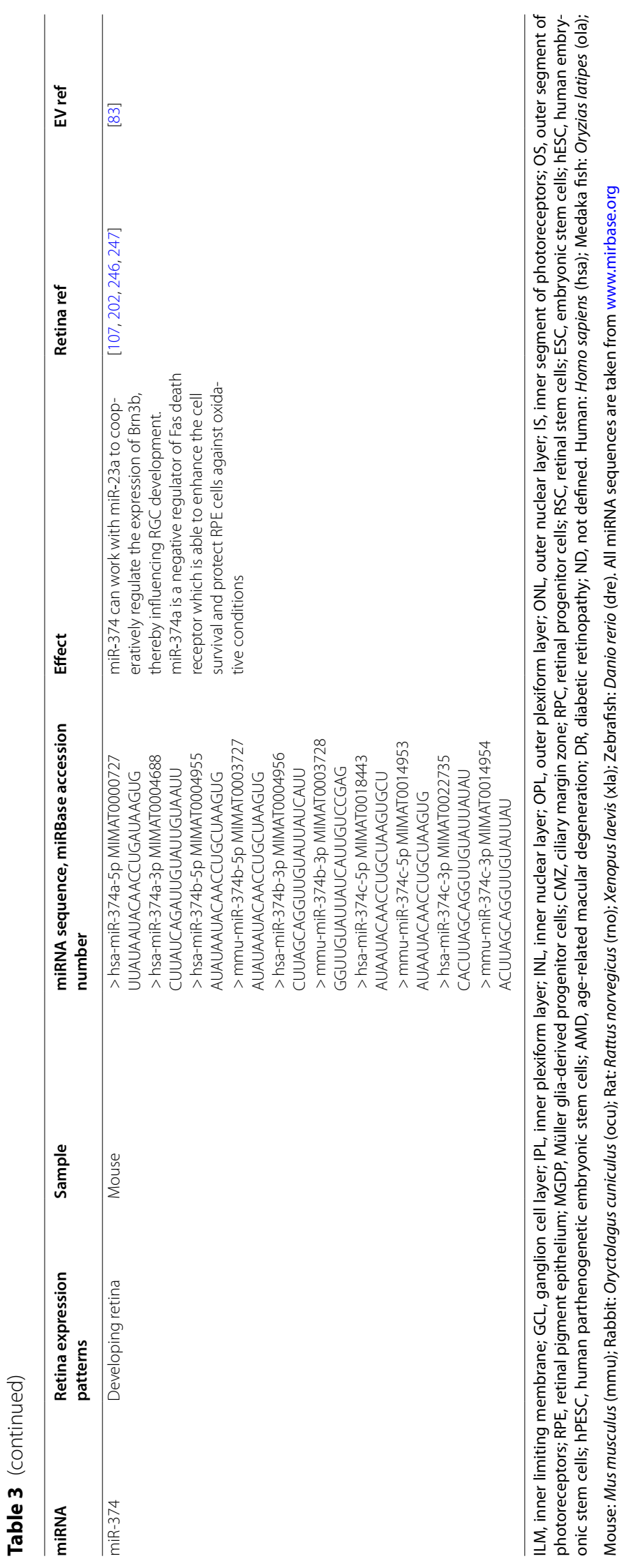


therapeutic effects on it. A few miRNAs have various proven functions in retina: for instance, miR-204 plays roles in differentiation, development and decreasing apoptosis whereas miR-124 has effects on differentiation, proliferation, survival of photoreceptors, plasticity and connectivity of neurons and a studied positive effect on retinal degeneration. The data are presented in detail in Table 3.

\section{Conclusions}

miRNAs have complicated functions in retinal health and disease which most of them are yet to be understood. Each miRNA can regulate the whole genetic program of a cell, so knowing their specific effects on different types of cells could be helpful for designing more beneficent studies and therapies. Owing to the fact that a miRNA has many mRNA targets, we should consider that we still don't know many functions of miRNAs and the procedures of their actions. Although multifunctional miRNAs such as miR-204, miR-124 seem more promising, the timing of their application should be planned more precisely to avoid undesired effects. Besides having other therapeutic agents, MSC-EVs are a great source of miRNAs which make them a good choice for a multifactorial therapy.

Identifying miRNAs that are common between retinal cells and MSC-EVs, with due attention to the role of miRNAs as master regulators, could help us to preserve or restore the state of retinal cells in a more accurate way in retinal degenerative diseases.

\begin{abstract}
Abbreviations
Ago: Argonaute; Ago2: Argonaute2; AMD: Age-related macular degeneration; ARPE-19: A human retinal pigment epithelial cell line; BMSC: Bone marrow mesenchymal stem cells; BRB: Blood retina barrier; CMZ: Ciliary margin zone; CNS: Central nervous system; DR: Diabetic retinopathy; ESC: Embryonic stem cells; EV: Extracellular vesicles; GCL: Ganglionic cell layer; hBMSC: Human bone marrow mesenchymal stem cells; hESC: Human embryonic stem cells; hnRNP: Heterogeneous nuclear ribonucleoproteins; hPESC: Human parthenogenetic embryonic stem cell; hRPE: Human retinal pigment epithelium; IBD: Inflammatory bowel disease; INL: Inner nuclear layer; IPF: Idiopathic pulmonary fibrosis; IPL: Inner plexiform layer; iPSCs: Induced pluripotent stem cells; ISCT: International Society for Cellular Therapy; MG: Müller glia; MGDP: Müller glia-derived progenitor cells; miRNA: MicroRNA; mRNA: Messenger RNA; MSCs: Mesenchymal stem cells; MSC-EVs: Mesenchymal stem cells extracellular vesicles; MSC-Exos: Mesenchymal stem cells exosomes; MVB: Multivesicular bodies; ONL: Outer nuclear layer; OS: Outer segments; PTEN: Phosphatase and tensin homolog; RBVS: Retinoblastoma vitreous seeding; RISC: RNA-induced silencing complex; RPC: Retinal progenitor cells; RSC: Retinal stem cells; RPE: Retinal pigment epithelium; siRNA: Short interfering RNA; SYNCRIP: Synaptotagminbinding cytoplasmic RNA-interacting protein; VEGF-A: : Vascular endothelial growth factor; WJ-MSC: Wharton's jelly mesenchymal stem cell.
\end{abstract}

\section{Acknowledgements}

Not applicable.

\section{Authors' contributions}

$A R D, A S$ and $H S$ contributed to conceptualization and writing - review and editing; ARD and AS contributed to writing-original draft preparation and visualization; HS contributed to supervision. All authors have read and agreed to the published version of the manuscript.

Funding

Not applicable.

Availability of data and material

Not applicable.

\section{Declarations}

Ethics approval and consent to participate

Not applicable.

Consent for publication

Not applicable.

Competing interests

The authors declare that they have no competing interests.

Received: 26 July 2021 Accepted: 9 September 2021

Published online: 07 October 2021

\section{References}

1. Salehi $\mathrm{H}$, et al. Overview of retinal differentiation potential of mesenchymal stem cells: a promising approach for retinal cell therapy. Ann Anat Anat Anz. 2017:210:52-63.

2. Hoffman LM, Carpenter MK. Characterization and culture of human embryonic stem cells. Nat Biotechnol. 2005;23(6):699-708.

3. Mead B, Tomarev S. Extracellular vesicle therapy for retinal diseases. Prog Retin Eye Res. 2020;79:100849.

4. Sahni JN, et al. Therapeutic challenges to retinitis pigmentosa: from neuroprotection to gene therapy. Curr Genomics. 2011;12(4):276-84.

5. Berry M, Ahmed Z, Logan A. Return of function after CNS axon regeneration: lessons from injury-responsive intrinsically photosensitive and alpha retinal ganglion cells. Prog Retin Eye Res. 2019;71:57-67.

6. Berry M, et al. Regeneration of axons in the visual system. Restor Neurol Neurosci. 2008;26(2, 3):147-74.

7. Zhang $\mathrm{M}$, et al. The condition medium of mesenchymal stem cells promotes proliferation, adhesion and neuronal differentiation of retinal progenitor cells. Neurosci Lett. 2017;657:62-8.

8. Rabesandratana O, Goureau O, Orieux G. Pluripotent stem cell-based approaches to explore and treat optic neuropathies. Front Neurosci. 2018;12:651.

9. Djojosubroto MW, Arsenijevic Y. Retinal stem cells: promising candidates for retina transplantation. Cell Tissue Res. 2008:331(1):347-57.

10. Ding SLS, Kumar S, Mok PL. Cellular reparative mechanisms of mesenchymal stem cells for retinal diseases. Int J Mol Sci. 2017;18(8):1406.

11. Flower T, Pulsipher V, Moreno A. A new tool in regenerative medicine: mesenchymal stem cell secretome. J Stem Cell Res Ther. 2015;1 (1):10-2.

12. Mead B, Tomarev S. Bone marrow-derived mesenchymal stem cells-derived exosomes promote survival of retinal ganglion cells through miRNA-dependent mechanisms. Stem Cells Transl Med. 2017;6(4):1273-85.

13. Johnson TV, et al. Neuroprotective effects of intravitreal mesenchymal stem cell transplantation in experimental glaucoma. Investig Ophthalmol Vis Sci. 2010;51(4):2051-9.

14. Mead B, et al. Intravitreally transplanted dental pulp stem cells promote neuroprotection and axon regeneration of retinal ganglion cells after optic nerve injury. Investig Ophthalmol Vis Sci. 2013;54(12):7544-56.

15. van der Merwe Y, Steketee MB. Extracellular vesicles: biomarkers, therapeutics, and vehicles in the visual system. Curr Ophthalmol Rep. 2017;5(4):276-82.

16. Safwat A, et al. Adipose mesenchymal stem cells-derived exosomes attenuate retina degeneration of streptozotocin-induced diabetes in rabbits. J Circ Biomark. 2018;7:1849454418807827. 
17. Yu B, Li X-R, Zhang X-M. Mesenchymal stem cell-derived extracellular vesicles as a new therapeutic strategy for ocular diseases. World J Stem Cells. 2020;12(3):178.

18. Fatima F, et al. Non-coding RNAs in mesenchymal stem cell-derived extracellular vesicles: deciphering regulatory roles in stem cell potency, inflammatory resolve, and tissue regeneration. Front Genet. 2017:8:161.

19. Özmert E, Arslan U. Management of retinitis pigmentosa by Wharton's jelly-derived mesenchymal stem cells: prospective analysis of 1-year results. Stem Cell Res Ther. 2020;11(1):1-17.

20. Harrell CR, et al. Therapeutic potential of mesenchymal stem cellderived exosomes in the treatment of eye diseases. Cell Biol Transl Med. 2018;2:47-57.

21. Harrell CR, et al. Mesenchymal stem cell-derived exosomes and other extracellular vesicles as new remedies in the therapy of inflammatory diseases. Cells. 2019;8(12):1605.

22. Johnson TV, Bull ND, Martin KR. Identification of barriers to retinal engraftment of transplanted stem cells. Investig Ophthalmol Vis Sci. 2010;51(2):960-70.

23. Teixeira FG, et al. Mesenchymal stem cells secretome: a new paradigm for central nervous system regeneration? Cell Mol Life Sci. 2013;70(20):3871-82.

24. Camussi $\mathrm{G}$, et al. Exosomes/microvesicles as a mechanism of cell-to-cell communication. Kidney Int. 2010;78(9):838-48.

25. Greening DW, et al. A protocol for exosome isolation and characterization: evaluation of ultracentrifugation, density-gradient separation, and immunoaffinity capture methods. In: Proteomic profiling. Springer; 2015, p. 179-209.

26. Shariati Najafabadi S, et al. Human adipose derived stem cell exosomes enhance the neural differentiation of PC12 cells. Mol Biol Rep. 2021;48(6):5033-43.

27. Nuzzi R, Caselgrandi P, Vercelli A. Effect of mesenchymal stem cellderived exosomes on retinal injury: a review of current findings. Stem Cells Int. 2020;2020:1-9.

28. Soung $\mathrm{YH}$, et al. Exosomes in cancer diagnostics. Cancers. 2017;9(1):8.

29. Galardi A, et al. Proteomic profiling of retinoblastoma-derived exosomes reveals potential biomarkers of vitreous seeding. Cancers. 2020;12(6):1555.

30. Patil SM, Sawant SS, Kunda NK. Exosomes as drug delivery systems: a brief overview and progress update. Eur J Pharm Biopharm. 2020;154:259-69.

31. Schindler $C$, et al. Exosomal delivery of doxorubicin enables rapid cell entry and enhanced in vitro potency. PLoS ONE. 2019;14(3):e0214545.

32. Tricarico C, Clancy J, D'Souza-Schorey C. Biology and biogenesis of shed microvesicles. Small GTPases. 2017;8(4):220-32.

33. Kanada M, et al. Differential fates of biomolecules delivered to target cells via extracellular vesicles. Proc Natl Acad Sci. 2015;112(12):E1433-42.

34. Quesenberry PJ, Dooner MS, Aliotta JM. Stem cell plasticity revisited: the continuum marrow model and phenotypic changes mediated by microvesicles. Exp Hematol. 2010;38(7):581-92.

35. Martins VR, Dias MS, Hainaut P. Tumor-cell-derived microvesicles as carriers of molecular information in cancer. Curr Opin Oncol. 2013;25(1):66-75.

36. Al-Nedawi K, Meehan B, Rak J. Microvesicles: messengers and mediators of tumor progression. Cell Cycle. 2009;8(13):2014-8.

37. Zhang W, Chen S, Liu M-L. Pathogenic roles of microvesicles in diabetic retinopathy. Acta Pharmacol Sin. 2018;39(1):1-11.

38. Hulsmans M, Holvoet P. MicroRNA-containing microvesicles regulating inflammation in association with atherosclerotic disease. Cardiovasc Res. 2013;100(1):7-18.

39. Battistelli M, Falcieri E. Apoptotic bodies: particular extracellular vesicles involved in intercellular communication. Biology. 2020;9(1):21.

40. Keshtkar S, Azarpira N, Ghahremani MH. Mesenchymal stem cellderived extracellular vesicles: novel frontiers in regenerative medicine. Stem Cell Res Ther. 2018;9(1):1-9.

41. Sun G, et al. hucMSC derived exosomes promote functional recovery in spinal cord injury mice via attenuating inflammation. Mater Sci Eng C. 2018:89:194-204.

42. Xin H, Li Y, Chopp M. Exosomes/miRNAs as mediating cell-based therapy of stroke. Front Cell Neurosci. 2014;8:377.
43. Ratajczak J, et al. Embryonic stem cell-derived microvesicles reprogram hematopoietic progenitors: evidence for horizontal transfer of mRNA and protein delivery. Leukemia. 2006;20(5):847-56

44. Valadi $\mathrm{H}$, et al. Exosome-mediated transfer of mRNAs and microRNAs is a novel mechanism of genetic exchange between cells. Nat Cell Biol. 2007;9(6):654-9.

45. Venugopal $\mathrm{C}$, et al. Dosage and passage dependent neuroprotective effects of exosomes derived from rat bone marrow mesenchymal stem cells: an in vitro analysis. Curr Gene Ther. 2017;17(5):379-90.

46. Xu J-F, et al. Altered microRNA expression profile in exosomes during osteogenic differentiation of human bone marrow-derived mesenchymal stem cells. PLoS ONE. 2014;9(12):e114627.

47. Eirin A, et al. Comparative proteomic analysis of extracellular vesicles isolated from porcine adipose tissue-derived mesenchymal stem/stromal cells. Sci Rep. 2016;6(1):1-12.

48. Eirin A, et al. Integrated transcriptomic and proteomic analysis of the molecular cargo of extracellular vesicles derived from porcine adipose tissue-derived mesenchymal stem cells. PLoS ONE. 2017;12(3):e0174303.

49. Chiou N-T, Kageyama R, Ansel KM. Selective export into extracellular vesicles and function of tRNA fragments during $T$ cell activation. Cell Rep. 2018;25(12):3356-3370.e4.

50. Kuriyan $A E$, et al. Vision loss after intravitreal injection of autologous "stem cells" for AMD. N Engl J Med. 2017;376(11):1047-53.

51. Yang $S$, et al. Mechanisms of epithelial-mesenchymal transition in proliferative vitreoretinopathy. Discov Med. 2015;20(110):207-17.

52. Mead B, et al. Mesenchymal stromal cell-mediated neuroprotection and functional preservation of retinal ganglion cells in a rodent model of glaucoma. Cytotherapy. 2016;18(4):487-96.

53. Kim JY, et al. Epiretinal membrane formation after intravitreal autologous stem cell implantation in a retinitis pigmentosa patient. Retinal Cases Brief Rep. 2017;11(3):227-31.

54. Mead B, et al. Paracrine-mediated neuroprotection and neuritogenesis of axotomised retinal ganglion cells by human dental pulp stem cells: comparison with human bone marrow and adipose-derived mesenchymal stem cells. PLoS ONE. 2014;9(10):e109305.

55. Emre E, et al. Neuroprotective effects of intravitreally transplanted adipose tissue and bone marrow-derived mesenchymal stem cells in an experimental ocular hypertension model. Cytotherapy. 2015;17(5):543-59.

56. Zuzic M, et al. Retinal miRNA functions in health and disease. Genes. 2019;10(5):377.

57. MacFarlane L-A, Murphy PR. MicroRNA: biogenesis, function and role in cancer. Curr Genomics. 2010;11(7):537-61.

58. Mirzaei $\mathrm{H}$, et al. MicroRNA: relevance to stroke diagnosis, prognosis, and therapy. J Cell Physiol. 2018;233(2):856-65.

59. Ha M, Kim VN. Regulation of microRNA biogenesis. Nat Rev Mol Cell Biol. 2014;15(8):509-24.

60. Karali M, Banfi S. Non-coding RNAs in retinal development and function. Hum Genet. 2019;138(8):957-71.

61. Eleuteri S, Fierabracci A. Insights into the secretome of mesenchymal stem cells and its potential applications. Int J Mol Sci. 2019;20(18):4597.

62. Ambros $V$, et al. A uniform system for microRNA annotation. RNA 2003;9(3):277-9.

63. de Lucia $\mathrm{C}$, et al. microRNA in cardiovascular aging and age-related cardiovascular diseases. Front Med. 2017:4:74.

64. Krol J, et al. Characterizing light-regulated retinal microRNAs reveals rapid turnover as a common property of neuronal microRNAs. Cell. 2010;141(4):618-31.

65. Sundermeier TR, Palczewski K. The impact of microRNA gene regulation on the survival and function of mature cell types in the eye. FASEB $J$. 2016:30(1):23-33.

66. Quintero $H$, Lamas M. microRNA expression in the neural retina: Focus on Müller glia. J Neurosci Res. 2018;96(3):362-70.

67. Li L, et al. Argonaute 2 complexes selectively protect the circulating microRNAs in cell-secreted microvesicles. PLoS ONE. 2012;7(10):e46957.

68. Gibbings DJ, et al. Multivesicular bodies associate with components of miRNA effector complexes and modulate miRNA activity. Nat Cell Biol. 2009:11(9):1143-9.

69. Jeppesen DK, et al. Quantitative proteomics of fractionated membrane and lumen exosome proteins from isogenic metastatic and 
nonmetastatic bladder cancer cells reveal differential expression of EMT factors. Proteomics. 2014;14(6):699-712.

70. Qiu G, et al. Mesenchymal stem cell-derived extracellular vesicles affect disease outcomes via transfer of microRNAs. Stem Cell Res Ther. 2018:9(1):1-9.

71. Villarroya-Beltri C, et al. Sumoylated hnRNPA2B1 controls the sorting of miRNAs into exosomes through binding to specific motifs. Nat Commun. 2013;4(1):1-10.

72. Santangelo $L$, et al. The RNA-binding protein SYNCRIP is a component of the hepatocyte exosomal machinery controlling microRNA sorting. Cell Rep. 2016;17(3):799-808.

73. lavello A, et al. Role of Alix in miRNA packaging during extracellular vesicle biogenesis. Int J Mol Med. 2016;37(4):958-66.

74. Mulcahy LA, Pink RC, Carter DRF. Routes and mechanisms of extracellular vesicle uptake. J Extracell Vesicles. 2014;3(1):24641.

75. Montecalvo A, et al. Mechanism of transfer of functional microRNAs between mouse dendritic cells via exosomes. Blood. 2012;119(3):756-66

76. Morelli $A E$, et al. Endocytosis, intracellular sorting, and processing of exosomes by dendritic cells. Blood. 2004;104(10):3257-66.

77. Escrevente C, et al. Interaction and uptake of exosomes by ovarian cancer cells. BMC Cancer. 2011;11(1):1-10.

78. French KC, Antonyak MA, Cerione RA. Extracellular vesicle docking at the cellular port: Extracellular vesicle binding and uptake. Semin Cell Dev Biol. 2017:67:48-55.

79. Parolini I, et al. Microenvironmental $\mathrm{pH}$ is a key factor for exosome traffic in tumor cells. J Biol Chem. 2009:284(49):34211-22.

80. Song $Y$, et al. Exosomal miR-146a contributes to the enhanced therapeutic efficacy of interleukin-1 $\beta$-primed mesenchymal stem cells against sepsis. Stem Cells. 2017;35(5):1208-21.

81. Shao $L$, et al. MiRNA-sequence indicates that mesenchymal stem cells and exosomes have similar mechanism to enhance cardiac repair. BioMed Res Int. 2017:2017:1-9.

82. Baglio SR, et al. Human bone marrow-and adipose-mesenchymal stem cells secrete exosomes enriched in distinctive miRNA and tRNA species. Stem Cell Res Ther. 2015;6(1):1-20.

83. Ferguson $\mathrm{SW}$, et al. The microRNA regulatory landscape of MSC-derived exosomes: a systems view. Sci Rep. 2018;8(1):1-12.

84. Luther KM, et al. Exosomal miR-21a-5p mediates cardioprotection by mesenchymal stem cells. J Mol Cell Cardiol. 2018:119:125-37.

85. Zhang $Y$, et al. Exosomes derived from mesenchymal stromal cells promote axonal growth of cortical neurons. Mol Neurobiol. 2017;54(4):2659-73.

86. Park KK, et al. Promoting axon regeneration in the adult CNS by modulation of the PTEN/mTOR pathway. Science. 2008;322(5903):963-6.

87. Berry $\mathrm{M}$, et al. Prospects for mTOR-mediated functional repair after central nervous system trauma. Neurobiol Dis. 2016;85:99-110.

88. Pan D, et al. UMSC-derived exosomes promote retinal ganglion cells survival in a rat model of optic nerve crush. J Chem Neuroanat. 2019;96:134-9.

89. Zhang $W$, Wang $Y$, Kong $Y$. Exosomes derived from mesenchymal stem cells modulate miR-126 to ameliorate hyperglycemia-induced retinal inflammation via targeting HMGB1. Investig Ophthalmol Vis Sci. 2019;60(1):294-303.

90. Huang KM, Dentchev T, Stambolian D. MiRNA expression in the eye. Mamm Genome. 2008;19(7):510-6.

91. Li W-B, et al. Development of retinal pigment epithelium from human parthenogenetic embryonic stem cells and microRNA signature. Investig Ophthalmol Vis Sci. 2012;53(9):5334-43.

92. Arora $A$, et al. Prediction of microRNAs affecting mRNA expression during retinal development. BMC Dev Biol. 2010;10(1):1-15.

93. Conte I, Banfi S, Bovolenta P. Non-coding RNAs in the development of sensory organs and related diseases. Cell Mol Life Sci. 2013;70(21):4141-55.

94. Sun LF, Chen XJ, Jin ZB. Emerging roles of non-coding RNAs in retinal diseases: a review. Clin Exp Ophthalmol. 2020:48(8):1085-101.

95. Rapicavoli NA, Blackshaw S. New meaning in the message: noncoding RNAs and their role in retinal development. Dev Dyn. 2009:238(9):2103-14.

96. Fuhrmann S, Zou C, Levine EM. Retinal pigment epithelium development, plasticity, and tissue homeostasis. Exp Eye Res. 2014;123:141-50
97. Huang $X-F$, et al. Retinal miRNAs variations in a large cohort of inherited retinal disease. Ophthalmic Genet. 2018;39(2):175-9.

98. Ryan DG, Oliveira-Fernandes M, Lavker RM. MicroRNAs of the mammalian eye display distinct and overlapping tissue specificity. Mol Vis. 2006:12(134-135):1175-84.

99. Xu S. microRNA expression in the eyes and their significance in relation to functions. Prog Retin Eye Res. 2009:28(2):87-116.

100. Maiorano NA, Hindges R. Chapter 19 - MicroRNAs in the Retina and in Visual Connectivity. In: Sen CK, editor. MicroRNA in Regenerative Medicine. Oxford: Academic Press; 2015. p. 489-514.

101. Karali M, et al. miRNeye: a microRNA expression atlas of the mouse eye. BMC Genomics. 2010;11(1):1-14.

102. Jun $\mathrm{S}$, et al. The impact of lipids, lipid oxidation, and inflammation on AMD, and the potential role of miRNAs on lipid metabolism in the RPE. Exp Eye Res. 2019;181:346-55.

103. Zhou J, et al. Retinal progenitor cells release extracellular vesicles containing developmental transcription factors, microRNA and membrane proteins. Sci Rep. 2018:8(1):1-15.

104. Sundermeier TR, Palczewski K. The physiological impact of microRNA gene regulation in the retina. Cell Mol Life Sci. 2012:69(16):2739-50.

105. Karali M, et al. Identification and characterization of microRNAs expressed in the mouse eye. Investig Ophthalmol Vis Sci. 2007:48(2):509-15.

106. Hackler $\mathrm{L}$, et al. MicroRNA profile of the developing mouse retina. Investig Ophthalmol Vis Sci. 2010;51(4):1823-31.

107. Reh TA, Hindges R. MicroRNAs in retinal development. Annu Rev Vis Sci. 2018:4:25-44

108. García-García D, Locker M, Perron M. Update on Müller glia regenerative potential for retinal repair. Curr Opin Genet Dev. 2020;64:52-9.

109. Rajaram K, et al. Dynamic miRNA expression patterns during retinal regeneration in zebrafish: reduced dicer or miRNA expression suppresses proliferation of Müller Glia-derived neuronal progenitor cells. Dev Dyn. 2014;243(12):1591-605.

110. Sanuki R, et al. miR-124a is required for hippocampal axogenesis and retinal cone survival through Lhx2 suppression. Nat Neurosci. 2011;14(9):1125-34.

111. Quintero H, Gomez-Montalvo A, Lamas M. MicroRNA changes through Müller glia dedifferentiation and early/late rod photoreceptor differentiation. Neuroscience. 2016;316:109-21.

112. Baba Y, Aihara Y, Watanabe S. MicroRNA-7a regulates Müller glia differentiation by attenuating Notch3 expression. Exp Eye Res. 2015:138:59-65.

113. La Torre A, Georgi S, Reh TA. Conserved microRNA pathway regulates developmental timing of retinal neurogenesis. Proc Natl Acad Sci. 2013;110(26):E2362-70.

114. Cremisi F. MicroRNAs and cell fate in cortical and retinal development. Front Cell Neurosci. 2013;7:141.

115. Tao Z, et al. Lin28B promotes müller glial cell de-differentiation and proliferation in the regenerative rat retinas. Oncotarget. 2016;7(31):49368.

116. Wohl SG, et al. Müller glial microRNAs are required for the maintenance of glial homeostasis and retinal architecture. Nat Commun. 2017;8(1):1-15.

117. Stappert L, Roese-Koerner B, Brüstle O. The role of microRNAs in human neural stem cells, neuronal differentiation and subtype specification. Cell Tissue Res. 2015;359(1):47-64.

118. Carrella S, et al. miR-181a/b control the assembly of visual circuitry by regulating retinal axon specification and growth. Dev Neurobiol. 2015;75(11):1252-67.

119. Zhuang $P$, et al. Combined microRNA and mRNA detection in mammalian retinas by in situ hybridization chain reaction. Sci Rep. 2020;10(1):1-10.

120. Busskamp V, et al. miRNAs 182 and 183 are necessary to maintain adult cone photoreceptor outer segments and visual function. Neuron. 2014:83(3):586-600

121. Peskova L, et al. miR-183/96/182 cluster is an important morphogenetic factor targeting PAX6 expression in differentiating human retinal organoids. Stem Cells. 2020;38(12):1557-67.

122. Li H, et al. Brain-derived neurotrophic factor is a novel target gene of the hsa-miR-183/96/182 cluster in retinal pigment epithelial cells following visible light exposure. Mol Med Rep. 2015;12(2):2793-9. 
123. Kutty RK, et al. MicroRNA expression in human retinal pigment epithelial (ARPE-19) cells: increased expression of microRNA-9 by N-(4-hydroxyphenyl) retinamide. Mol Vis. 2010;16:1475

124. Shahriari F, et al. MicroRNA profiling reveals important functions of miR-125b and let-7a during human retinal pigment epithelial cell differentiation. Exp Eye Res. 2020;190:107883.

125. Hu G, et al. Identification of miRNA signatures during the differentiation of hESCs into retinal pigment epithelial cells. PLOS ONE. 2012;7(7):e37224.

126. Jiang C, et al. MicroRNA-184 promotes differentiation of the retinal pigment epithelium by targeting the AKT2/mTOR signaling pathway. Oncotarget. 2016;7(32):52340.

127. Yan, N., et al., Profiling MicroRNAs Differentially Expressed in Rabbit Retina, in Retinal Degenerative Diseases: Laboratory and Therapeutic Investigations, R.E. Anderson, J.G. Hollyfield, and M.M. LaVail, Editors. 2010, Springer New York: New York, NY. p. 203-209.

128. Agrawal S, Chaqour B. MicroRNA signature and function in retinal neovascularization. World J Biol Chem. 2014;5(1):1

129. Wang $\mathrm{H}-\mathrm{C}$, et al. Profiling the microRNA expression in human iPS and iPS-derived retinal pigment epithelium. Cancer Inform. 2014;13:CIN. S14074.

130. Murad N, et al. miR-184 regulates ezrin, LAMP-1 expression, affects phagocytosis in human retinal pigment epithelium and is downregulated in age-related macular degeneration. FEBS J. 2014;281(23):5251-64

131. Wang $Q$, et al. Regulation of retinal inflammation by rhythmic expression of MiR-146a in diabetic retina. Investig Ophthalmol Vis Sci. 2014;55(6):3986-94

132. Xiong F, et al. Altered retinal microRNA expression profiles in early diabetic retinopathy: an in silico analysis. Curr Eye Res. 2014;39(7):720-9.

133. Wang $Y$, et al. Identification of key miRNAs and genes for mouse retinal development using a linear model. Mol Med Rep. 2020;22(1):494-506.

134. Murray AR, et al. MicroRNA-200b downregulates oxidation resistance 1 (Oxr1) expression in the retina of type 1 diabetes model. Investig Ophthalmol Vis Sci. 2013;54(3):1689-97.

135. Hou Q, et al. Inhibitory effect of microRNA-34a on retinal pigment epithelial cell proliferation and migration. Investig Ophthalmol Vis Sci. 2013;54(10):6481-8.

136. Karali M, et al. High-resolution analysis of the human retina miRNome reveals isomiR variations and novel microRNAs. Nucleic Acids Res. 2016;44(4):1525-40

137. Ye E-A, Steinle JJ. miR-15b/16 protects primary human retinal microvascular endothelial cells against hyperglycemia-induced increases in tumor necrosis factor alpha and suppressor of cytokine signaling 3. J Neuroinflamm. 2015;12(1):1-8.

138. Li X, Jin P. Roles of small regulatory RNAs in determining neuronal identity. Nat Rev Neurosci. 2010;11(5):329-38.

139. Li M, et al. MicroRNA-29b regulates TGF- $\beta 1$-mediated epithelial-mesenchymal transition of retinal pigment epithelial cells by targeting AKT2. Exp Cell Res. 2016;345(2):115-24.

140. Silva VA, et al. Expression and cellular localization of microRNA-29b and RAX, an activator of the RNA-dependent protein kinase (PKR), in the retina of streptozotocin-induced diabetic rats. Mol Vis. 2011;17:2228

141. Ji H-P, et al. MicroRNA-28 potentially regulates the photoreceptor lineage commitment of Müller glia-derived progenitors. Sci Rep. 2017;7(1):1-9.

142. Hui Y, Yin Y. MicroRNA-145 attenuates high glucose-induced oxidative stress and inflammation in retinal endothelial cells through regulating TLR4/NF-kB signaling. Life Sci. 2018;207:212-8.

143. Jun JH, Joo C-K. MicroRNA-124 controls transforming growth factor $\beta 1$-induced epithelial-mesenchymal transition in the retinal pigment epithelium by targeting RHOG. Investig Ophthalmol Vis Sci. 2016;57(1):12-22.

144. Decembrini S, et al. MicroRNAs couple cell fate and developmental timing in retina. Proc Natl Acad Sci. 2009;106(50):21179-84.

145. Walker JC, Harland RM. microRNA-24a is required to repress apoptosis in the developing neural retina. Genes Dev. 2009;23(9):1046-51.

146. Zhang Y, et al. miR-29a regulates the proliferation and differentiation of retinal progenitors by targeting Rbm8a. Oncotarget. 2017;8(19):31993.

147. Yan $L$, et al. Single and compound knock-outs of MicroRNA (miRNA)155 and its angiogenic gene target CCN1 in mice alter vascular and neovascular growth in the retina via resident microglia. J Biol Chem. 2015;290(38):23264-81.

148. Van Battum EY, et al. An image-based miRNA screen identifies miRNA$135 \mathrm{~s}$ as regulators of CNS axon growth and regeneration by targeting Krüppel-like factor 4. J Neurosci. 2018;38(3):613-30.

149. Taylor SM, et al. The MicroRNA, miR-18a, regulates NeuroD and photoreceptor differentiation in the retina of zebrafish. Dev Neurobiol. 2019;79(2):202-19.

150. Sun N, et al. miR-17 regulates the proliferation and differentiation of retinal progenitor cells by targeting CHMP1A. Biochem Biophys Res Commun. 2020:523(2):493-9.

151. Liu C-H, et al. Endothelial microRNA-150 is an intrinsic suppressor of pathologic ocular neovascularization. Proc Natl Acad Sci. 2015;112(39):12163-8.

152. Heldring $N$, et al. Therapeutic potential of multipotent mesenchymal stromal cells and their extracellular vesicles. Hum Gene Ther. 2015;26(8):506-17.

153. Yaghoubi Y, et al. Human umbilical cord mesenchymal stem cells derived-exosomes in diseases treatment. Life Sci. 2019;233:116733.

154. Chen TS, et al. Mesenchymal stem cell secretes microparticles enriched in pre-microRNAs. Nucleic Acids Res. 2010;38(1):215-24.

155. Fujita $Y$, et al. Clinical application of mesenchymal stem cell-derived extracellular vesicle-based therapeutics for inflammatory lung diseases. J Clin Med. 2018;7(10):355.

156. Park K-S, et al. Enhancement of therapeutic potential of mesenchymal stem cell-derived extracellular vesicles. Stem Cell Res Ther. 2019;10(1):1-15.

157. Quesenberry PJ, et al. Role of extracellular RNA-carrying vesicles in cell differentiation and reprogramming. Stem Cell Res Ther. 2015;6(1):1-10.

158. Pers Y-M, et al. Contribution of microRNAs to the immunosuppressive function of mesenchymal stem cells. Biochimie. 2018;155:109-18.

159. Abbaszadeh $\mathrm{H}$, et al. Human umbilical cord mesenchymal stem cell-derived extracellular vesicles: a novel therapeutic paradigm. J Cell Physiol. 2020;235(2):706-17.

160. Rad F, et al. Mesenchymal stem cell-based therapy for autoimmune diseases: emerging roles of extracellular vesicles. Mol Biol Rep. 2019:46(1):1533-49.

161. Ngadiono E, Hardiany NS. Advancing towards effective glioma therapy: MicroRNA derived from umbilical cord mesenchymal stem cells' extracellular vesicles. Malays J Med Sci MJMS. 2019;26(4):5.

162. He L, Zhang H. MicroRNAs in the migration of mesenchymal stem cells. Stem Cell Rev Rep. 2019;15(1):3-12.

163. Vilaça-Faria H, Salgado AJ, Teixeira FG. Mesenchymal stem cells-derived exosomes: a new possible therapeutic strategy for Parkinson's disease? Cells. 2019;8(2):118.

164. Phinney DG, Pittenger MF. Concise review: MSC-derived exosomes for cell-free therapy. Stem Cells. 2017;35(4):851-8.

165. Qian X, et al. Exosomal microRNAs derived from umbilical mesenchymal stem cells inhibit hepatitis C virus infection. Stem Cells Transl Med. 2016:5(9):1190-203.

166. Zhu Z, et al. MicroRNAs and mesenchymal stem cells: hope for pulmonary hypertension. Braz J Cardiovasc Surg. 2015;30(3):380-5.

167. Zhu L, et al. Transplantation of adipose tissue-derived stem cell-derived exosomes ameliorates erectile function in diabetic rats. Andrologia. 2018;50(2):e12871.

168. Casado-Díaz A, Quesada-Gómez JM, Dorado G. Extracellular vesicles derived from mesenchymal stem cells (MSC) in regenerative medicine: applications in skin wound healing. Front Bioeng Biotechnol. 2020. https://doi.org/10.3389/fbioe.2020.00146.

169. Katsuda T, Ochiya T. Molecular signatures of mesenchymal stem cellderived extracellular vesicle-mediated tissue repair. Stem Cell Res Ther. 2015;6(1):1-8.

170. Konala VBR, et al. The current landscape of the mesenchymal stromal cell secretome: a new paradigm for cell-free regeneration. Cytotherapy. 2016;18(1):13-24.

171. Chang Y-H, et al. Exosomes and stem cells in degenerative disease diagnosis and therapy. Cell Transplant. 2018;27(3):349-63.

172. Sun $\mathrm{L}$, et al. Exosomes derived from human umbilical cord mesenchymal stem cells protect against cisplatin-induced ovarian granulosa cell stress and apoptosis in vitro. Sci Rep. 2017;7(1):1-13. 
173. Wang $X$, et al. Mesenchymal stem cell-derived exosomes have altered microRNA profiles and induce osteogenic differentiation depending on the stage of differentiation. PLoS ONE. 2018;13(2):e0193059.

174. Collino F, et al. Microvesicles derived from adult human bone marrow and tissue specific mesenchymal stem cells shuttle selected pattern of miRNAs. PLoS ONE. 2010;5(7):e11803.

175. Fang S, et al. Umbilical cord-derived mesenchymal stem cell-derived exosomal microRNAs suppress myofibroblast differentiation by inhibiting the transforming growth factor- $\beta / S M A D 2$ pathway during wound healing. Stem Cells Transl Med. 2016;5(10):1425-39.

176. Chen $X$, et al. Bone marrow mesenchymal stem cell-derived extracellular vesicles containing miR-497-5p inhibit RSPO2 and accelerate OPLL. Life Sci. 2021;279:119481.

177. Xin $\mathrm{H}$, et al. MicroRNA-17-92 cluster in exosomes enhance neuroplasticity and functional recovery after stroke in rats. Stroke. 2017;:48(3):747-53.

178. Sun $X$, et al. Exosomal microRNA-23b-3p from bone marrow mesenchymal stem cells maintains Thelper/Treg balance by downregulating the $\mathrm{PI3K} / \mathrm{Akt} / \mathrm{NF}-\mathrm{KB}$ signaling pathway in intracranial aneurysm. Brain Res Bull. 2020;165:305-15.

179. Pawlick JS, et al. MiRNA regulatory functions in photoreceptors. Front Cell Dev Biol. 2021;8:1913.

180. Chu-Tan JA, et al. MicroRNA-124 Dysregulation is associated with retinal inflammation and photoreceptor death in the degenerating retina. Investig Ophthalmol Vis Sci. 2018;59(10):4094-105.

181. He Y, et al. MiR-124 promotes the growth of retinal ganglion cells derived from Müller cells. Cell Physiol Biochem. 2018;45(3):973-83.

182. Indrieri $\mathrm{A}$, et al. The pervasive role of the miR-181 family in development, neurodegeneration, and cancer. Int J Mol Sci. 2020;21 (6):2092.

183. Miltner AM, La Torre A. Retinal ganglion cell replacement: current status and challenges ahead. Dev Dyn. 2019;248(1):118-28.

184. Hu Y, et al. Reciprocal actions of microRNA-9 and TLX in the proliferation and differentiation of retinal progenitor cells. Stem Cells Dev. 2014;23(22):2771-81.

185. Nguyen-Ba-Charvet KT, Rebsam A. Neurogenesis and specification of retinal ganglion cells. Int J Mol Sci. 2020;21(2):451.

186. Qi X. The role of miR-9 during neuron differentiation of mouse retinal stem cells. Artif Cells Nanomed Biotechnol. 2016;44(8):1883-90.

187. Jin Z, Ren J, Qi S. Exosomal miR-9-5p secreted by bone marrow-derived mesenchymal stem cells alleviates osteoarthritis by inhibiting syndecan-1. Cell Tissue Res. 2020;381:99-114.

188. Wu K-C, et al. Deletion of miR-182 leads to retinal dysfunction in mice. Investig Ophthalmol Vis Sci. 2019;60(4):1265-74.

189. Mead B, et al. Viral delivery of multiple miRNAs promotes retinal ganglion cell survival and functional preservation after optic nerve crush injury. Exp Eye Res. 2020;197:108071.

190. Zhao J, et al. Mesenchymal stromal cell-derived exosomes attenuate myocardial ischaemia-reperfusion injury through miR-182-regulated macrophage polarization. Cardiovasc Res. 2019;115(7):1205-16.

191. Laine SK, et al. MicroRNAs miR-96, miR-124, and miR-199a regulate gene expression in human bone marrow-derived mesenchymal stem cells. J Cell Biochem. 2012;113(8):2687-95.

192. Sundermeier TR, et al. DICER1 is essential for survival of postmitotic rod photoreceptor cells in mice. FASEB J. 2014;28(8):3780-91.

193. Collino F, et al. Exosome and microvesicle-enriched fractions isolated from mesenchymal stem cells by gradient separation showed different molecular signatures and functions on renal tubular epithelial cells. Stem Cell Rev Rep. 2017;13(2):226-43.

194. Han F, et al. MicroRNA-30b promotes axon outgrowth of retinal ganglion cells by inhibiting Semaphorin3A expression. Brain Res. 2015;1611:65-73.

195. Zhou Q, et al. Strand and cell type-specific function of microRNA-126 in angiogenesis. Mol Ther. 2016;24(10):1823-35.

196. Villain G, et al. miR-126-5p promotes retinal endothelial cell survival through SetD5 regulation in neurons. Development. 2018;145(1):dev156232.

197. Bai X, et al. MicroRNA-126 reduces blood-retina barrier breakdown via the regulation of VCAM-1 and BCL2L11 in ischemic retinopathy. Ophthalmic Res. 2017;57(3):173-85.
198. Yao K, et al. Wnt regulates proliferation and neurogenic potential of Müller glial cells via a Lin28/let-7 miRNA-dependent pathway in adult mammalian retinas. Cell Rep. 2016;17(1):165-78.

199. Fairchild CL, et al. Let-7 regulates cell cycle dynamics in the developing cerebral cortex and retina. Sci Rep. 2019;9(1):1-21.

200. Konar GJ, et al. miRNAs and Müller glia reprogramming during retina regeneration. Front Cell Dev Biol. 2021;8:1851.

201. Ni N, et al. Effects of let-7b and TLX on the proliferation and differentiation of retinal progenitor cells in vitro. Sci Rep. 2014;4(1):1-10.

202. Rasheed VA, et al. Developmental wave of Brn3b expression leading to RGC fate specification is synergistically maintained by miR-23a and miR-374. Dev Neurobiol. 2014;74(12):1155-71.

203. Chang W, Wang J. Exosomes and their noncoding RNA cargo are emerging as new modulators for diabetes mellitus. Cells. 2019;8(8):853.

204. Wang J-H, et al. MicroRNA-143 plays a protective role in ischemiainduced retinal neovascularization. bioRxiv. 2019;53:548297.

205. McArthur K, et al. MicroRNA-200b regulates vascular endothelial growth factor-mediated alterations in diabetic retinopathy. Diabetes. 2011;60(4):1314-23

206. Ye E-A, Steinle JJ. miR-146a attenuates inflammatory pathways mediated by TLR4/NF-KB and TNFa to protect primary human retinal microvascular endothelial cells grown in high glucose. Mediators Inflamm. 2016;2016:1-9.

207. Hu Z, et al. Protective effects of microRNA-22-3p against retinal pigment epithelial inflammatory damage by targeting NLRP3 inflammasome. J Cell Physiol. 2019;234(10):18849-57.

208. Zhou J, et al. Human retinal organoids release extracellular vesicles that regulate gene expression in target human retinal progenitors. bioRxiv. 2021;3:1.

209. Wang J, et al. MicroRNA-148a-3p alleviates high glucose-induced diabetic retinopathy by targeting TGFB2 and FGF2. Acta Diabetol. 2020;57(12):1435-43.

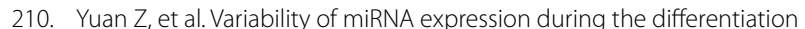
of human embryonic stem cells into retinal pigment epithelial cells. Gene. 2015;569(2):239-49.

211. Zhao W, et al. Arbutin attenuates hydrogen peroxide-induced oxidative injury through regulation of microRNA-29a in retinal ganglion cells. Biomed Pharmacother. 2019;112:108729.

212. Tang W, et al. MicroRNA-29b-3p inhibits cell proliferation and angiogenesis by targeting VEGFA and PDGFB in retinal microvascular endothelial cells. Mol Vis. 2020;26:64.

213. Xia X, Teotia P, Ahmad I. miR-29c regulates neurogliogenesis in the mammalian retina through REST. Dev Biol. 2019;450(2):90-100.

214. Li T, et al. Bone marrow mesenchymal stem cell-derived exosomal miRNA-29c decreases cardiac ischemia/reperfusion injury through inhibition of excessive autophagy via the PTEN/Akt/mTOR signaling pathway. Circ J. 2020;84(8):1304-11.

215. Guduric-Fuchs J, et al. Deep sequencing reveals predominant expression of miR-21 amongst the small non-coding RNAs in retinal microvascular endothelial cells. J Cell Biochem. 2012;113(6):2098-111.

216. Bao $\mathrm{H}$, et al. Astragaloside protects oxygen and glucose deprivation induced injury by regulation of microRNA-21 in retinal ganglion cell line RGC-5. Biomed Pharmacother. 2019;109:1826-33.

217. Deng C-L, et al. Photoreceptor protection by mesenchymal stem cell transplantation identifies exosomal MiR-21 as a therapeutic for retinal degeneration. Cell Death Differ. 2021;28(3):1041-61.

218. Fulzele $S$, et al. MicroRNA-146b-3p regulates retinal inflammation by suppressing adenosine deaminase- 2 in diabetes. BioMed Res Int 2015;2015:1-8.

219. Shao Y, et al. miRNA-451a regulates RPE function through promoting mitochondrial function in proliferative diabetic retinopathy. Am J Physiol Endocrinol Metab. 2019;316(3):E443-52.

220. LiY, et al. A microRNA, mir133b, suppresses melanopsin expression mediated by failure dopaminergic amacrine cells in RCS rats. Cell Signal. 2012;24(3):685-98.

221. Li Z, et al. Protective effects on retinal ganglion cells by miR-133 via MAPK/Erk2 signaling pathway in the N-methyl-D-aspartate-induced apoptosis model. Nanosci Nanotechnol Lett. 2018;10(12):1726-31. 
222. Wang Y, Tang Z, Gu P. Stem/progenitor cell-based transplantation for retinal degeneration: a review of clinical trials. Cell Death Dis. 2020;11(9):1-14

223. van Mil A, et al. MicroRNA-214 inhibits angiogenesis by targeting Quaking and reducing angiogenic growth factor release. Cardiovasc Res. 2012;93(4):655-65.

224. Maiorano NA, Hindges R. Non-coding RNAs in retinal development. Int J Mol Sci. 2012;13(1):558-78.

225. Lian C, et al. MicroRNA-24 protects retina from degeneration in rats by down-regulating chitinase-3-like protein 1. Exp Eye Res. 2019;188:107791.

226. Xu S, et al. MicroRNA (miRNA) transcriptome of mouse retina and identification of a sensory organ-specific miRNA cluster. J Biol Chem. 2007;282(34):25053-66.

227. Chen N, et al. MicroRNA-410 reduces the expression of vascular endothelial growth factor and inhibits oxygen-induced retinal neovascularization. PLoS ONE. 2014;9(4):e95665

228. Mak HK, et al. MicroRNA-19a-PTEN axis is involved in the developmental decline of axon regenerative capacity in retinal ganglion cells. Mol Ther Nucleic Acids. 2020;21:251-63.

229. Wang Y, et al. MicroRNA-93/STAT3 signalling pathway mediates retinal microglial activation and protects retinal ganglion cells in an acute ocular hypertension model. Cell Death Dis. 2021;12(1):1-12.

230. Li R, et al. MiR-93-5p targeting PTEN regulates the NMDA-induced autophagy of retinal ganglion cells via AKT/mTOR pathway in glaucoma. Biomed Pharmacother. 2018;100:1-7.

231. Bruno S, et al. Renal regenerative potential of different extracellular vesicle populations derived from bone marrow mesenchymal stromal cells. Tissue Eng Part A. 2017;23(21-22):1262-73.

232. Marler KJ, et al. BDNF promotes axon branching of retinal ganglion cells via miRNA-132 and p250GAP. J Neurosci. 2014:34(3):969-79.

233. Liu B, et al. MiR-361-5p inhibits cell proliferation and induces cell apoptosis in retinoblastoma by negatively regulating CLDN8. Childs Nerv Syst. 2019;35(8):1303-11.

234. Zhao D, Cui Z. MicroRNA-361-3p regulates retinoblastoma cell proliferation and stemness by targeting hedgehog signaling. Exp Ther Med. 2019;17(2):1154-62.

235. Intartaglia D, Giamundo G, Conte I. The impact of miRNAs in health and disease of retinal pigment epithelium. Front Cell Dev Biol. 2021;8:1811.
236. Katsman D, et al. Embryonic stem cell-derived microvesicles induce gene expression changes in Müller cells of the retina. PLOS ONE. 2012;7(11):e50417.

237. Wang Q, et al. Dual anti-inflammatory and anti-angiogenic action of miR-15a in diabetic retinopathy. EBioMedicine. 2016;11:138-50.

238. Fernando N, et al. MicroRNA-223 regulates retinal function and inflammation in the healthy and degenerating retina. Front Cell Dev Biol. 2020;8:516.

239. Fuller-Carter Pl, et al. Integrated analyses of zebrafish miRNA and mRNA expression profiles identify miR-29b and miR-223 as potential regulators of optic nerve regeneration. BMC Genomics. 2015;16(1):1-19.

240. Mak HK, Leung CK. MicroRNA-based therapeutics for optic neuropathy: opportunities and challenges. Neural Regen Res. 2021;16(10):1996.

241. Morquette $B$, et al. MicroRNA-223 protects neurons from degeneration in experimental autoimmune encephalomyelitis. Brain. 2019;142(10):2979-95.

242. Li J, et al. microRNA-497 overexpression decreases proliferation, migration and invasion of human retinoblastoma cells via targeting vascular endothelial growth factor A. Oncol Lett. 2017;13(6):5021-7.

243. Zhang Y, Chen F, Wang L. Metformin inhibits development of diabetic retinopathy through microRNA-497a-5p. Am J Transl Res. 2017:9(12):5558.

244. Liao Y, et al. MiR-140-5p suppresses retinoblastoma cell growth via inhibiting c-Met/AKT/mTOR pathway. 2018. Biosci Rep. https://doi.org/ 10.1042/BSR20180776.

245. Chan AS, et al. The protective role of MicroRNA-140 in retinal ischemia. Investig Ophthalmol Vis Sci. 2011:52(14):517-517.

246. Bian $\mathrm{H}$, et al. The latest progress on miR-374 and its functional implications in physiological and pathological processes. J Cell Mol Med. 2019;23(5):3063-76

247. Tasharrofi N, et al. Survival improvement in human retinal pigment epithelial cells via Fas receptor targeting by miR-374a. J Cell Biochem. 2017:118(12):4854-61.

\section{Publisher's Note}

Springer Nature remains neutral with regard to jurisdictional claims in published maps and institutional affiliations.
Ready to submit your research? Choose BMC and benefit from:

- fast, convenient online submission

- thorough peer review by experienced researchers in your field

- rapid publication on acceptance

- support for research data, including large and complex data types

- gold Open Access which fosters wider collaboration and increased citations

- maximum visibility for your research: over 100M website views per year

At BMC, research is always in progress.

Learn more biomedcentral.com/submissions 